NASA Contractor Report 3198

\title{
Evaluation of a Locally Homogeneous Model of Spray Evaporation
}

\author{
A. J. Shearer and G. M. Faeth
}

GRANT NGR 39-009-077

OCTOBER 1979

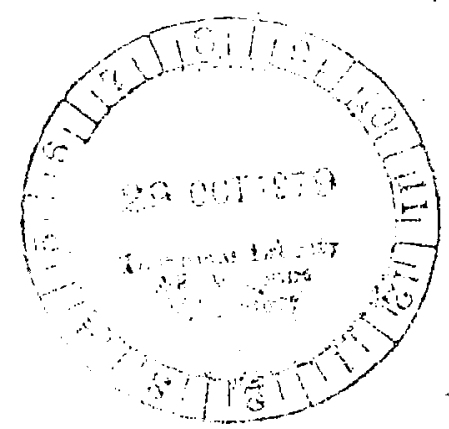


NASA Contractor Report 3198

\section{Evaluation of a Locally Homogeneous Model of Spray Evaporation}

A. J. Shearer and G. M. Faeth

The Pennsylvania State University

University Park, Pennsylvania

Prepared for

Lewis Research Center

under Grant NGR 39-009-077

\section{N/Sก}

National Aeronautics

and Space Administration

Scientific and Technical Information Branch 
$-\cdots$ 
NOMENCLATURE . . . . . . . . . . . . . . . . . . v v

SUMMARY . . . . . . . . . . . . . . . . . . I ix

I. INTRODUCTION. . . . . . . . . . . . . . . . . 1

1.I General Statement of the Problem . . . . . . . . . . 1

1.2 Previous Related Studies .............. 4

1.2.1 Locally Homogeneous Flow Models . . . . . . 4

1.2.2 Two-Phase Flow Mode1s . . . . . . . . 6

1.2.3 Turbulence Mode1s . . . . . . . . . . 7

1.3 Specific Objectives of the Study . . . . . . . . 8

II. EXPERIMENTAI APPARATUS AND PROCEDURE. . . . . . . . . . 10

2.1 Introduction . . . . . . . . . . . . . . 10

2.2 Experimental Apparatus ... . . . . . . . . 10

2.2.1 Test Apparatus............... 10

2.2.2 Velocity Measurement. . . . . . . . . 12

2.2.3 Concentration Measurement . . . . . . . 15

2.2.4 Temperature Measurement . . . . . . . . . 15

2.2.5 Drop Size and L1quid Flux Measurements. . . 17

2.2.6 Jet Momentum Measurement. . . . . . . . 17

2.3 Experimental Conditions. . . . . . . . . 17

III. THEORETICAL CONSIDERATIONS. . . . . . . . . . . . . 20

3.1 Description of Mode1............... 20

3.2 Equation of State. . . . . . . . . . . . . 22

3.3 Probability Density Function Mode1 . . . . . . . 25

3.4 Governing Equations. . . . . . . . . . . . 28

3.5 Numerical Solution . . . . . . . . . . . 29

3.5.1 Generalized Computer Code . . . . . . . . 29

3.5.2 Concentration Fluctuation Mode1 . . . . . 32

IV. RESULTS AND DISCUSSION OF THE LOCALLY HOMOGENEOUS

FLOW MODEL. • . • . • . • • • • • • • • • • . 32

4.1 Introduction .................. . 32

4.2 Radial Variation of Mean Quantities. . . . . . . 33

4.3 Radial Variation of Turbulence Quant1ties. . . . . 39

4.4 Axial Variation. . . . . . . . . . . . . 45

4.5 Droplet Size................... 53 
TABLE OF CONTENTS (Concluded)

$\underline{\text { Page }}$

V. DROPLET LIFE-HISTORY CALCULATIONS . . . . . . . . . . 53

5.1 Theoretical Model of Droplet-ife History. . . . . 53

5.2 Calibration Apparatus. . . . . . . . . . . 56

5.3 Calibration Test Results . . . . . . . . . . . 58

5.4 Droplet Life-History Calculations in Evaporating Spray.................. 60

VI. SUMMARY AND CONCLUSIONS . . . . . . . . . . . . 62

6.1 Summary. . . . . . . . . . . ..... 62

6.2 Conclusions. . . . . . . . . . . . . . . . 63

6.3 Recommendations for Further Research . . . . . . 64

REFERENCES . . . . . . . . . . . . . . . . 65

APPENDIX A: EVALUATION OF TURBULENCE QUANTITIES . . . . . . . 71

APPENDIX B: EQUATIONS OF STATE. . . . . . . . . . . . 73

B.1 Isothermal Air Jet . . . . . . . . . . . 73

B.2 Heated Air Jet in Air. . . . . . . . . . . 73

B.3 Dense Gas Jet in Air . . . . . . . . . . . 74

B.4 Air Jet in Water . . . . . . . . . . . . 74

B.5 Evaporating Spray in Air............. 75

B.6 Property Data. . . . . . . . . . . . . 77

APPENDIX C: PROBABILITY DENSITY FUNCTION TABLE. •. . . . . 79

APPENDIX D: ORDER OF MAGNITUDE ANALYSIS OF GOVERNING

EQUATIONS . . . . . . . . . . . . . 82

APPENDIX E: EVALUATION OF PROPERTIES FOR DROPLET-LIFE

HLSTORY MODEL . . . . . . . . . . . . 88

E.1 Thermal Conductivity . . . . . . . . . . 88

E.2 Viscosity. . . . . . . . . . . . . . 88

E.3 Gas Properties . . . . . . . . . . . . . 89

APPENDIX F: EXPERIMENTAL DATA . . . . . . . . . . . . . 90

F.1 Axial Variation of Quantities. . . . . . . . . 90

F.2 Radial Variation of Quantities........... . 92 
NOMENCLATURE

\begin{tabular}{|c|c|}
\hline a & Acceleration of gravity \\
\hline A & Dirac delta function at $f=0$ \\
\hline$\overline{\mathrm{A}}$ & Constant used in Equation (3.28) \\
\hline$A^{\prime}$ & Constant used in Equation (B.19) \\
\hline B & Dirac delta function at $f=1$ \\
\hline$\overline{\mathrm{B}}$ & Constant used in Equation (3.28) \\
\hline$B^{\prime}$ & Constant used in Equation (B.19) \\
\hline $\mathrm{B}_{\mathrm{y}}$ & Mass transfer driving potential \\
\hline $\mathrm{C}$ & Constant used in Equation (A.5) \\
\hline $\mathrm{C}_{\mathrm{f}}$ & Droplet drag coefficient \\
\hline $\mathrm{C}_{\mathrm{p}}$ & Specific heat \\
\hline$C_{i}$ & Parameters used in turbulence model \\
\hline$\overline{\mathrm{C}}$ & Constant used in Equation (3.28) \\
\hline $\mathrm{d}$ & Injector diameter \\
\hline$d_{f}$ & Distance between fringes \\
\hline $\mathrm{D}$ & Droplet diameter \\
\hline$\overline{\mathrm{D}}$ & Constant used in Equation (3.28) \\
\hline $\mathbf{f}$ & Mixture fraction \\
\hline$e^{\prime}$ & Fluctuating voltage \\
\hline $\mathrm{E}$ & Instantaneous vo1tage \\
\hline $\mathbf{F}$ & Frequency \\
\hline $\mathbf{g}$ & Square of mixture fraction fluctuations \\
\hline & Enthalpy \\
\hline
\end{tabular}




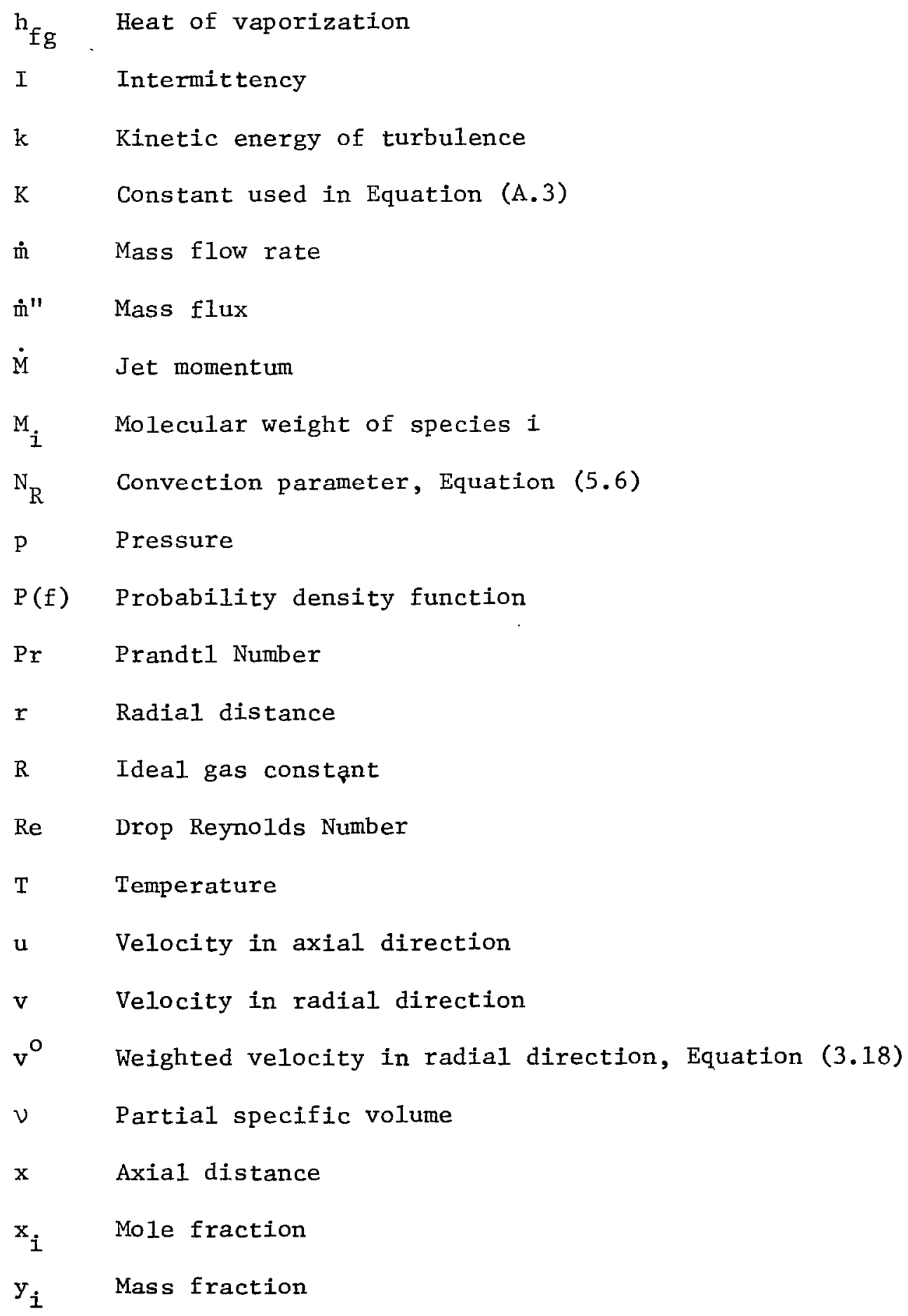




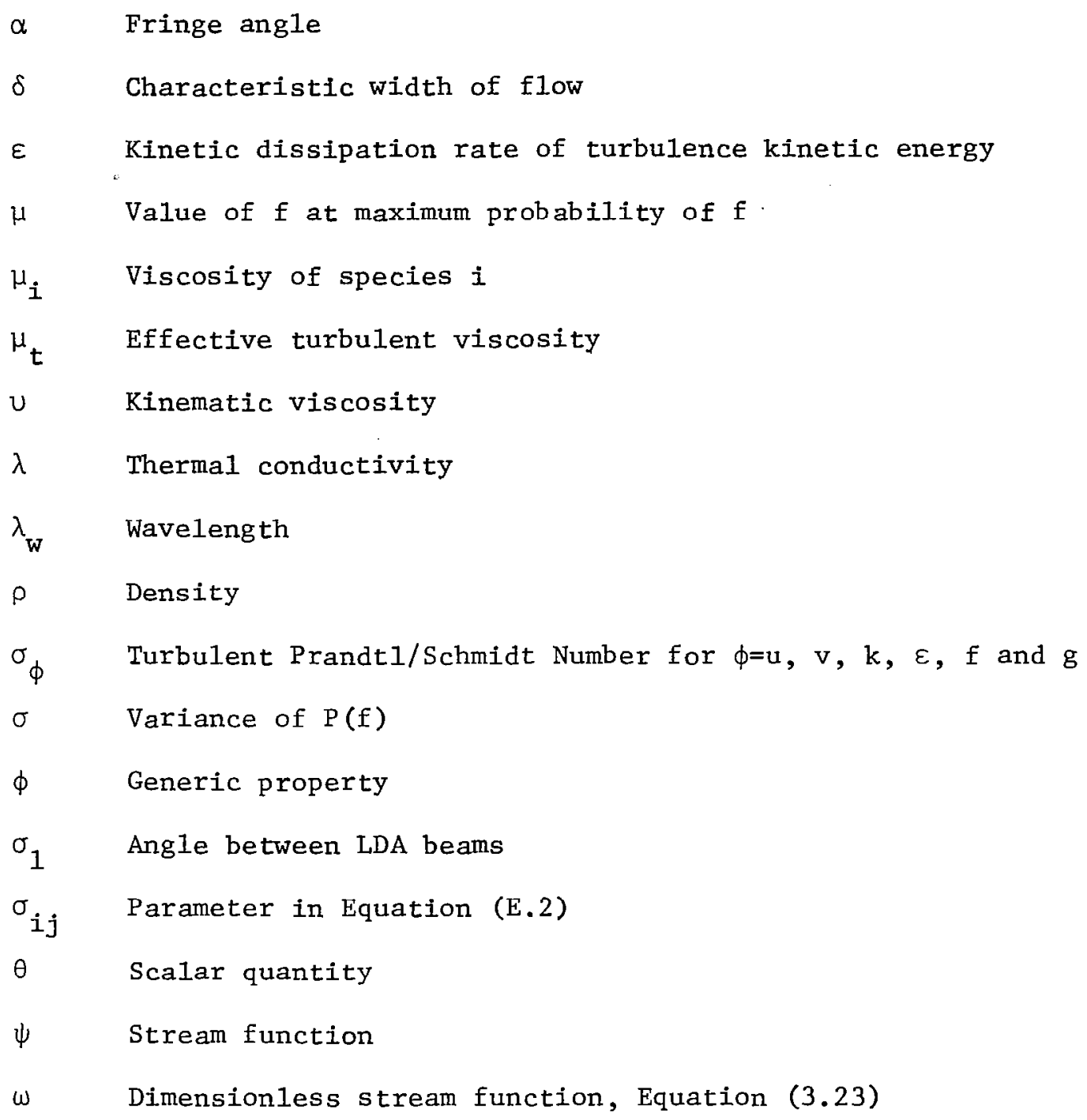


viii

\begin{tabular}{ll} 
I & Inner boundary \\
$\mathrm{p}$ & Drop quantity \\
$\mathrm{R}$ & Reference state \\
$\mathrm{S}$ & Sulfur hexafluoride \\
$\mathrm{W}$ & Water \\
0 & Injector exit conditions \\
$\infty$ & Ambient conditions \\
& Time-averaged quantity \\
\hline & F1uctuating quantity
\end{tabular}




\section{SUMMARY}

The objective of the study was to develop and evaluate a locally homogeneous flow (LHF) model of spray evaporation which employs a secondorder turbulence model. The LHF approximation is a simplified approach for modeling two-phase flows, where it is assumed that interphase transport rates are infinitely fast. The turbulence model was based on the Reynolds-averaged form of the conservation equations. The equations were solved using the GENMIX computer program. Solutions were obtained for both single and two-phase jets in stagnant air.

Measurements to check the predictions were obtained for an isothermal air jet, an isothermal dense gas jet (sulfur hexafluoride), and an evaporating spray (Freon-11, Sauter mean diameter $29 \mu \mathrm{m}$ ). A singlechannel LDA was used to measure mean velocities, turbulcnt fluctuations and Reynolds stress. Composition was measured by isokinetic sampling and gas chromatography. Temperatures were measured with a fine wire thermocouple. Drop size distributions and liquid flux were measured by slide impaction. The evaluation also considered measurements reported in the literature. The evaluation proceeded systematically through the following flows:

1. isothermal air jet in air

2. heated air jet in air

3. dense gas $\mathrm{jet}$ in air

4. air jet in water

5. evaporating spray in air

The model provided reasonably good predictions of mean and turbulent quantities in the single phase flows, using constants in the turbulence model established during earlier work. The model provides a reasonably good estimation of radial variations of mean and turbulent quantities in the spray, but tends to overestimate the overall state of development in the axial direction. For example, in the fully developed region, predicted values of mean axial velocity and mixture fraction tended to be $10-20$ and 40 percent below the measurements, respectively.

Predicted drop life histories along the centerline of the jet were used to assess the effect of finite rate interphase transport on the LHF model predictions. The results suggest that a spray having a Sauter mean diameter less than $10 \mu \mathrm{m}$ would be required for quantitative accuracy with the LHF model, for present test conditions. The need for such smal1 drop sizes for quantitative accuracy with the LHF model is due to the rapid development of the flow resulting from the small injector diameter. Based on these findings, LHF models provide a useful qualitative picture of spray structure; however, more complex models allowing for finite interphase transport rates are required for quantitative accuracy in most practical sprays.

The authors wish to acknowledge the assistance of $\mathrm{H}$. Tamura, of the National Aerospace Laboratory, Kakuda Branch, Japan, While in residence at Penn State, Mr. Tamura contributed significantly to the development of the computer program used in this study. 


\section{CHAPTER I}

\section{INTRODUCTION}

\subsection{General Statement of the Problem}

The combustion of liquid fuels accounts for a significant fraction of the current energy supply. For example, liquid petroleum products provided $46 \%$ of the energy supply in the U.S. in 1973, with a similar fraction being representative of world supplies (1). For combustion to occur, fuel and air must be intimately mixed. Almost without exception, mixing involves the use of an evaporating spray at some point in the combustion process. In some cases mixing is separated from combustion as in the carburetor of a spark ignition engine. However, in most cases, the evaporation and combustion of the spray occur simultaneously at the point of injection. The overall objective of the present study is to model the spray evaporation process with a simplified but widely used approach and evaluate the model with a series of well defined experiments.

The spray evaporation process to be considered involves the vaporization of a well-atomized liquid jet. A spray is considered to be wellatomized if the liquid jet disintegrates into a mist of droplets immediately after injection and if the droplets are small in comparison to the injector diameter. For a constant area injector with no swirl, the ratio of the injector diameter to the diameter of the largest drops should be in the range of 10 to 100 to be considered well-atomized (2). After being formed at the injector exit, the droplets travel through the flow field until complete vaporization occurs.

Figure 1 is a schematic representation of the spray evaporation process. The nozzle is a full-cone pressure atomized injector with no swirl. The surrounding environment is a stagnant inert gas which does not contain the evaporating substance as a vapor.

The distribution of droplets in the spray is nonuniform with the smaller drops on the periphery and the larger drops near the centerline. The small drops readily exchange momentum with the gas causing the spray to entrain the surrounding gas similar to a gas jet. Near the injector exit, the velocity difference between the drops and the gas is the greatest, and the momentum of the liquid is transferred to the gas over an extended distance. Therefore, the development of the turbulent spray is retarded in comparison to a gas jet which affects the rate of entrainment and mixing characteristics of the flow.

The behavior of the large drops is significantly different from that of smaller droplets. Small drops tend to follow the flow and are largely confined to fuel-rich eddies. The paths of larger droplets do not follow the turbulent eddies because of their greater inertia. The larger droplets pass through both injected fluid regions and regions composed largely of the entrained gas. The variation of composition and temperature between these regions significantly affects the evaporation rates of the individual droplets. 


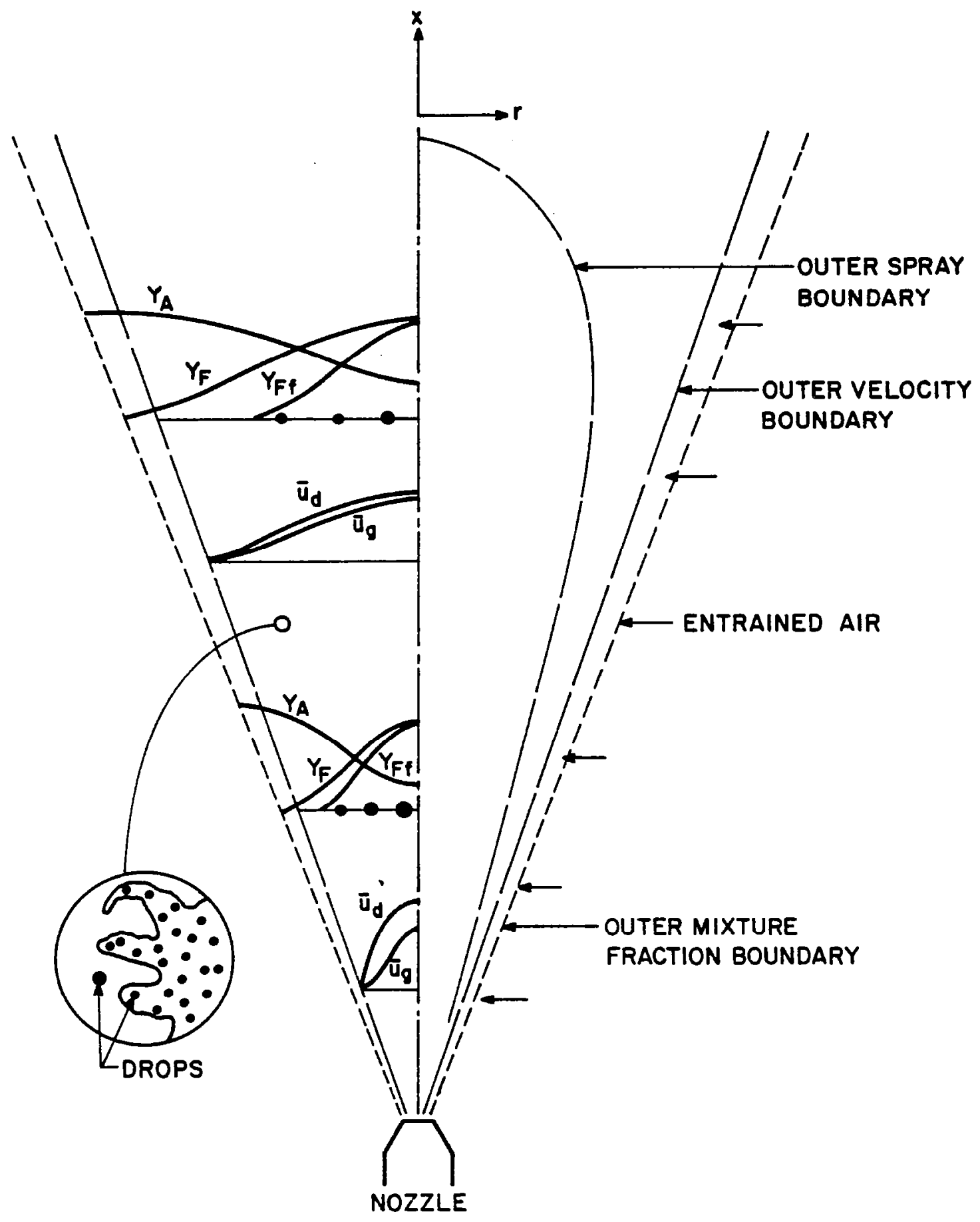

Figure 1 Schematic Diagram of the Spray Evaporation Process 
The spray evaporation process is composed of several complex phenomena: the hydrodynamics of spray formation, the transport characteristics of the individual drops and the turbulent two-phase flow of the spray. A11 of these processes must be considered in a complete two-phase flow model. In order to model the spray the initial drop size and velocity distributions generated by the injector must be specified. This information is very difficult to acquire and is rarely available for practical sprays. The effect of turbulence on drop transport in actual spray conditions is not well understood and must be accounted for in a complete two-phase flow model. The effect of the droplets on the generation and dissipation of turbulence in a spray is not well defined. Solution of these problems will require extensive research into each area.

One way to overcome many of the difficulties in a two-phase spray process is the use of a locally homogeneous flow model. The basic assumption of the locally homogeneous flow model is that the transport between the phases is infinitely fast. This implies that the droplets are in thermal equilibrium with the local gas environment (the gas immediately surrounding the droplet), and that there is no velocity difference (no slip) between the liquid and gas phases.

The major advantages of the locally homogeneous flow model are as follows:

1. The model requires little information concerning injector characteristics, e.g., the flow rate, the momentum, the composition and the temperature at the injector exit.

2. The theoretical model of the flow is equivalent to that of a singlephase flow, bypassing the difficulties involved with correctly modeling interactions between the phases and minimizing the number of empirical parameters to be specified.

3. Calculations with the model can employ the highly developed general purpose computer programs for single-phase flows, with only minor modifications.

The major disadvantage involves inaccuracies due to failure of the assumption of infinitely fast transport rates between the phases. The difficulty becomes more important when drop sizes are large, when the rate of development of the process as a whole is fast (the process is completed near the injector) and when liquid densities are much greater than gas densities.

A major objective of the present study will be to examine the capabilities of locally homogeneous flow models to predict spray evaporation and to develop a means of assessing their potential validity for a given application. 


\subsection{Previous Related Studies}

\subsubsection{Locally Homogeneous Flow Models}

The locally homogeneous flow model has been applied to a wide range of two-phase systems. Both gas-liquid and liquid-gas processes have been modeled with the locally homogeneous assumption. These studies should provide the basis for a detailed model of spray evaporation.

Weimer, Faeth and 01son (3) successfully modeled condensing gas jets injected into subcooled liquids using an integral model of the turbulent flow along with the locally homogeneous assumption. Vapor penetration lengths for condensing water, ethylene glycol and iso-octane jets were correlated irrespective of the vapor-liquid system. A variable density entrainment law was used to account for the mixing of the injected fluid and the surroundings.

A turbulent air-water jet has been successfully modeled with the locally homogeneous assumption (4). Measurements of the velocity, void fraction and momentum flux were completed throughout the jet. A locally homogeneous integral model was used to correlate the axial and radial distributions of the quantities.

The locally homogeneous assumption has also been used to model a reacting gas-liquid system (5). This involved the combustion of a gaseous oxidizer jet in a liquid metal fuel. The locally homogeneous assumption was used to model the two-phase nature of the jet. A unified correlation of flame length, temperatures, and velocities was developed for the reacting two-phase system. The model also gave good results when applied to reacting single-phase jets and condensing gas jets.

Newman and Brzustowski (6) applied the locally homogeneous assumption to a liquid carbon dioxide jet, with the liquid near the thermodynamic critical point, which was injected into a stagnant atmosphere of carbon dioxide and nitrogen. The locally homogeneous approximation is appealing near the critical region since the gas density and the liquid density are nearly equal. For this condition, the droplets quickly reach equilibrium with the gaseous environment. Mean velocities and temperatures were predicted quite well for the carbon dioxide and nitrogen system, however, the model was not tested against any other variable density systems.

The locally homogeneous flow model has also been applied to a nonreacting Diesel fuel spray. Wakuri, et al, (7) conducted photographic measurements of fuel sprays with a high speed motion picture camera. A non-dimensional correlation was developed for the spray length as a function of the density ratio of the liquid to the gaseous environment, inlet velocity, initial diameter, and time. It was concluded that for their experimental conditions the relative velocity difference between the phases was negligible and therefore the two phases could be treated as a homogeneous mixture.

There have been several attempts to extend the locally homogeneous assumption to the combusting spray in Diesel engines (8-12). However, 
due to the transient three-dimensional nature of Diese1 combustion, convincing evaluation of the models has not been achieved. The correlations developed by these studies are limited in their applications to the design of Diesel engines and have not been extended to consider other spray combustion processes.

Thring and Newby (13) analyzed the spray combustion process in a reacting oil spray. The two-phase spray was taken to be equivalent to a single-phase jet of the same momentum and equal stoichiometry. Qualitative agreement was obtained for the prediction of overall quantities, such as the spray length, based on the locally homogeneous as sumption.

The results of several other experimental investigations indicate that the locally homogeneous model can, at times, be valid for reacting two-phase sprays. Onuma and Ogasawara $(14,15)$ and Chigier and coworkers $(16,17)$ have investigated several types of two-phase reacting sprays at atmospheric conditions. In these studies the spray structure was defined by the gas temperatures, droplet sizes, velocities, and concentrations. It was concluded that droplets in a flame do not burn individually but that the fuel vapor diffuses from a region of droplet evaporation and reacts in a way similar to a single-phase reacting jet.

However, the results of more recent investigations indicate that the locally homogeneous assumption cannot be successfully applied to all two-phase reacting sprays. Khalil and Whitelaw (18) measured the velocity, turbulence intensity, temperature and droplet concentration in a hollow-cone spray at atmospheric pressure. The flame length for a spray with a Sauter mean diameter of $45 \mu \mathrm{m}$ was 1 arger than the flame length of the simulated gaseous diffusion flame. The difference indicates the assumption of a locally homogeneous flow, which does not provide for dropsize effects, can be invalid for sprays having a Sauter mean diameter as small as $45 \mu \mathrm{m}$. Recent calculations by Khalil (19) show better agreement between theory and experiment; however, this was obtained for sclectivc cascs by introducing several empirical parameters which have not been systematically evaluated.

Failure of the locally homogeneous model has been illustrated for pressureatomized reacting sprays even at elevated pressures. Shearer (20) compared experimental measurements of flame shape and spray length with theoretical predictions for a full cone spray at ambient pressures of 100 to $9000 \mathrm{kPa}$. A locally homogeneous mode1, in conjunction with an integral model for the flow, correctly predicted the trends of the data, but underestimated the extent of the spray and flame boundaries by 30 to 50 percent. Although the Sauter mean diameter of the spray was approximately $30 \mathrm{~mm}$, it was concluded that there was significant slip velocity between the liquid and gas.

In summary, the locally homogeneous flow model is based on the assumption that all phases have the same velocity and are in thermodynamic equilibrium at each point in the flow. This requirement is most easily met when the dispersed phase is a gas and the continuous phase is a liquid due to the relatively low inertia and thermal capacity of the gas phase. Therefore, locally homogeneous flow models have been reasonably successful for describing processes of condensation and reaction when gas jets are injected into liquids. 
In contrast, the ability of the locally homogeneous model to predict the behavior of an evaporating or combusting spray has not been clearly defined. Qualitative agreement between predicted results and the experimental results has been obtained, however, the locally homogeneous model tends to overestimate the rate of development of the flow. An in-depth evaluation of the locally homogeneous assumption has not been conducted.

\subsubsection{Two-Phase Flow Mode1s}

A number of two-phase flow models have been developed to predict the behavior of evaporating or combusting sprays. All of the two-phase models attempt to treat the interaction between phases; however, the models vary widely in regard to the thoroughness with which the interactions are treated.

A major distinguishing feature of the present two-phase flow models is the consideration of the relative velocity (slip) between the phases. One group of models (21-24) ignores slip between the phases as opposed to more complete models $(25-32)$ where slip is considered. If slip is ignored, the models are similar to the locally homogeneous flow models, except that finite heat and mass transfer rates are considered between the phases. Ignoring slip considerably simplifies the calculations; however, such models involve limitations in accuracy similar to locally homogeneous flow models.

In most two-phase flow models it is assumed that the spray is dilute. This implies that single drop models $(33-42)$ can be used to describe drop transport rates, that the presence of the drops has a negligible effect on the constitutive equations describing the transport characteristics of the gas phase, and that drop collisions can be ignored.

The void fraction requirement of all of these assumptions is not well defined. For monodisperse particles, it is recognized that single particle transport formulas apply reasonably well if the center-to-center distance between two particles is greater than two particle diameters (43). If the particles have equal spacing, this requirement implies a void fraction greater than 0.92 .

For a reacting spray with no swirl in a stagnant environment, void fractions in the range of 0.92 are reached approximately 6 to 12 injector diameters from the injector (20). This suggests that the dilute spray assumption is adequate for the bulk of the two-phase region. However, the near injector region requires a different formulation.

The manner in which the initial conditions of the spray are specified has a strong bearing on the need to treat the low void fraction region, Two-phase flow models which consider slip require size and velocity distributions as a function of position at some point in the flow, Few measurements of these quantities have been conducted due to current experimental limitations.

Mode1 development, however, has far outstripped systematic efforts at model validation. Where predictions have been compared with experiments, injector characteristics have not been defined adequately for a two-phase 
flow model and measurements within the flow have been limited. The models are very complex, involving numerous assumptions and empirical parameters. Convincing validation will require careful testing of injectors and simple well defined experiments. Present two-phase flow models are not capable of accurate, a priori, predictions of evaporating or combusting sprays (2).

\subsubsection{Turbulence Mode1s}

Second-order turbulence models have been applied to a wide variety of single-phase non-reacting flows. Launder, et al., (44) developed a turbulence model based upon the turbulent kinetic energy and the dissipation rate. Solution of the turbulence model was accomplished by introducing the equations for the turbulent kinetic energy and the dissipation rate into the GENMIX computer program developed by Patankar and Spa1ding (45). The predicted values for the mean velocity and the turbulent kinetic energy were in good agreement with most of the experimental results. However, it was suggested that the analytical model would not adequately represent flows with large density gradients.

A second-order turbulence model has also been successfully applied to single-phase reacting jets by Lockwood and Naguib (46). Turbulence was modeled using differential equations for the turbulent kinetic energy, the dissipation rate, and concentration fluctuations. A Reynoldsaveraging procedure which neglects the effect of density fluctuations was used to model the conservation equations. A clipped Gaussian probability density function was employed to represent the relationship between mixture fraction and other properties.

Lockwood and Naguib (46) used a systematic approach to evaluate the model. The predictions were compared with data for isothermal inert flows, non-isothermal inert flows and reacting flows, Good agreement was obtained between predictions and experimental results for all three cases, however additional data is required to completely evaluate the mode1. In particular, more information is needed for highly non-isothermal inert flows in order to fully evaluate the effect of large density differences in the flow.

A second-order turbulence model which includes the effect of density fluctuations has been successfully applied to single-phase reacting jets by Gosman, Lockwood and Syed (47). Horizontal and vertical diffusion flames were modeled and the theoretical predictions were compared with measurements. The model employed equations for the conservation of mass, momentum, energy and mixture fraction in conjunction with a second-order turbulence closure. The turbulence was modeled with equations for the turbulent kinetic energy, dissipation rate, and concentration fluctuations. Terms involving the density fluctuations were retained in portions of the model, although complete variable density modeling was not achieved. The equations for three dimensional flow were solved using the TEACH-3P computer program (48).

The Gosman, Lockwood and Syed (47) model has only been tested against measurements of temperature and oxygen concentration from a single experiment. The results for the vertical reacting jet compare moderately 
well with the predictions, however, additional evaluation of the model is required before any definite conclusions concerning the validity of all aspects of the model can be reached.

The combination of a second-order turbulence model and a Favre-averaging procedure has been successfully applied to a single-phase reacting jet. A Favre-averaged quantity represents a density weighted average. In this approach, the fluctuating density effects are included in the density weighted average. Kent and Bilger (49) used Favre-averaged equations for the conservation of mass, momentum, and mixture fraction and a turbulence model based on the turbulent kinetic energy, dissipation rate, and concentration fluctuations to model a reacting singlephase jet. With their turbulence model in the Favre-averaged form, the equations to be solved are identical to the incompressible flow equations.

The Favre-averaged mode1 (49) was tested against measurements of velocity, temperature, and pollutant concentrations for a reacting jet in a co-flowing air stream. The experimental measurements and theoretical predictions comparc very favorably. Evaluation of the model, however, was limited to examining a single data set.

The effectiveness of several turbulence models has been examined in a variable density planar shear layer by Parker and Sirignano (50). The study included a mixing length model, a Favre-averaged second order turbulence model, and a conventional Reynolds-averaged second order turbulence model which ignores density fluctuations. For the casc of a variable density planar shear flow the Favre-averaged model provided a better prediction of the boundary layer than the Reynolds-averaged model. However, the mixing length model provided a better prediction of the flow than either of the second-order turbulence models.

Second-order turbulence models have been applied to a wide variety of single-phase flows. However, only the Lockwood and Naguib (46) model has been systematically studied for a wide range of variable density flows. There is also evidence to suggest that the effect of density fluctuations is significant and should be considered.

\subsection{Specific Objectives of the Study}

The availability of an accurate two-phase flow model for sprays would provide a most useful design tool. Models of this type, however, require systematic validation, which is difficult at the present time due to experimental problems in accurately describing initial drop size and velocity distributions which are needed in the analysis. Locally homogeneous flow models provide a simpler approach, where the need for detailed injector characteristics is eliminated. While the locally homogeneous flow method provides a logical first-step toward the goal of validated two-phase flow models, the previous discussion indicates that systematic validation of even this simplified approach has not yet been reported. 
Based on this assessment of current knowledge, the objective of the present investigation is to develop and evaluate a locally homogeneous model of spray evaporation. Following the recent studies, a secondorder turbulence model will be employed in the analysis. The turbulence model used by Gosman, Lockwood and Syed (47) has been subjected to the most systematic evaluation of the various methods reported to date; therefore, this procedure will be employed in the present study. Aside from comparing the predictions of the model with spray experiments, effects of slip will also be evaluated directly by completing drop life-history calculations using the predictions of the model to supply the local conditions surrounding the drop.

The evaluation of the model will consider a wide range of conditions for both single and two-phase flows. This will include single-phase constant density jets, single-phase variable density jets, two-phase gas-liquid jets and evaporating sprays. In this manner, the various parameters in the model can be established in single phase flows, prior to evaluation of the locally homogeneous flow approximation in the two-phase flows.

The single-phase constant density jet is the least complicated flow to model. In this case, the predictions can be compared with existing air jet measurements reported by Wygnanski and Fiedler (51), Becker, et al., (52) and Hetsroni and Sokolov (53). Experiments in this flow will also be conducted in this investigation in order to establish the validity of present experimental techniques by comparison with the earlier measurements.

Data for single-phase variable density jets are more limited (54). Therefore, additional measurements in this flow will be undertaken in the present investigation. This will involve a sulfur hexafluoride gas jet, which has a high density in comparison to air due to its higher molecular weight, injected into stagnant air.

Tross (4) provides data on velocity and composition profiles in the flow resulting when an air jet is injected into a stagnant water bath. These results will be employed to test the locally homogeneous flow model under conditions where this assumption is generally satisfied.

Data for an evaporating spray will be generated in the present investigation. The configuration will consist of a Freon-11 spray produced by an air atomizing injector without any swirl. The flow will be injected into stagnant air.

The specific objectives of the present study can be summarized as follows:

1. Develop a model of the spray evaporation based on the locally homogeneous assumption in conjunction with a second-order turbulence model.

2. Experimentally measure mean and fluctuating velocities $\left(u, v, u^{\prime}, v^{\prime}\right.$, $\left.w^{\prime}, u^{\prime} v^{\prime}\right)$ throughout single-phase constant density and single-phase variable density jets as well as a two-phase evaporating spray.

3. Experimentally measure the injected fluid concentration throughout single-phase variable density jet and two-phase evaporating spray. 
4. Experimentally measure the gas temperature and drop size throughout an evaporating spray.

5. Compare the theoretical predictions of the model with the experimental measurements and previous studies.

6. Develop a model for the behavior of a single drop in the evaporating spray to determine the effect of slip in the evaporating spray.

CHAPTFR I I

EXPERIMENTAL APPARATUS AND PROCEDURE

\subsection{Introduction}

The experimental apparatus was used for measurements in both single and two-phase evaporating sprays. The flows examined during the present study are as follows:

1. Isothermal air jet in air

2. Isothermal dense gas jet in air (sulfur hexafluoride)

3. Evaporating spray in air (Freon-11).

In all cases, the jet issued vertically downward into stagnant air.

A variety of measurements were performed to define the flow. Jet flow rates and the total momentum of the jet were determined to define initial conditions. Profiles of mean gas velocity, velocity fluctuations, and Reynolds stress were measured for all flows. Mean concentration measurements were completed for the isothermal dense gas jet and the evaporating spray. Mean temperature and dropsize distribution profiles were measured for the evaporating spray.

\subsection{Experimenta1 Apparatus}

\subsubsection{Test Apparatus}

The nozzle was positioned near the top of the test stand and oriented vertically downward. The test stand was an area $2.0 \mathrm{~m}$ high by 0.92 m square enclosed with a 16 mesh screen. Two traversing mechanisms were used to position the nozzle in a horizontal plane.

An air-atomizing nozzle was used throughout the investigation. The nozzle was manufactured by Spraying Systems Company (Mode1 1/4 J 2050 fluid nozzle and 67147 air nozzle). The outlet diameter of the nozzle was $1.194 \mathrm{~mm}$.

The fluid supply system consisted of a gas supply portion and a liquid supply section. A schematic of the fluid supply system is shown in Figure 2. The same fluid supply system was used for all three flows.

The gas supply system controlled the air flow rate for the evaporating spray and the isothermal air $j$ et and the gas flow rate for the variable density single-phase jet. The gas flow rates were metered and controlled 


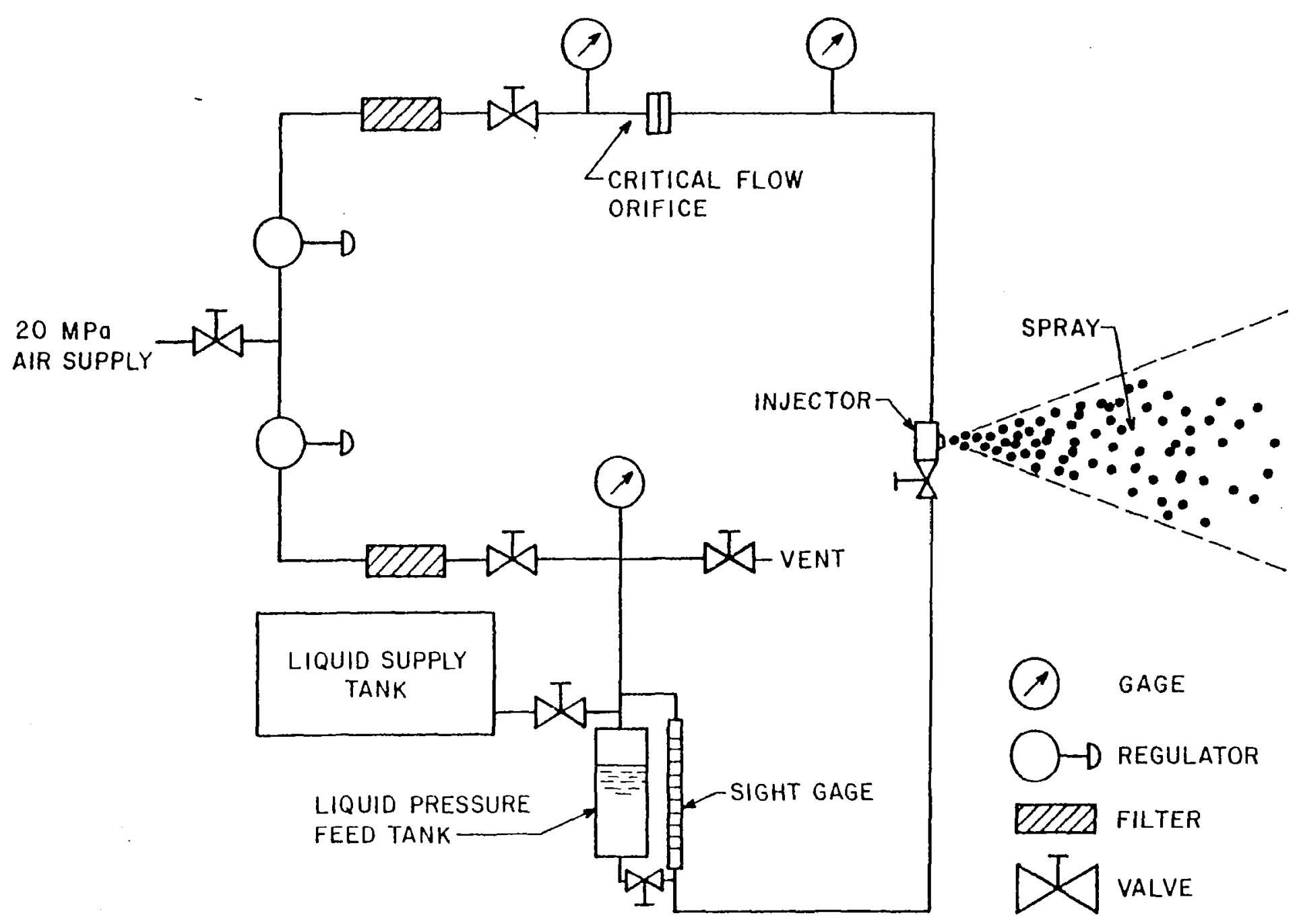

Figure 2 Spray Evaporation Test Apparatus 
with a critical-flow orifice and pressure regulator combination. The pressure regulator was a Matheson model 4 regulator with a $0-20.68 \mathrm{MPa}$ output capacity. The pressure upstream of the critical-flow orifice was measured with a Heise absolute pressure gauge with a 0-5.17 MPa capacity. The orifice was calibrated with a Precision Scientific Company wet-test meter $(0.283 \mathrm{\ell} / \mathrm{rev}$.$) .$

The liquid supply system was only required for the evaporating spray tests. The liquid was contained in a feed tank with a calibrated sight glass. The liquid flow rate was measured by timing the fall of the liquid level in the sight glass. The fluid was delivered to the nozzle by pressurizing the feed tank with air. A Matheson model 8 regulator was used to control the pressure. The pressure was measured with a 0-0.41 MPa gauge manufactured by Ashcroft Corporation. A liquid supply tank was connected to the system to supply additional liquid.

\subsubsection{Velocity Measurement}

Velocity measurements in the single-phase jets and the two-phase evaporating spray were conducted with a single-channel laser Doppler anemometer (LDA). An equipment list for the LDA is supplied in Table 1. The sending and receiving optics had a focal length of $595 \mathrm{~mm}$ with a 4.70 angle between beams. The aperture diameter of the photodetector was $0.256 \mathrm{~mm}$. The signal was focused on the photodetector with a $200 \mathrm{~mm}$ lens. This produced an ellipsoidal measuring volume $6.224 \mathrm{~mm}$ in length with a diameter of $.763 \mathrm{~mm}$. $\Lambda$ schematic of the LDA arrangement is shown in Figure 3.

Oil drops were used as the seeding material in the flow. The exhaust from a vacuum pump operating at its maximum flow rate contained a large nunber of suspended oil particles. These oil droplets were used to seed the surrounding gas. The average diameter of the particles was 0.618 $\mu \mathrm{m}$ at a concentration of $2.8 \times 10^{10}$ particles $/ \mathrm{m}^{3}$. The injected flow was not seeded, which limited measurements to the region far from the injector where a large number of oil particles had been entrained. Addition of the seeding particles changed the density and specific heat of the air less than 0.01 percent.

The seeding characteristics of the air was analyzed with a Royco model 230 light scattering particle counter. A 100 to 1 sample diluter was used to bring the concentration of the air sample within the range of the instrument. The samples were examined for one minute periods at 0.283 liters per minute flow rate.

Mean and fluctuating velocity components were measured in the axial, radial and tangential directions at several axial distances from the injector for all three test conditions. The measurements were repeatable within 10 percent for different traverses. Because the LDA system was limited to a single channel, $\bar{u}$ and ${\overline{u^{1}}}^{2}, \bar{v}$ and $\overline{v^{12}}$, and $\overline{w^{12}}$ were measured during three separate traverses of the flow with a different beam orientation for each traverse. An integration period of one minute was used to determine the mean quantities. A measurement of $\vec{u}^{\top} v^{\top}$ may also be derived by combining the results of several traverses (55). The 
Table 1

LDA Equipment List

\begin{tabular}{lcc}
\hline \multicolumn{1}{c}{ Component } & Manufacturer & Model \\
\hline Helium-Neon Laser & Spectra Physics & $125 \mathrm{~A}$ \\
Integrated Optics & Thermo-Systems & 900 \\
Frequency Shifter & Thermo-Systems & 980 \\
Photodetector & Thermo-Systems & 960 \\
Tracker & Thermo-Systems & 1090 \\
RMS Voltmeter & Thermo-Systems & 1076 \\
Dual Beam Oscilloscope & Tektronix & 912 \\
Integrating Voltmeter & Hewlett-Packard & $240 I \mathrm{C}$ \\
\hline
\end{tabular}




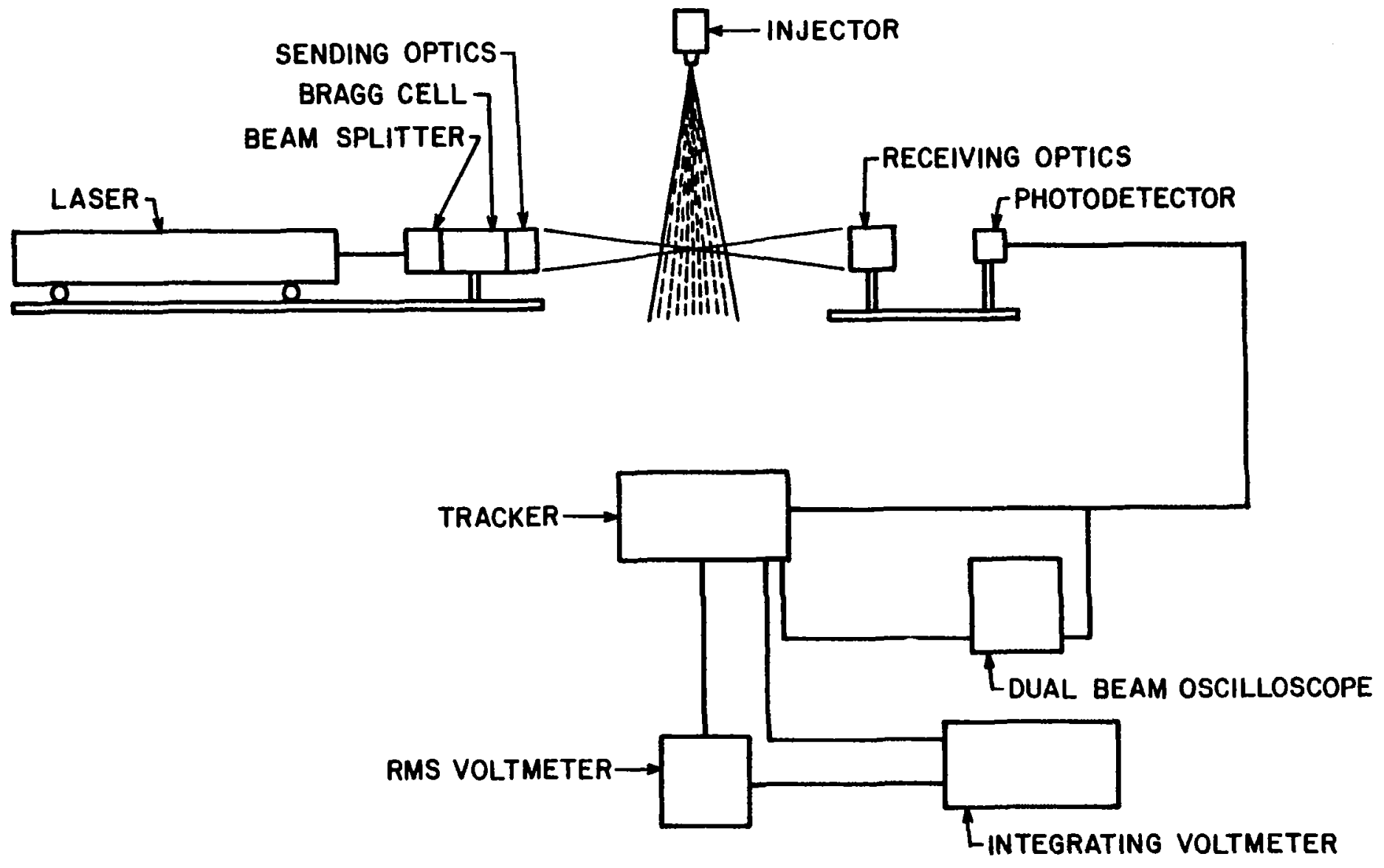

Figure 3 Schematic Diagram of the LDA System 
evaluation of the turbulence quantities from these measurements is described in Appendix A.

\subsubsection{Concentration Measurement}

Mean concentration mcasurements of the injected fluid were conducted for the variable density single-phase jets and the two-phase evaporating spray. Mean concentration measurements across the entire radius of the flow were obtained at axial positions of 203, 406 and 609 injector diameter from the injector.

The sampling probe tip is illustrated in Figure 4. The flows were isokinetically sampled by applying suction to the sampling probe and measuring the sampling flow rate. The sampling flow rate was adjusted to match the local flow rate determined from the velocity measurements. The sampling flow rate was measured with a Precision Scientific wettest meter $(0.0283 \mathrm{l} / \mathrm{rev}$.$) . The tip of the sampling probe could be$ heated to prevent water in the air from condensing and freezing at the probe inlet during evaporating spray tests.

The samples were analyzed with a Perkin Elmer Mode1 880 gas chromatograph using a hot-wire detector. A $5 \mathrm{ml}$ gas tight syringe was used to transfer the sample from the sampling port to the gas chromatograph.

The separating column for sulfur hexafluoride was stainless steel, $6.35 \mathrm{~mm}$ O.D. by $122 \mathrm{~cm}$ in length packed with 80-100 mesh silica gel. The column was placed in an ice bath and operated at $0^{\circ} \mathrm{C}$. The detector was operated at $250^{\circ} \mathrm{C}$. Helium was used as the carrier gas and maintained at a flow rate of $15 \mathrm{cc} / \mathrm{min}$.

The chromatograph was calibrated for sulfur hexafluoride-air mixtures using a commercially prepared sample purchased from Matheson Gas Products. The calibration procedure indicated that in the range of interest the peak area was a linear function of concentration.

The separating column for Freon-11 was stainless steel, $3.175 \mathrm{~mm}$ 0.D. by $183 \mathrm{~cm}$ in length packed with PORAPAK Q (80-100 mesh). This column was placed in the chromatograph oven and maintained at $150^{\circ} \mathrm{C}$. The detector was maintained at $250^{\circ} \mathrm{C}$. Helium was used as the carrier gas at a flow rate of $20 \mathrm{cc} / \mathrm{min}$. Various mixtures of Freon-11 and air and a commercially prepared sample of Freon-11 and helium (purchased from Matheson Gas Products) were used to calibrate the chromatograph. The calibration procedure indicated that the peaks were symmetrical and the concentration was a linear function of peak height for the concentration range of interest.

\subsubsection{Temperature Measurement}

Gas temperatures were measured at several axial locations in the spray with a fine wire thermocouple. Temperature measurements were conducted across the entire radius of the spray at several axial positions. The temperature measurements can only be considered qualitative estimates of the gas temperature because the effect of droplet impingement on the thermocouple was not considered. 


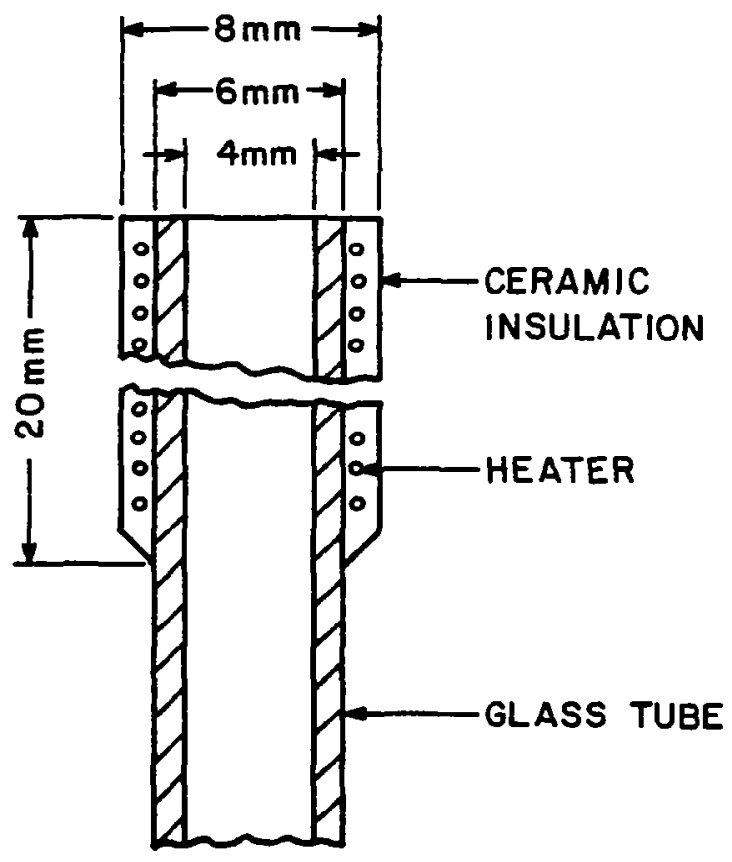

Figure 4 Sketch of the Sampling Probe 
An illustration of the thermocouple probe is shown in Figure 5 . The probe was manufactured from $0.076 \mathrm{~mm}$ diameter Chrome1-Alumel wire and was spot welded onto $0.75 \mathrm{~mm}$ diameter wire leads of the same material. The reference junction was placed in a reference cell manufactured by $\mathrm{Hy}-\mathrm{Ca} 1$ Engineering maintained at $0^{\circ} \mathrm{C}$. A Hewlett-Packard integrating digital voltmeter, model 240 IC, was used to integrate the signal over a one minute period, in order to determine the mean temperature.

\subsubsection{Drop Size and Liquid Flux Measurements}

An inertial impaction method was used to determine the droplet size distribution and the liquid mass-flux. Small glass slides were coated with magnesium oxide and exposed to the two-phase spray for a specified time period. As each drop hits the slide, it leaves an impression in the oxide coating, proportional to its size. The slide was examined under a microscope and each drop impression was sized and counted. This permitted determination of the dropsize distribution over a cross-section of the spray and the point-to-point vaxiation in the dropsize across a spray cross-section. A measurement of the 1iquid mass-flux was also determined. These measurements were performed at several axial locations to indicate the axial variation in dropsize distribution and the liquid mass-flux.

A shutter mechanism was designed to expose the slide to the spray for a given time period. A sketch of the shutter mechanism is shown in Figure 6. Compressed air forces the shutter to move across the slide. The shutter speed was timed at 20 milliseconds. The collection efficiency of the shutter mechanism may be calculated for a range of droplet sizes for a given relative velocity (56). This was used to correct the number of droplets collected.

The droplet size distribution was measured at several axial locations. At each axial location, the droplet distribution was measured across the entire width of the spray. The Sauter mean diameter and the average droplet diameter are determined directly from the droplet size distribution. The liquid mass flux was determined by dividing the total liquid mass collected by the collection area and the exposure time.

\subsubsection{Jet Momentum Measurement}

The momentum of each flow was determined by measuring the axial force on an impingement plate held near the exit of the nozzle (100 mm square plate, $25 \mathrm{~mm}$ from the nozzle). A Unimeasure 80 force transducer was used to measure the force. The transducer was calibrated, in turn, by placing known weights on the plate. The initial velocity was then determined from the jet momentum and the mass flow rate.

\subsection{Experimenta1 Conditions}

The air for the system was supplied by a reciprocating type Ingersol1Rand compressor. The compressed air was filtered with a Matheson type 451 filter to remove oil and particles greater than $5 \mu \mathrm{m}$. 


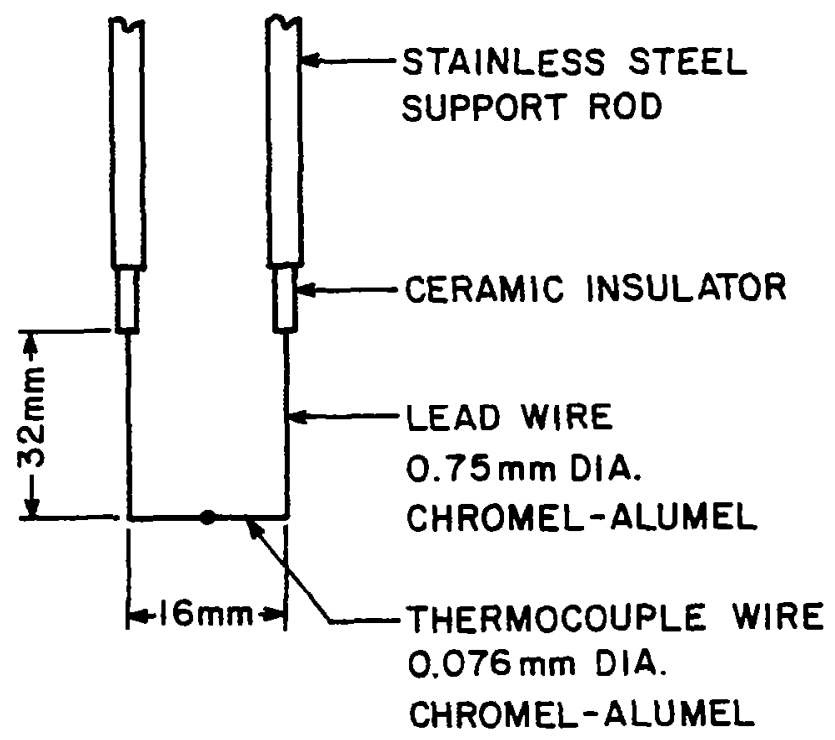

Figure 5 Sketch of the Thermocouple Probe 


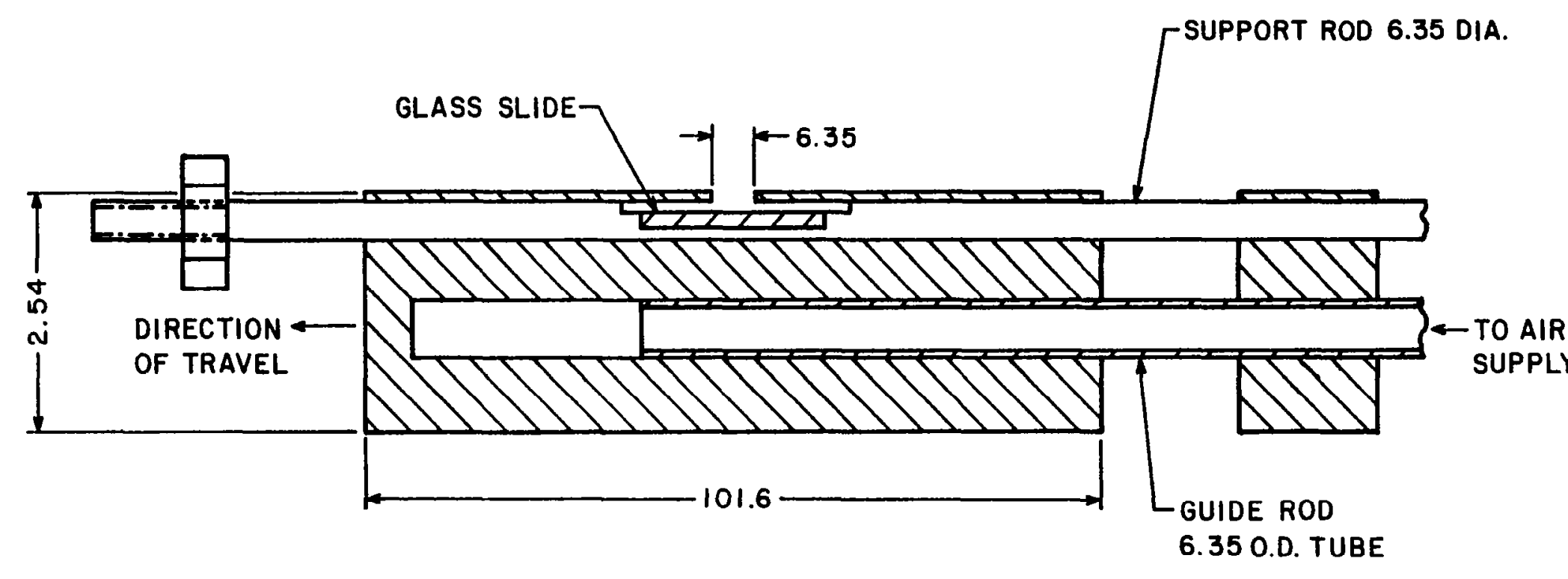

Figure 6 Sketch of the Droplet Impactor 
The sulfur hexafluoride was produced by Matheson Gas Products. The gas was contained in a cylinder under its own vapor pressure (2200 $\mathrm{kPa}$ at $294 \mathrm{~K}$ ). The gas was certified purity grade with a listed purity of 99.8 percent.

The Freon-11 was supplied by E.I. DuPont de Nemours and Company. The purity of the liquid was 99.9 percent.

The test conditions for the three cases are summarized in Table 2.

CHLAPTER III

THEORETICAL CONSIDERATIONS

\subsection{Description of Model}

The theoretical model considers a steady, axisymmetric, turbulent jet in an infinite, stagnant media. The overall configuration of the flow is illustrated in Figure 1. The jets to be considered are as follows:

1. Isothermal air jet in air.

2. Heated air jet in air.

3. Dense gas jet in air.

4. Air jet in water.

5. Evaporating spray in air.

The analysis generally follows the procedure developed by Lockwood and coworkers $(46,47)$, since this approach has been successful in earlier analyses of single-phase jets. The contribution of the present analysis is consideration of two-phase jets using the locally homogeneous flow approximation.

The locally homogencous flow approximation for a gas-liquid jet or evaporating spray implies that liquid and gas velocities are the same and that the two-phase mixture is in thermodynamic equilibrium at each point in the flow. This means that the temperature of both phases is the same and that phase equilibrium is maintained, i.e., the chemical potential of each species is the same in both phases.

In order to satisfy the locally homogeneous flow approximation, the rates of transport between the phases must be fast in comparison to the rate of development of the flow as a whole. The validity of the approximation can best be assessed when some information is available concerning conditions within the flow. In the present study, the locally homogeneous flow model was used as a first estimate of the flow, followed by particle trajectory calculations in order to evaluate transport rates between the phases.

Utilizing the assumption of locally homogeneous flow, the remainder of the analysis parallels models for single-phase flow. Typical of analyses of low Mach number jets, it is assumed that the boundary layer approximations apply, and that viscous dissipation effects and kinetic energy are negligible. Due to the relatively low temperature levels and small temperature differences encountered in the measurements to be 
Table 2

Summary of Test Conditions ${ }^{a}$

\begin{tabular}{|c|c|c|c|}
\hline Case & 1 & 2 & 3 \\
\hline Injector Fluid & Air & Sulfur Hexafluoride & Freon-11 \\
\hline $\begin{array}{l}\text { Injector Flow Rates } \\
(\mathrm{g} / \mathrm{s})\end{array}$ & & & \\
\hline Gas & 0.467 & 0.103 & 0.225 \\
\hline Liquid & 0 & 0 & 1.548 \\
\hline \multicolumn{4}{|l|}{$\begin{array}{l}\text { Injector Pressures } \\
\qquad(\mathrm{kPa})\end{array}$} \\
\hline Gas & 203 & 186 & 211 \\
\hline Liquid & -- & -- & 138 \\
\hline $\begin{array}{l}\text { Jet Momentum } \\
(\mathrm{N})\end{array}$ & 0.100 & 0.0093 & 0.132 \\
\hline $\begin{array}{l}\text { Sauter Mean Diameter } \\
(\mu \mathrm{m})\end{array}$ & - & -- & 29 \\
\hline $\begin{array}{l}\text { Initial Velocity } \\
(\mathrm{m} / \mathrm{s})\end{array}$ & 214.1 & 90.30 & 74.45 \\
\hline
\end{tabular}

$\mathrm{a}_{\mathrm{T}_{\infty}}=296 \mathrm{~K}, \mathrm{P}_{\infty}=97 \mathrm{kPa}$

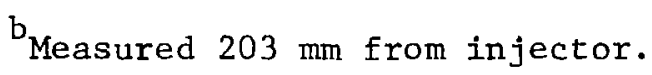


considered with the analysis, radiation is also ignored.

Following Lockwood and coworkers $(46,47)$ among others, it is assumed that the exchange coefficients for all species and heat are the same. This implies equality of both the laminar and turbulent components of the exchange coefficients. This is a reasonable approximation for singlephase flows $(46,47,57,58)$, but is more questionable for gas-1iquid mixtures. For example, even at the locally homogeneous flow limit, the laminar diffusivity of small drops is much smaller than gas molecules, although turbulent diffusion rates are nearly the same (59). However, the approximation is reasonable, since the effect of laminar diffusion in turbulent flow is not thought to be large, at least for mean properties (58).

The assumption of equal exchange coefficients for all species and heat implies that, $f$, the mixture fraction (defined as the fraction of mass at a given point which originated from the injector) is a passive scalar or conserved property of the flow. In combination with the other assumptions discussed earlier, this implies that the properties at each point in the flow correspond to the thermodynamic state attained when an amount $f$ of injector fluid and (1-f) of ambient fluid, at their initial states, are adiabatically mixed at the ambient pressure of the jet.

The turbulent flow model is based on the approach used by Gosman, Lockwood and Syed (47) for single-phase jets. This involves the solution of Reynolds-averaged conservation equations. The transport of mean quantities is given by conservation equations for mass, momentum and mixture fraction (equilibrium thermodynamics gives all other properties, temperature, density and composition, as a function of mixture fraction). Turbulence characteristics are based on a second-order model requiring the solution of model equations for turbulent kinetic energy, dissipation and concentration fluctuations $(k-\varepsilon-g$ mode 1$)$. While buoyancy is considered in the mean equations, its effect on turbulence production and dissipation is ignored. This general procedure has been successful for a variety of turbulent single-phase jets $(46,47,57,58,60-62)$.

\subsection{Equation of State}

The relationship between mixture enthalpy, composition, temperature and density and the mixture fraction is provided by the equation of state. Each type of flow to be considered requires a separate equation of state.

The experimental results to be compared with the analysis were all obtained at relatively low pressures. Therefore, all gases are assumed to be ideal gases. Since combustion is not treated, chemical reactions are ignored. Finally, it should be recalled that the mixing process is adiabatic and occurs at constant pressure, under the assumptions of the present analysis.

Considering $\mathrm{N}$ species in the flow, the expression for the composition of the mixture is: 


$$
Y_{i}=Y_{i o} f+Y_{i \infty}(1-f) \quad, \quad i=1, \ldots, N
$$

where each species may exist in both the gaseous or liquid state

$$
Y_{i}=Y_{f i}+Y_{g i} \text {. }
$$

The enthalpy of the mixture can be expressed as

$$
h=h_{o} f=h_{\infty}(1-f)
$$

where at any condition

$$
\mathrm{h}=\sum_{\mathrm{N}}\left(\mathrm{Y}_{f i} \mathrm{~h}_{f i}+\mathrm{Y}_{\mathrm{gi}} \mathrm{h}_{\mathrm{gi}}\right) \quad \mathrm{i}=1, \ldots, \mathrm{N}
$$

The density of the mixture is given by

$$
\rho=\sum_{N}\left(Y_{f i} \nu_{f i}+Y_{g 1} \nu_{g i}\right)^{-1} \quad i=1, \ldots, N
$$

where $\nu_{f i}$ and $\nu_{g i}$ are the partial specific volumes of species $i$ in the liquid and gas gitases.

Given the relationships between enthalpy and density of each species and the composition, temperature and pressure, Equations (3.1) - (3.5) are sufficient to describe the composition, temperature and density of the mixture. The relative composition of the gas and liquid phases is obtained from Equation (3.2) and the requirement that the chemical potential of each species must be the same in both phases. This requires that each type of flow must be examined separately.

A gas jet injected into a stagnant gas environment is the least complicated flow to be examined. The present study considered three gas-gas systems: an isothermal air-air jet, a heated air-air $j$ et, and a sulfur hexafluoride-air jet. All gases were modeled as ideal gases with a constant specific heat. Details of the gas-gas equations of state are presented in Appendix B.1 - B.3.

An equation of state for the two-phase air-water system investigated by Tross (4) has been formulated in the present study. The flow was considered to be isothermal and the air was assumed to behave as an ideal gas. It was assumed that the effect of water vapor was negligible and that no air was dissolved in the water. The details of the air-water equation of state are described in Appendix B.4. The equation of state for the air-water system is shown in Figure 7 . The mass fractions of the air and water vary linearly with the mixture fraction. However, the variation of density with mixture fraction is very non-1inear.

The most complicated flow considered was the case of an evaporating spray. It was assumed that all gases behaved as ideal gases and that no air was dissolved in the liquid phase. The equation of state for the 


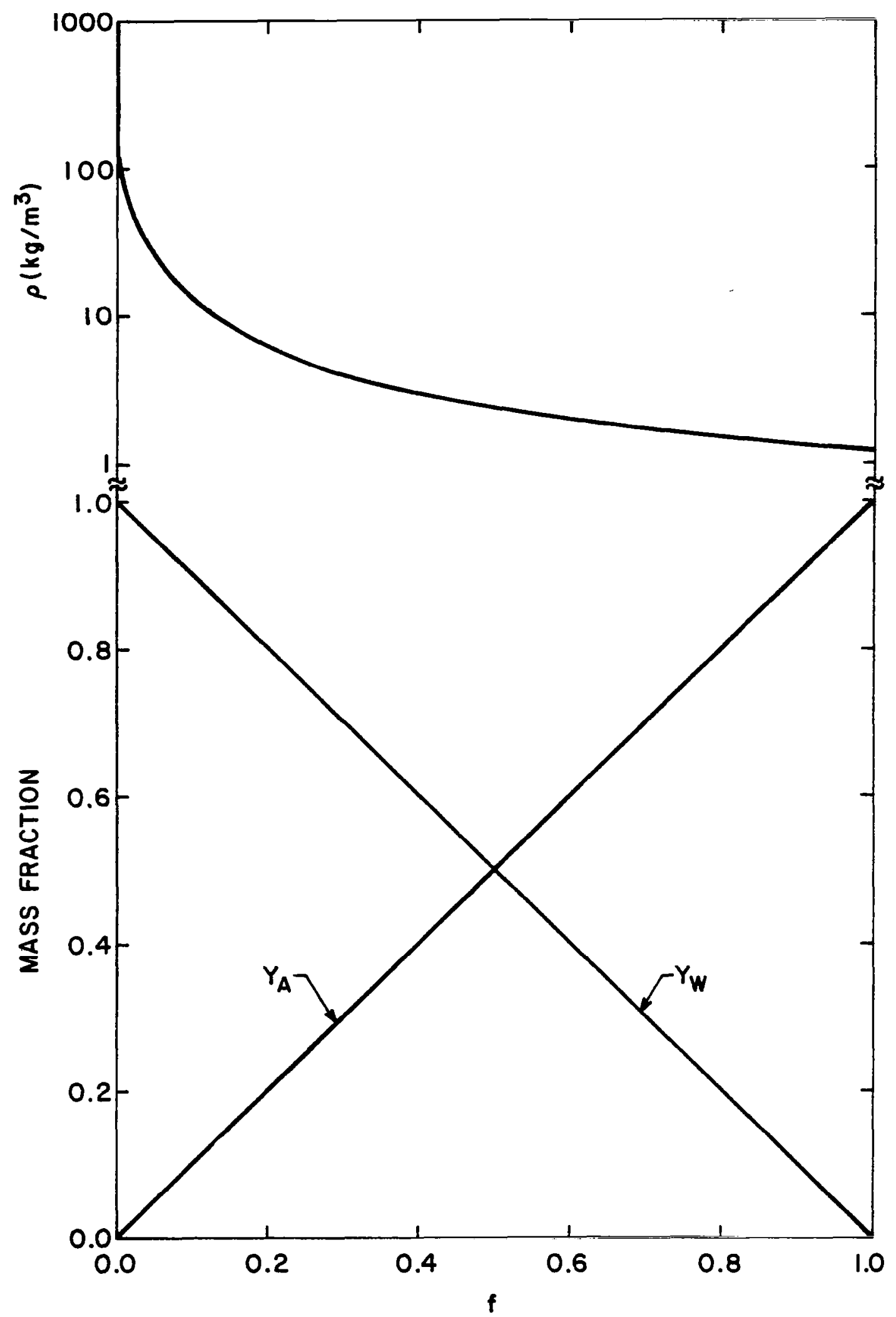

Figure 7 Equation of State for the Air-Water System [4] 
evaporating spray is shown in Figure 8. In this case, both air and Freon 11-1iquid and vapor leave the injector, while the surrounding gas contains no Freon-11. The total mass fractions of air and Freon-11 are linear. The presence of liquid, however, causes the non-linear behavior of mixture temperature and density. Details of the evaporating spray equation of state are described in Appendix B.5. The physical properties used for all the flows are summarized in Appendix B.6.

\subsection{Probability Density Function Mode1}

The mean value of any scalar quantity $\theta$ (other than $f, k, \varepsilon$ and $g$ ) can be determined from its variation with $f$ if the probability density function of $f, P(f)$ is known as a function of position in the flow. Given $P(f)$, the mean value of any scalar is given by (46)

$$
\theta=\int_{0}^{1} \theta(f) P(f) d f
$$

Following Lockwood and Naguib (46), a clipped Gaussian probability density function was assumed in the present study. This distribution is represented by a Gaussian function for the range $0<f<1$, with the tails of the distribution being represented by delta functions at $f=0$ and 1 , respectively. This distribution is represented by the following equations

$$
\begin{aligned}
& P(f)=\frac{1}{\sigma(2 \pi)^{1 / 2}} \exp \left[-\frac{1}{2}\left(\frac{f-\mu}{\sigma}\right)^{2}\right], 0<f<1 \\
& P(0)=A=\int_{-\infty}^{0} \frac{1}{\sigma(2 \pi)^{1 / 2}} \exp \left[-\frac{1}{2}\left(\frac{f-\mu}{\sigma}\right)^{2}\right] d f \\
& P(1)=B=\int_{1}^{\infty} \frac{1}{\sigma(2 \pi)^{1 / 2}} \exp \left[-\frac{1}{2}\left(\frac{f-\mu}{\sigma}\right)^{2}\right] \mathrm{df}
\end{aligned}
$$

and is illustrated in Figure 9.

The most probable value of the distribution, $\mu$, and the variance, $\sigma$, can be determined by noting that

$$
\begin{aligned}
& \bar{f}=\int_{0}^{1} f P(f) d f \\
& g=\int_{0}^{1}(f-\bar{f})^{2} P(f) d f
\end{aligned}
$$



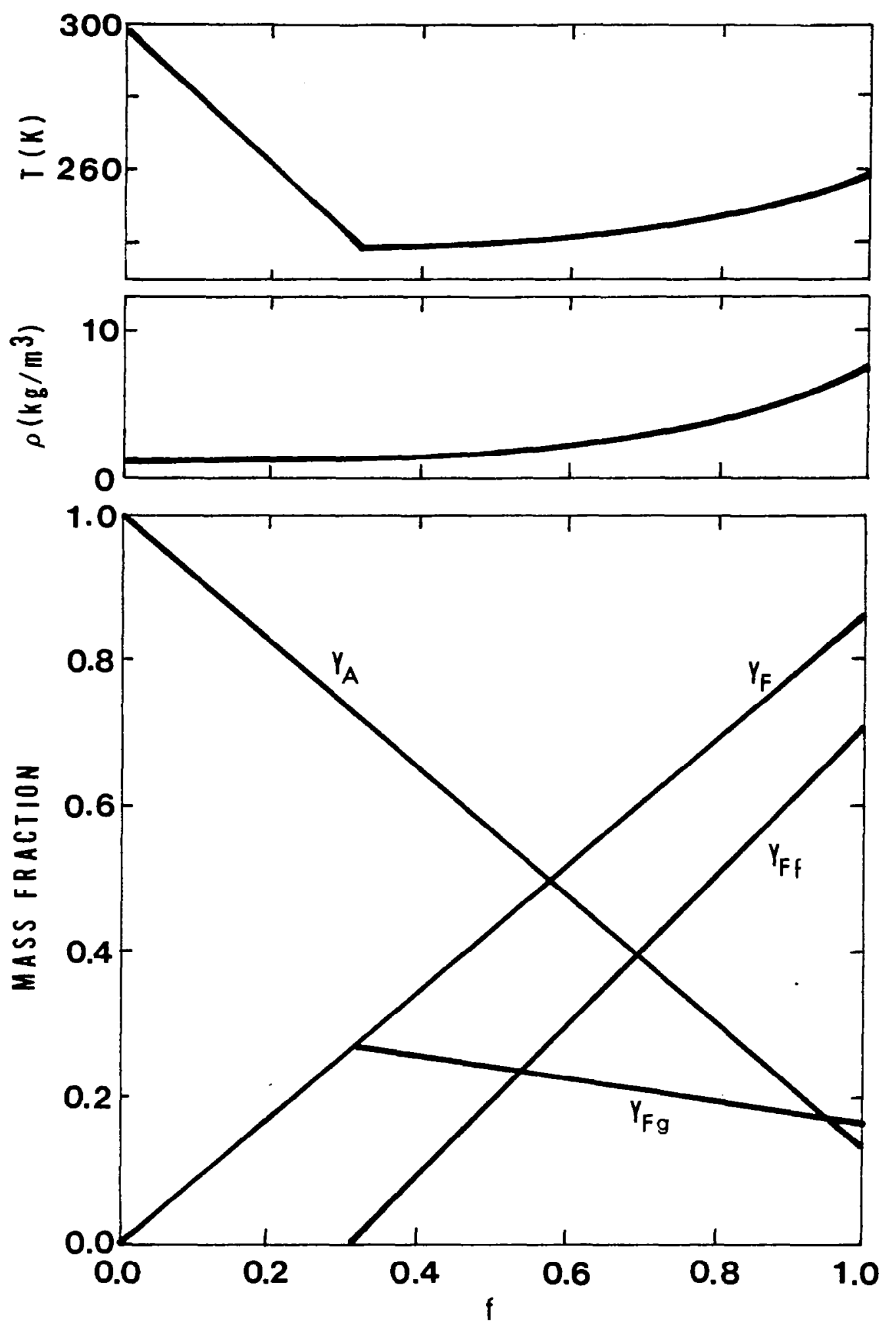

Figure 8 Equation of State for the Evaporating Freon-11 Spray 


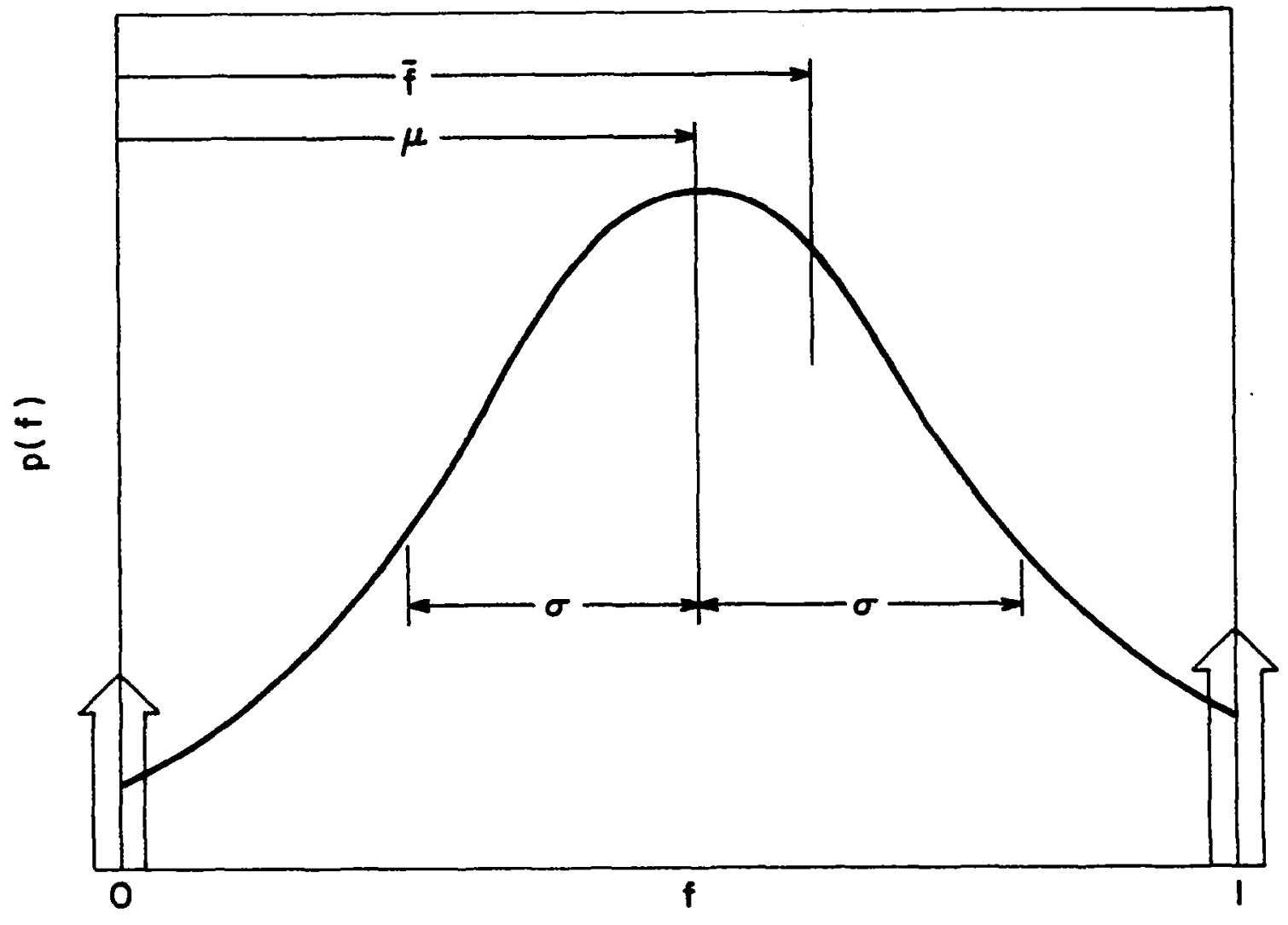

Figure 9 Probability Density Function for Mixture Fraction 
Both $\bar{f}$ and $g$ are known from the integration of the conservation equations. Therefore, Equations (3.10) and (3.11) provide two implicit equations to solve for $\sigma$ and $\mu$. This completes the specification of the probability density function. Values of $\bar{\rho}, \bar{T}, \bar{Y}_{j}$, etc., can then be obtained by integrating Equation (3.6), where $\theta(\mathrm{f})$ is specified by the equation of state.

\subsection{Governing Equations}

Employing the assumptions discussed in Section 3.1, the Reynolds-averaged form of the conservation equations of mass, momentum, mixture fraction, turbulent kinetic energy, turbulent dissipation rate and concentration fluctuations are obtained as described in Appendix D. The final form of the equations are as follows:

Conservation of Mass

$$
\frac{\partial \bar{p} \bar{u}}{\partial x}+\frac{1}{r} \frac{\partial}{\partial r}\left(r \bar{\rho} \bar{v}^{0}\right)=0
$$

Conservation of Momentum

$$
D(\bar{u})=a\left(\bar{\rho}_{\infty}-\bar{\rho}\right)
$$

Conservation of Mixture Fraction

$$
D(\vec{f})=0
$$

Conservation of Turbulent Kinetic Energy

$$
D(k)=\mu_{t}\left(\frac{\partial \bar{u}}{\partial r}\right)^{2}-\overline{\rho \varepsilon}
$$

Conservation of Turbulent Dissipation

$$
D(\varepsilon)=C_{\varepsilon_{1}} \mu_{t} \frac{\varepsilon}{k}\left(\frac{\partial \bar{u}}{\partial r}\right)^{2}-C_{\varepsilon_{2}} \vec{\rho} \frac{\varepsilon^{2}}{k}
$$

Conservation of Concentration Fluctuations

$$
\mathrm{D}(\mathrm{g})=\mathrm{C}_{\mathrm{g}_{1}} \mu_{t}\left(\frac{\partial \overline{\mathrm{f}}}{\partial \mathrm{r}}\right)^{2}-\mathrm{C}_{\mathrm{g}_{2}} \bar{\rho} \frac{\varepsilon \mathrm{g}}{\mathrm{k}}
$$

where

$$
\bar{\rho} \bar{v} 0=\bar{\rho} \bar{v}+\overline{\rho^{\prime} v^{\prime}}
$$


and

$$
D(\phi)=\bar{\rho} \bar{u} \frac{\partial \phi}{\partial x}+\bar{\rho} \frac{v}{0} \frac{\partial \phi}{\partial r}-\frac{1}{r} \frac{\partial}{\partial r}\left(r \frac{\mu_{t}}{\sigma_{\phi}} \frac{\partial \phi}{\partial \dot{r}}\right)
$$

for $\phi=\bar{u}, \bar{f}, k, \varepsilon$ or $g$.

The boundary conditions for these equations are:

$$
r=0, \frac{\partial \phi}{\partial r}=0 \quad ; \quad r \rightarrow \infty \quad, \quad \phi=0
$$

The initial conditions of the flow are

$$
\begin{gathered}
\mathrm{x}=0, \mathrm{r}<\mathrm{d} / 2, \overline{\mathrm{u}}=\dot{\mathrm{M}}_{0} / \dot{\mathrm{m}}_{0}, \overline{\mathrm{f}}=1, \mathrm{~g}=0 \\
\mathrm{k}=\mathrm{k}_{0}, \quad \varepsilon=\varepsilon_{0}
\end{gathered}
$$

The parameters $k_{0}$ and $\varepsilon_{0}$ are assumed to have the values appropriate for fully developed flow in tubes.

The turbulent viscosity is obtained from the following constitutive equation:

$$
\mu_{t}=C_{\mu} \quad \overline{\rho k}^{2} / \varepsilon
$$

Equations (3.12) - (3.22) represent the final set of equations to be solved in this analysis. This set is applicable to all the flows considered in the present study.

\subsection{Numerical Solution}

\subsubsection{Generalized Computer Code}

A general purpose computer code, GENMIX, developed by Patankar and Spalding (45) for boundary layer flows, was used to solve the governing equations. In order to solve the governing equations using GENMIX (45), they must be transformed into a coordinate system based on the axial distance $x$ and a dimensionless stream function $w$. The dimensionless stream function is defined as:

$$
\omega=\frac{\psi-\psi_{I}}{\psi_{E}-\psi_{I}}
$$

where $\psi_{\text {and }} \psi_{E}$ are the values of the stream function at the inner and externat boundaries of the flow. 
The stream function is defined as:

$$
\frac{\partial \psi}{\partial x}=-r \bar{\rho} \bar{v} 0
$$

and

$$
\frac{\partial \psi}{\partial r}=r \bar{\rho} \bar{u}
$$

The use of the stream function insures the solution of Equation (3.12). At the inner and external boundaries the stream function can be expressed as

$$
\frac{\partial \psi_{I}}{\partial x}=-r_{I^{m}}{ }^{\prime \prime}
$$

and

$$
\frac{\partial \psi_{E}}{\partial \mathrm{x}}=-r_{E} \dot{\mathrm{m}}_{E}^{\prime \prime}
$$

where $\dot{\mathrm{m}}^{\prime \prime}$ and $\dot{\mathrm{m}}_{F} "$ are the mass transfer rates across the inner and externat boundaries.

These transformations permit Equations (3.13) through (3.18) to be put in the general form

$$
\frac{\partial \phi}{\partial \mathbf{x}}+(\overline{\mathrm{A}}+\overline{\mathrm{B}} \omega) \frac{\partial \phi}{\partial \omega}=\frac{\partial}{\partial \omega}\left(\overline{\mathrm{C}} \frac{\partial \phi}{\partial \omega}\right)+\overline{\mathrm{D}}
$$

where $\phi$ represents the dependent variables $\bar{u}, \bar{f}, k, \varepsilon$ and $g$. The other terms in Equation (3.28) are defined in Table 3. This set of equations is integrated from the injector to a value of $x$ equal to 550 diameters downstream for values of $\omega$ ranging from zero to one.

The GENMIX program (45) has the capability for as many as 30 crossstream nodes. All of the present calculations were performed using 30 cross-stream nodes. The cross-stream grid spacing varied to include the entire width of the flow.

In order to maintain the program as general as possible, the forward step was also varied throughout the flow. The forward step was limited so that the quantity of fluid added during the mixing step is a certain fraction of the total fluid in the flow to that position in the flow.

$$
\Delta x=\frac{(0.10)\left(\psi_{E}-\psi_{I}\right)}{r_{I^{\prime}}^{\prime \prime}-r_{E}^{m_{E}^{\prime \prime}}}
$$


31

Table 3

Definition of Terms in the Generalized GENMIX Program ${ }^{a}$

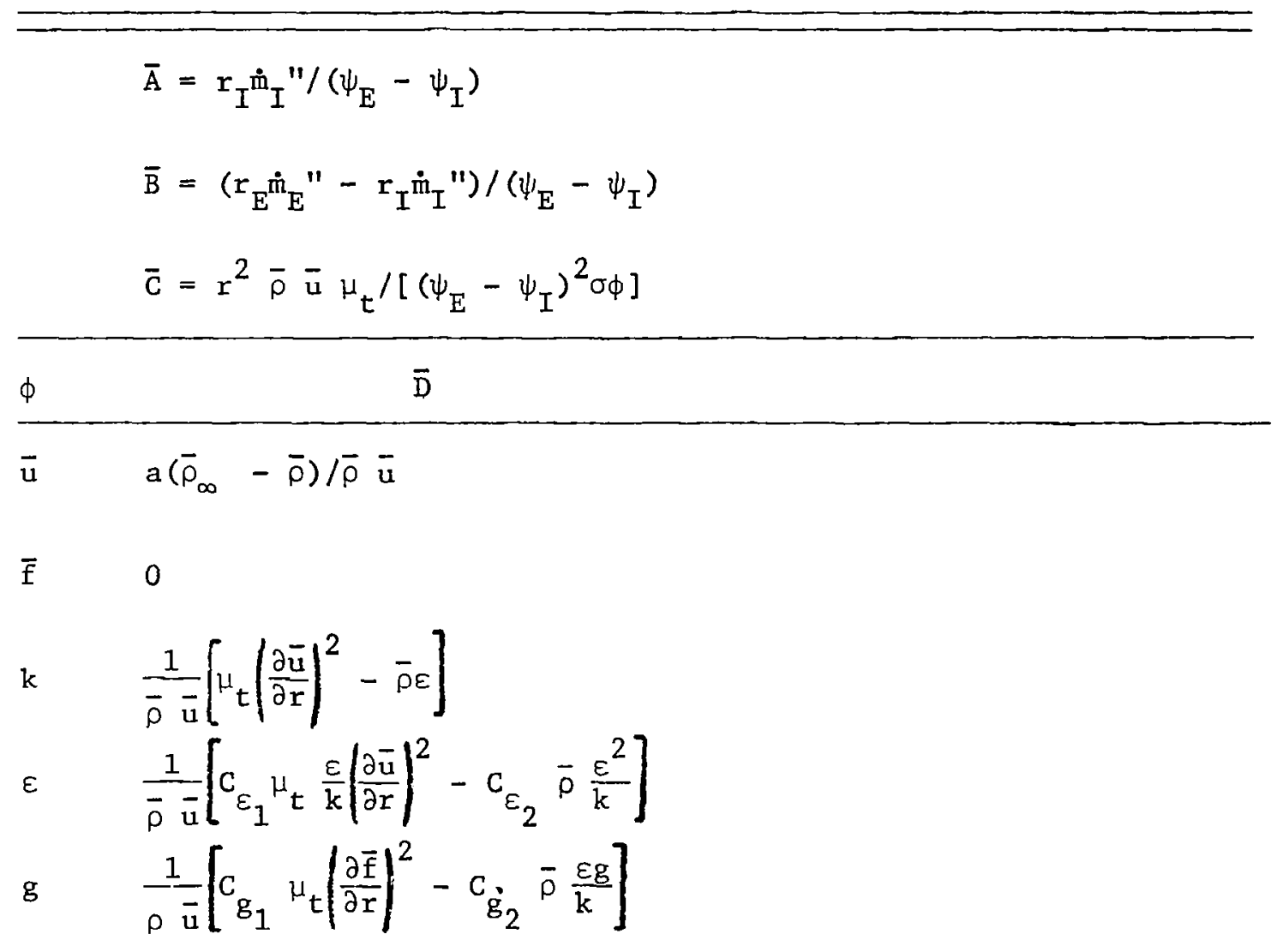

$$
a_{\phi}=\bar{u}, \bar{f}, \bar{k}, \varepsilon \text { or } g \text {. }
$$


In the present calculations the forward step was limited so that the ratio of additional fluid to the total fluid in the flow was 0.10 . This ratio was set as $10 \mathrm{w}$ as 0.001 without significant differences in the results, however, the larger value reduces the computation time.

\subsubsection{Concentration Fluctuation Mode1}

The relationships between $\bar{f}$ and $g$ and $\mu$ and $\sigma$ in the equations are difficult and time consuming to solve. The relationships between these quantities were computed once and stored in table form. These tables are shown in Appendix D.

After the solution of the governing equations at each grid node, the table was consulted using the specified values of $\bar{f}$ and $g$ to determine values of $\mu$ and $\sigma$.

The probability density function at each grid point is specified by the values of $\mu$ and $\sigma$. The Dirac delta functions at mixture fractions of zero and one can be calculated from Equations (3.8) and (3.9).

The time averaged temperature, density, and component mass fractions can now be calculated at each grid point with the relationship.

$$
\bar{\phi}=\mathrm{A} \phi_{0}+\mathrm{B} \phi_{\infty}+\frac{1}{\sigma 2 \pi} \int_{0}^{1} \phi(f) \exp \left[-\frac{1}{2}\left(\frac{f-\mu}{\sigma}\right)^{2}\right] \mathrm{df}
$$

where $\phi=T, \rho, Y_{i}$, etc.

The relationships for $\phi(f)$ are provided by the equation of state. The integral in Equation (3.30) is evaluated numerically, in a stepwise fashion. The value of $\phi$ was taken to be constant over several regions of the flow. This permitted the error function to be integrated independent of the quantity to be averaged.

\section{CHAPTER IV}

RESULTS AND DISCUSSION OF THE LOCALLY HOMOGENEOUS FLOW MODEL

\subsection{Introduction}

The major objective of the present study was to systematically evaluate a locally homogeneous model of spray evaporation. In order to evaluate the model, it was tested against a wide variety of single-phase and twophase flows. This included single-phase constant density jets, singlephase variable density jets, two-phase gas-liquid jets and an evaporating spray. Theoretical predictions of the axial and radial variations of mean and turbulent quantities were compared with the experimental results of the present study and results of previous investigations $(4,51,52$, $53,54)$.

The analytical model used in the present study, Equations (3.12) - (3.19), contains various constants which must be specified. The parameters used 
in the present study were those suggested by Lockwood and Naguib (46). These values are summarized in Table 4.

This group of constants has been optimized to produce the best overall agreement between predictions and measurements for axisymmetric flow. One undesirable feature is that $C_{\varepsilon}$ and $C_{g}$ must be modified in going from constant density to variable $\varepsilon_{2} \quad g_{2}$ density jets (46). This is probably due to the rather gross simplifications required to obtain model equations for variable density flows, using Reynolds averaging, e.g., dropping most density fluctuation terms. The use of Favre averaging might eliminate this difficulty, but at the expense of postulating a Favre joint probability density distribution. In general, planar jets require different constants than axisymmetric jets, which is another defect of the turbulence model. Due to this fact, different constants are frequently used for the potential core region of axisymmetric jets (which is nearly planar, initially), than for the fully developed portion of the flow. This modification was not found to be necessary during the present study. The same constants were used throughout the flow field.

\subsection{Radial Variation of Mean Quantities}

The theoretical predictions of the radial variation of mean axial velocity, mixture fraction, temperature, and liquid mass flux were compared with the experimental results found during the present study and several previous investigations $(4,51-54)$. The results were examined in a systematic fashion beginning with single-phase constant density jets and concluding with the two-phase jets.

Figure 10 is an illustration of the radial profile of the axial velocity for an isothexnal single-phase jet, a variable density single-phase jet and an evaporating spray. The axial velocity is normalized by the velocity at the centerline. The radial coordinate is normalized by the axial distance from the injector so that a direct measure of the prediction of the width of the flow can be obtained.

The isothermal single-phase $j e t$ is an air jet injected into an air environment at the same temperature. The theoretical prediction was compared with the experimental results of Wygnanski and Fiedler (51), Hetsroni and Sokolov (53), which were obtained with a hot-wire anemometer, and the experimental results of the present study, employing the 1aser Doppler anemometer. The experimental results are in the fully developed region of the flow extending from 35 injector diameters to 510 injector diameters from the injector. The experimental results of the present study were in good agreement with the results of the previous air jet investigations. The theoretical prediction of the axial velocity profile is in good agreement with all of the experimental measurements.

Analysis of the variable density single-phase jet considers experimental measurements within an isothermal sulfur hexafluoride gas jet injected into an air environment, obtained during the present investigation. Measurements of the velocity were limited to the region far downstream of the injector. The theoretical prediction slightly underestimates the radial spread of the jet, but is in generally good agreement with the experimental results. 
Table 4

Constants in the Turbulence Model

\begin{tabular}{lc}
\hline Constant & Value \\
\hline$C_{\mu}$ & 0.09 \\
$C_{\varepsilon_{1}}$ & 1.44 \\
$C_{\varepsilon_{2}}=C_{g_{2}}$ & $1.89,1.84^{2}$ \\
$C_{g_{1}}$ & 2.8 \\
$\sigma_{k}$ & 1.0 \\
$\sigma_{\varepsilon}$ & 1.3 \\
$\sigma_{f}$ & 0.7 \\
$\sigma_{g}$ & 0.7 \\
\hline
\end{tabular}

${ }^{a}$ Constant density and variable density flows, respectively. 


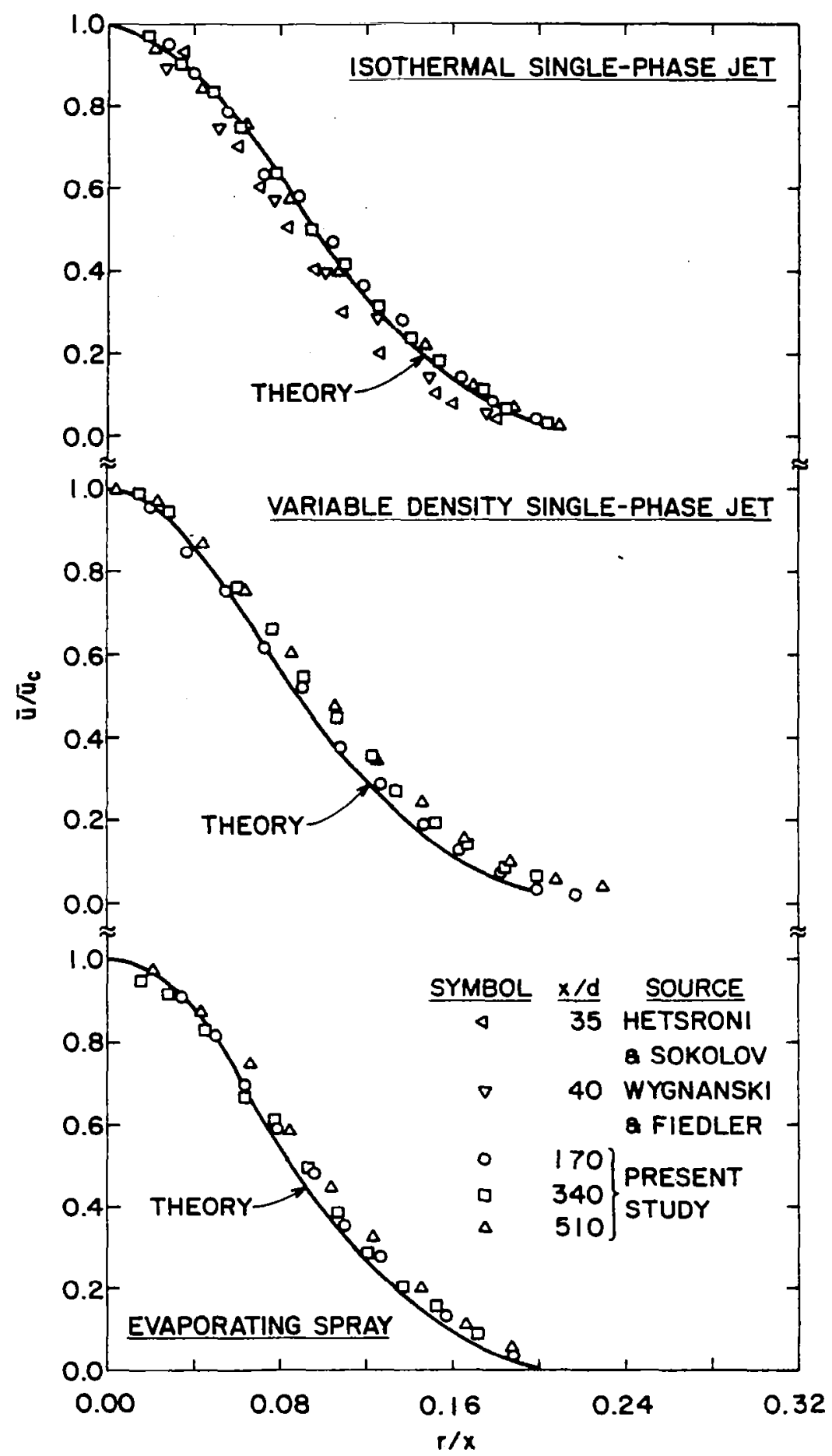

Figure 10 Radial Variation of Mean Axial Velocity 
The effectiveness of the present model for the case of an evaporating spray was evaluated by examining a well atomized Freon-11 spray. The experimental results were confined to the region far downstream of the injector. Although the model slightly underestimates the spreading rate of the spray, the agreement between theory and experiment is relatively good.

The theoretical model was also evaluated on the basis of its ability to predict the radial variation of mean mixture fraction. The comparison between the predicted and experimental results is shown in Figure 11 for an isothermal single-phase jet, a variable density single-phase jet and an evaporating spray. The mean mixture fraction is normalized by the mean mixture fraction at the centerline. The radial coordinate is normalized by the axial distance from the injector.

The ability of the theoretical model to predict the radial variation of mean mixture fraction for an isothermal single-phase jet was evaluated by comparing the theoretical prediction with experimental results obtained by Becker, et al., (52). These results were obtained in an isothermal air jet.. The theoretical predictions compare well with the experimental results.

The theoretical model also provides a good prediction of the radial variation of mean mixture fraction for single-phase variable density jets and two-phase evaporating sprays. The experimental measurements for both cases were confined to the region far downstream of the injector. Both theory and experiment indicate self-preserving flow in this region.

The locally homogeneous two-phase model was also applied to the two-phase air-water jet investigated by Tross (4). Comparison of the radial profiles for the axial velocity and mean mixture fraction are shown in Figure 12. The model tends to underestimate the radial width of the mixture fraction and axial velocity profiles. This disagreement is disappointing since the low inertia of bubbles in a continuous liquid phase should be favorable to the application of the locally homogeneous flow model. In view of the reasonably good predictions for the other single-phase and two-phase flows, e.g., Figures 10 and 11 , problems with the experiment may be a factor. In particular, the probe used by Tross to measure void fraction tends to underestimate the void fraction due to surface tension effects. The theory also has unique problems with this flow, particularly near the edge of the $j$ et. As discussed in Appendix $D$, omission of terms involving $\overline{\rho^{\prime} f^{\prime}}$ in the turbulence model is particularly questionable in this case due to the very large density gradients in the flow. Other terms involving density fluctuations may also be more important than in the other flows, involving more modest density variations. Finally, the velocity difference between the bubbles and the liquid is more appreciable near the edge of the flow, where the liquid velocity is relatively low. In view of these factors, the comparison between predictions and measurements in Figure 12 is not conclusive, and further theoretical and experimental study of this flow would be desirable.

The radial variation of temperature in an evaporating spray was also considered in the present study. Predictions and measurements of the normalized temperature decrement for the evaporating Freon-11 spray are 


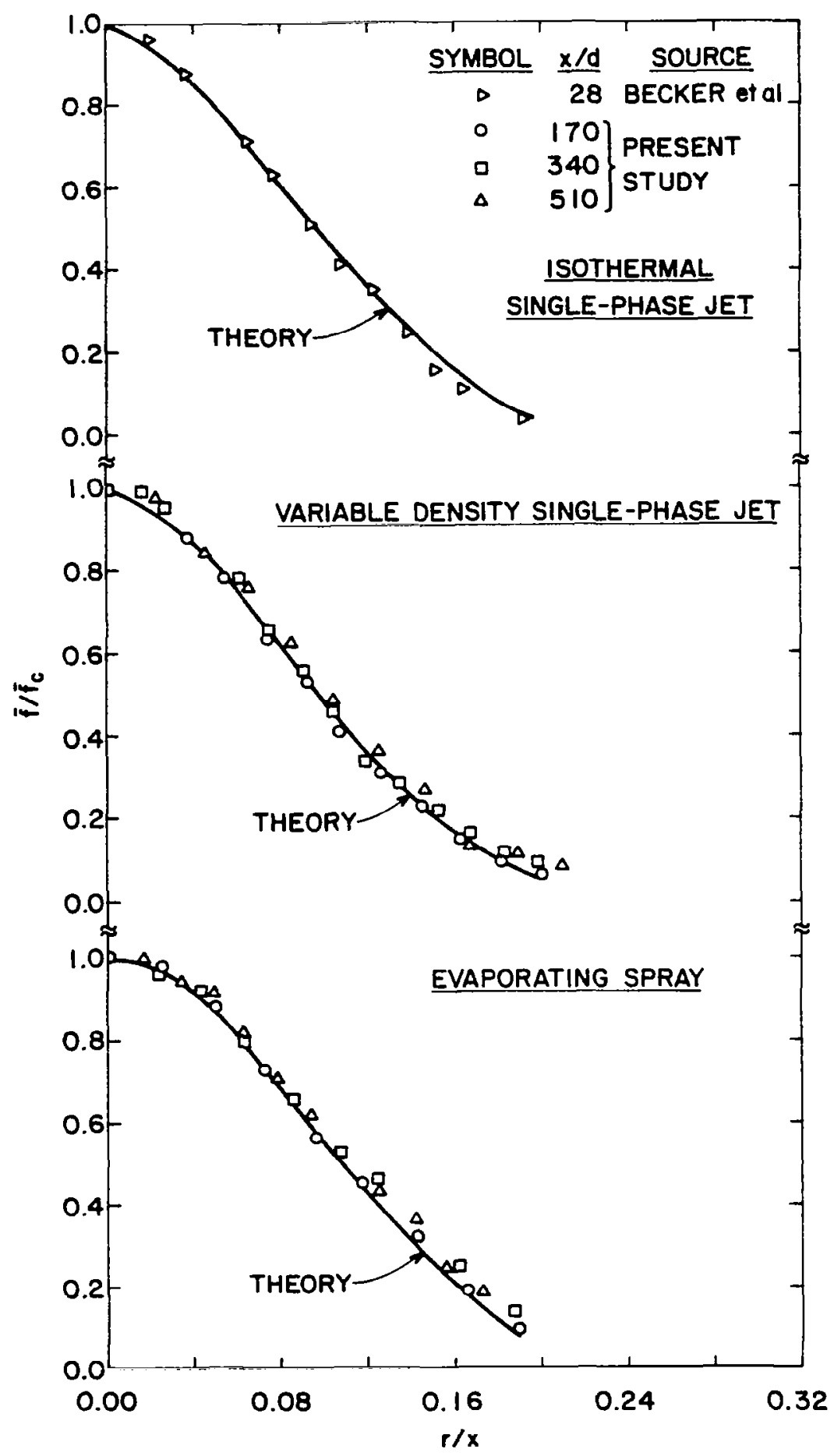

Figure 11 Radia1 Variation of Mean Mixture Fraction 


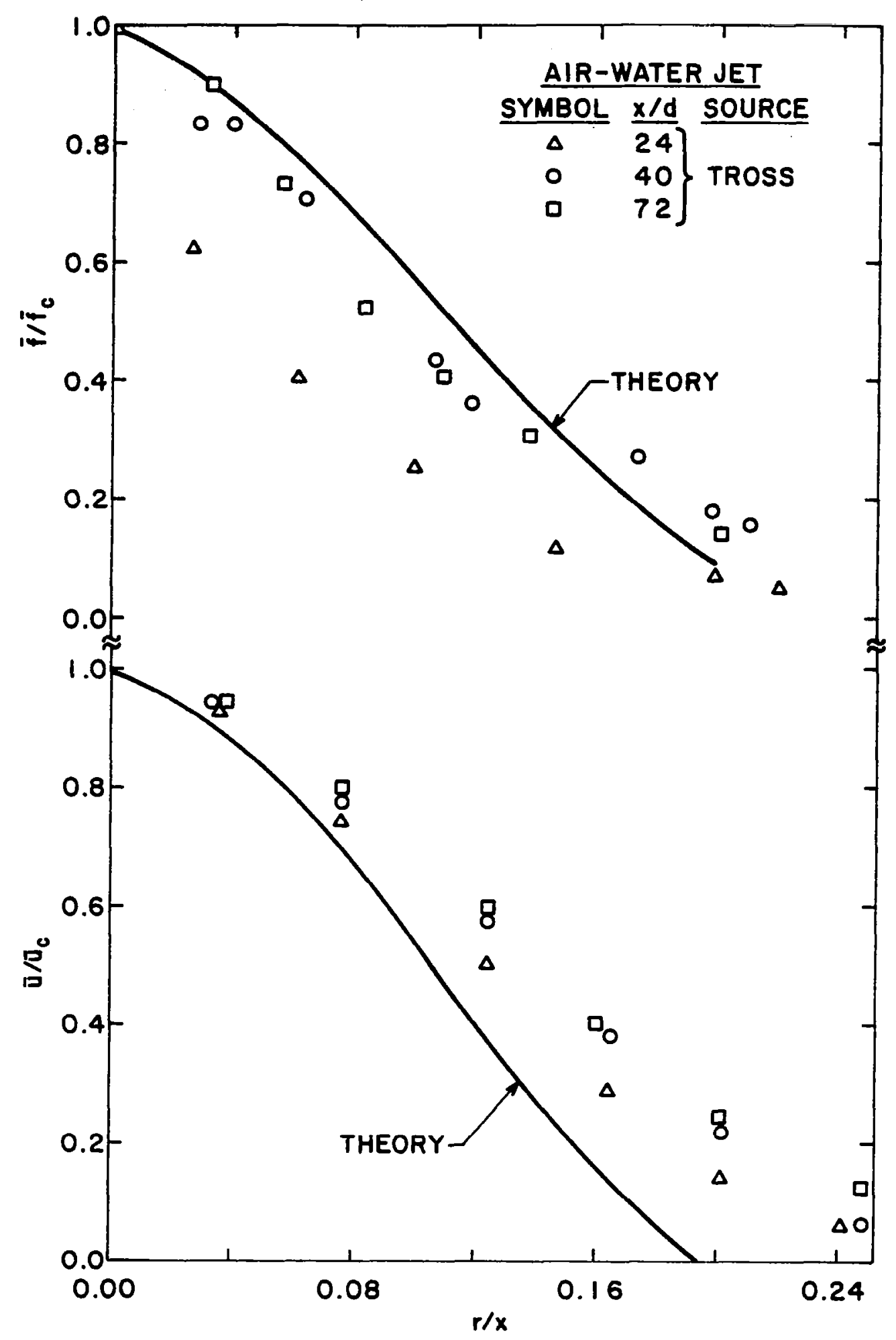

Figure 12 Radial Variation of Mean Axial Velocity and Mean Mixture Fraction for the Air-Water System [4] 
illustrated in Figure 13. Temperature measurements were obtained at 340 and 510 injector diameters from the injector. Temperature measurements could not be conducted closer to the injector, since water vapor in the air condensed and froze on the thermocouple junction in this region. The radial width of the temperature profile is somewhat overestimated by the theory. This is probably because the theory predicts that the Freon-11 should have already evaporated, the lack of any liquid material would account for higher temperatures.

The radial variation of the liquid mass flux is shown in Figure 14. The liquid mass flux was measured in the evaporating spray at 3 axial positions far from the injector. However, the locally homogeneous theory predicts that all of the liquid has vaporized less than 165 injector diameters from the injector. If the experimental measurements of the liquid mass flux are compared with the theoretical prediction of a position of 30 injector diameters from the injector, good agreement is obtained between the theory and the experimental results.

Overall, the locally homogeneous theory predicts the radial variation of mean quantities reasonably well. In the case of a spray the twophase nature of the flow does not appear to affect the radial variation of mean quantities for the present test conditions. Differences between the theory and the experiment for an evaporating spray are similar to the differences between theory and experiment for a single-phase variable density jet. The comparison between theory and experiment for the gas liquid jet was the least satisfactory of all the flows studied. However, there are unique experimental and theoretical difficulties with this flow which deserve further study.

\subsection{Radial Variation of Turbulence Quantities}

The radial variations of the intermittency and the normalized mean square mixture fraction for an isothermal air jet are shown in Figures 15 and 16. The theory is compared to the results of Becker, et al., (52). Fair agreement is achieved for the variation of the intermittency prediction over most of the width of the jet. However, the theory begins to fill near the edge of the flow. A similar effect is found for the variation of the mean square concentration fluctuations. Agreement is fair near the center of the flow but is less satisfactory near the edge of the jet.

The radial variation of the normalized Reynolds stress is illustrated in Figure 17 for an isothermal air jet, a variable density single-phase jet, and an evaporating spray. The Reynolds stress is normalized by the square of the axial velocity at the centerline.

The theoretical prediction of the Reynolds stress for an isothermal singlephase jet is compared with experimental results from Wygnanski and Fiedler (51) which exhibit more scatter. In general, the present calculations are in fair agreement with the measurements. 


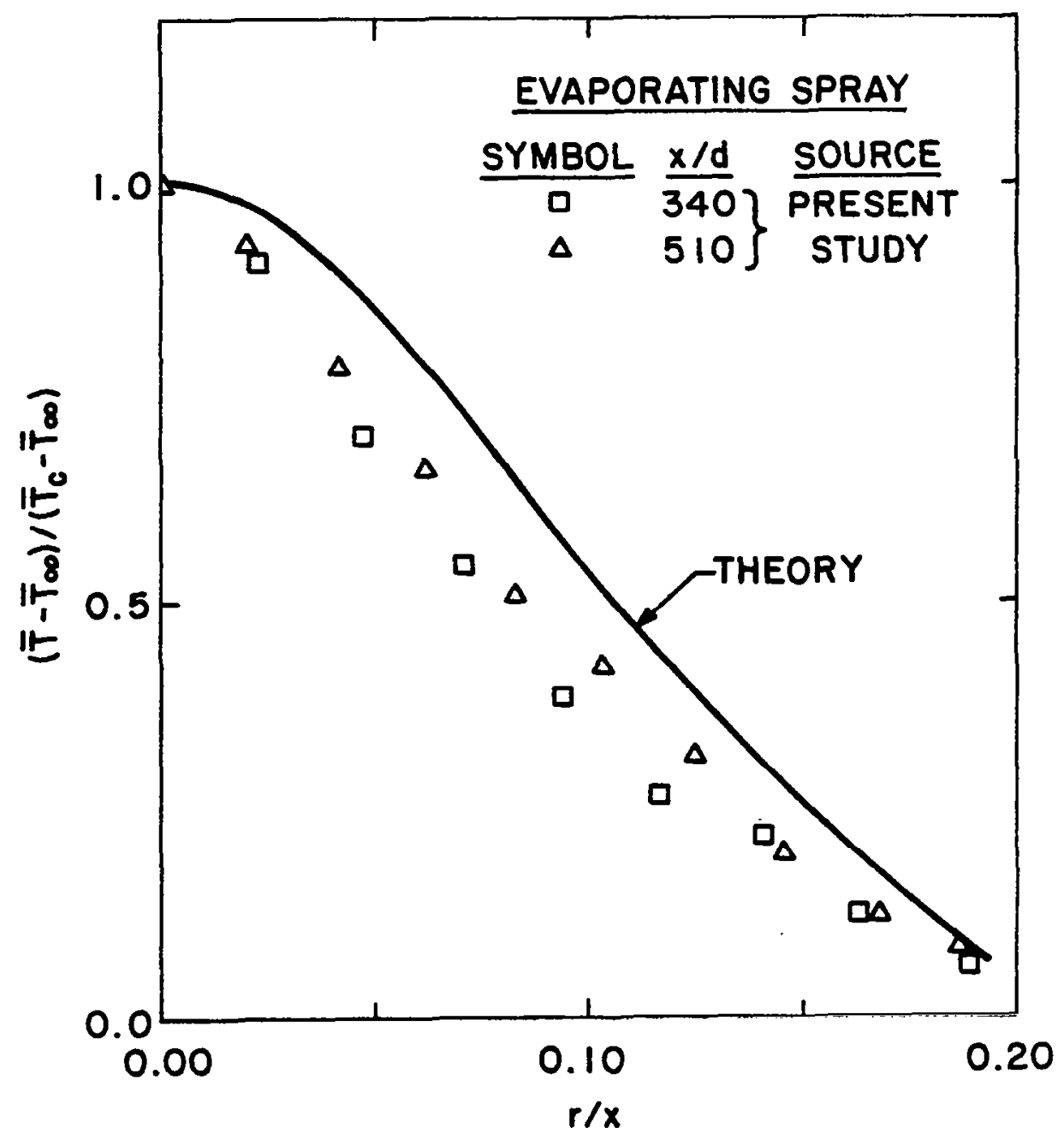

Figure 13 Radial Varlation of Temperature in an Evaporating Freon-11 Spray 


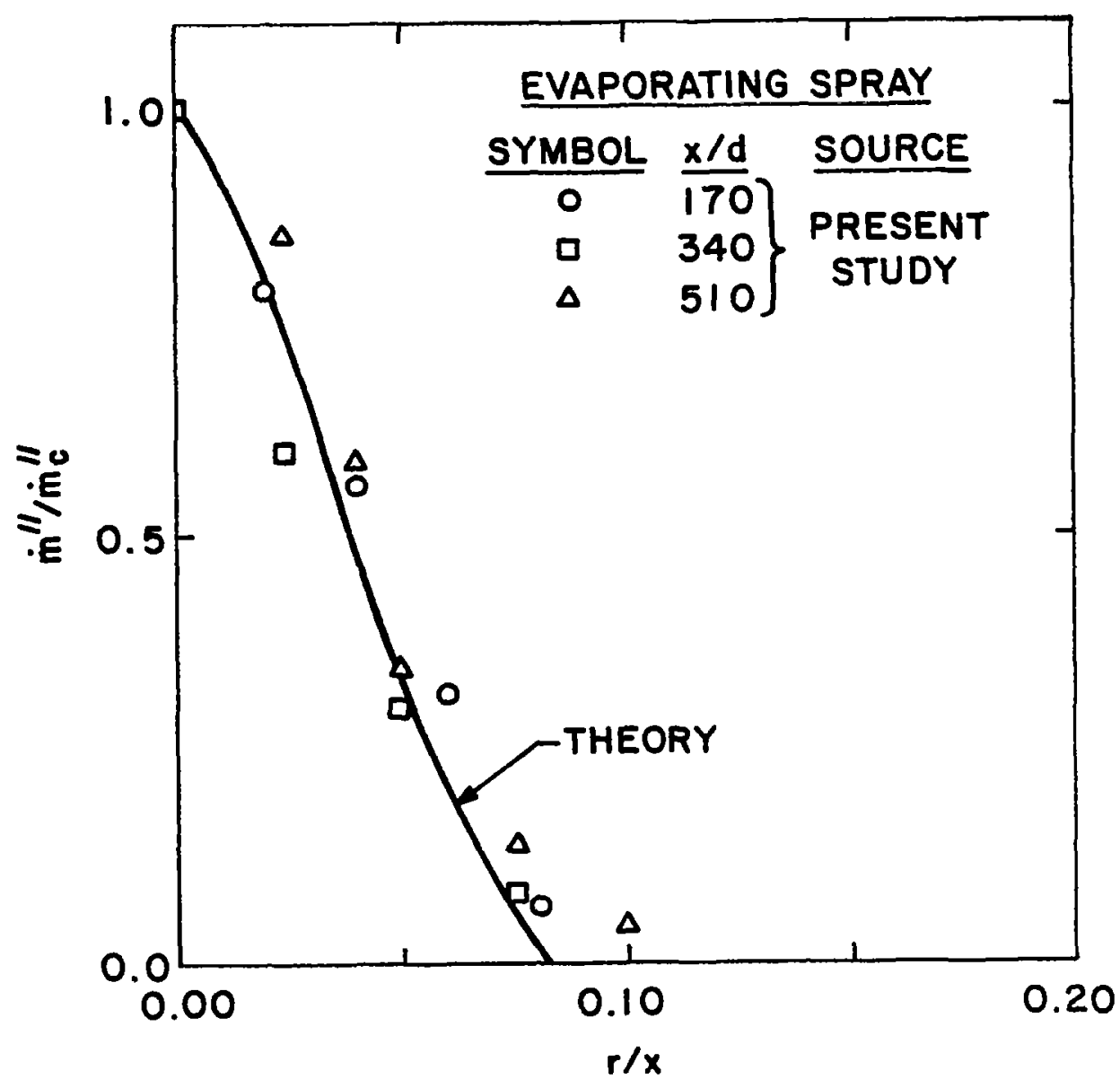

Figure 14 Radial Variation of Liquid Mass Flux in an Evaporating Freon-11 Spray 


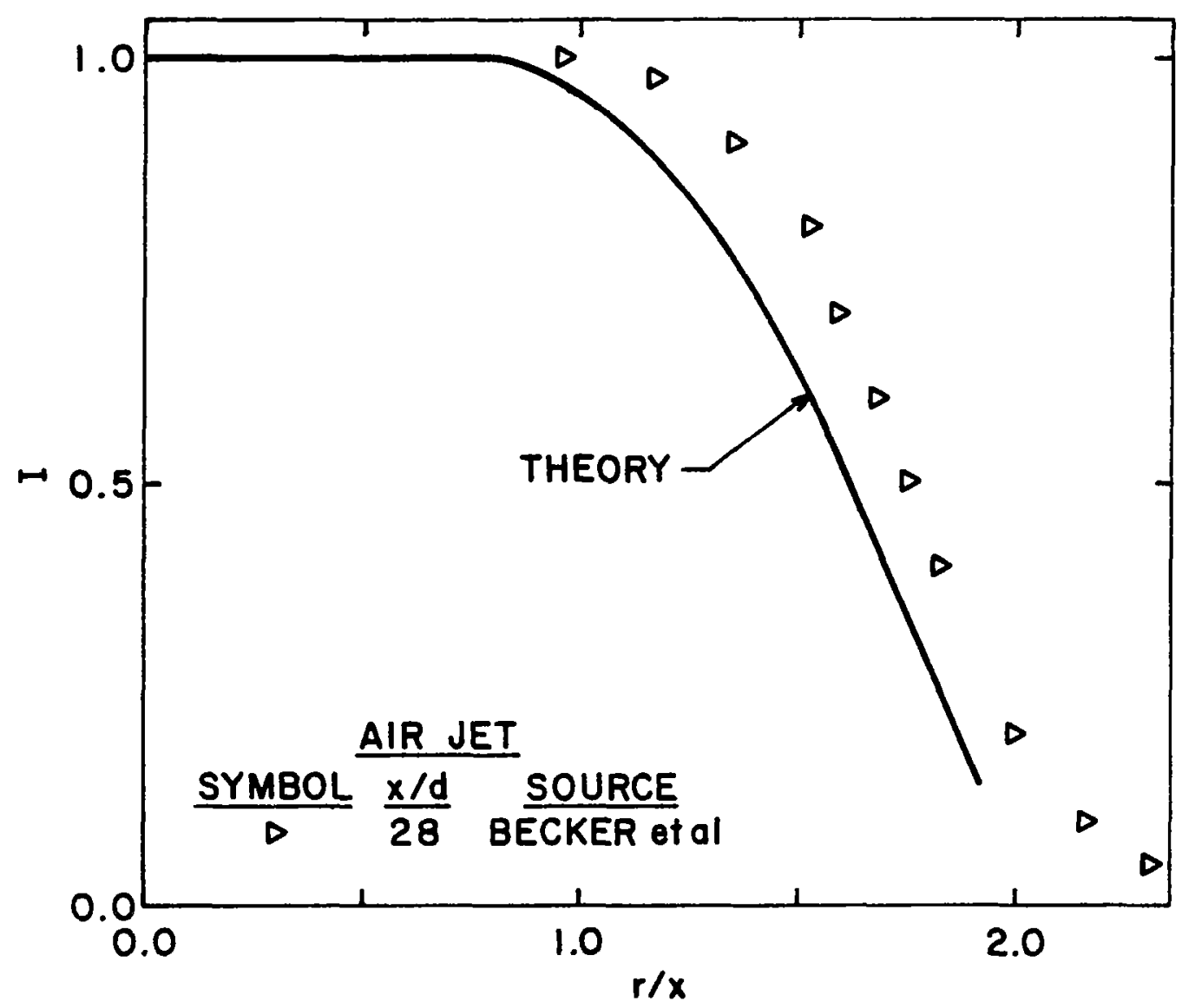

Figure 15 Radial Variation of Intermittency in an Isothermal Air-Air Jet [52] 


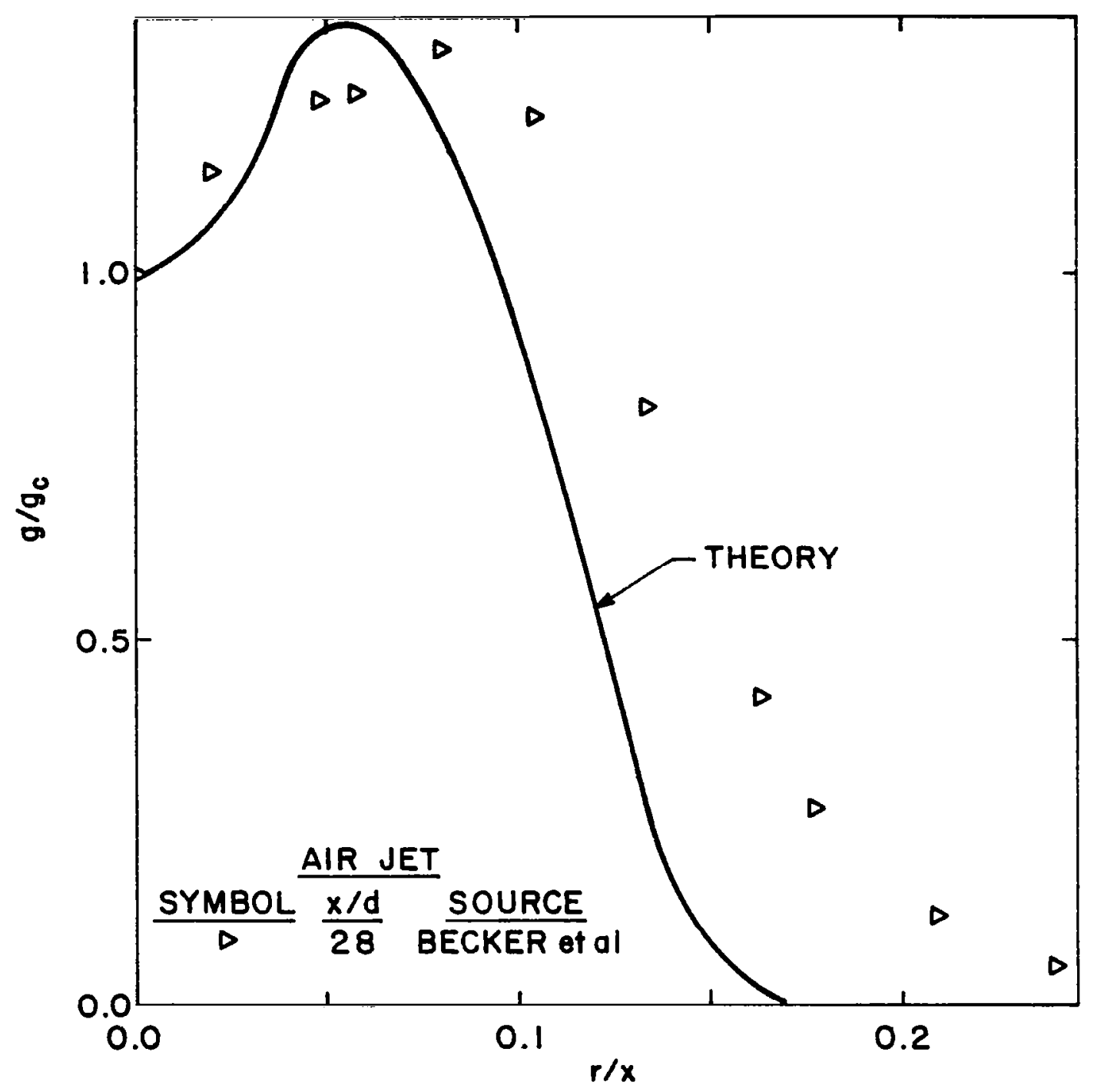

Figure 16 Radial Variation of Mean Square Mixture Fraction in an Isothermal Air-Air Jet [52] 


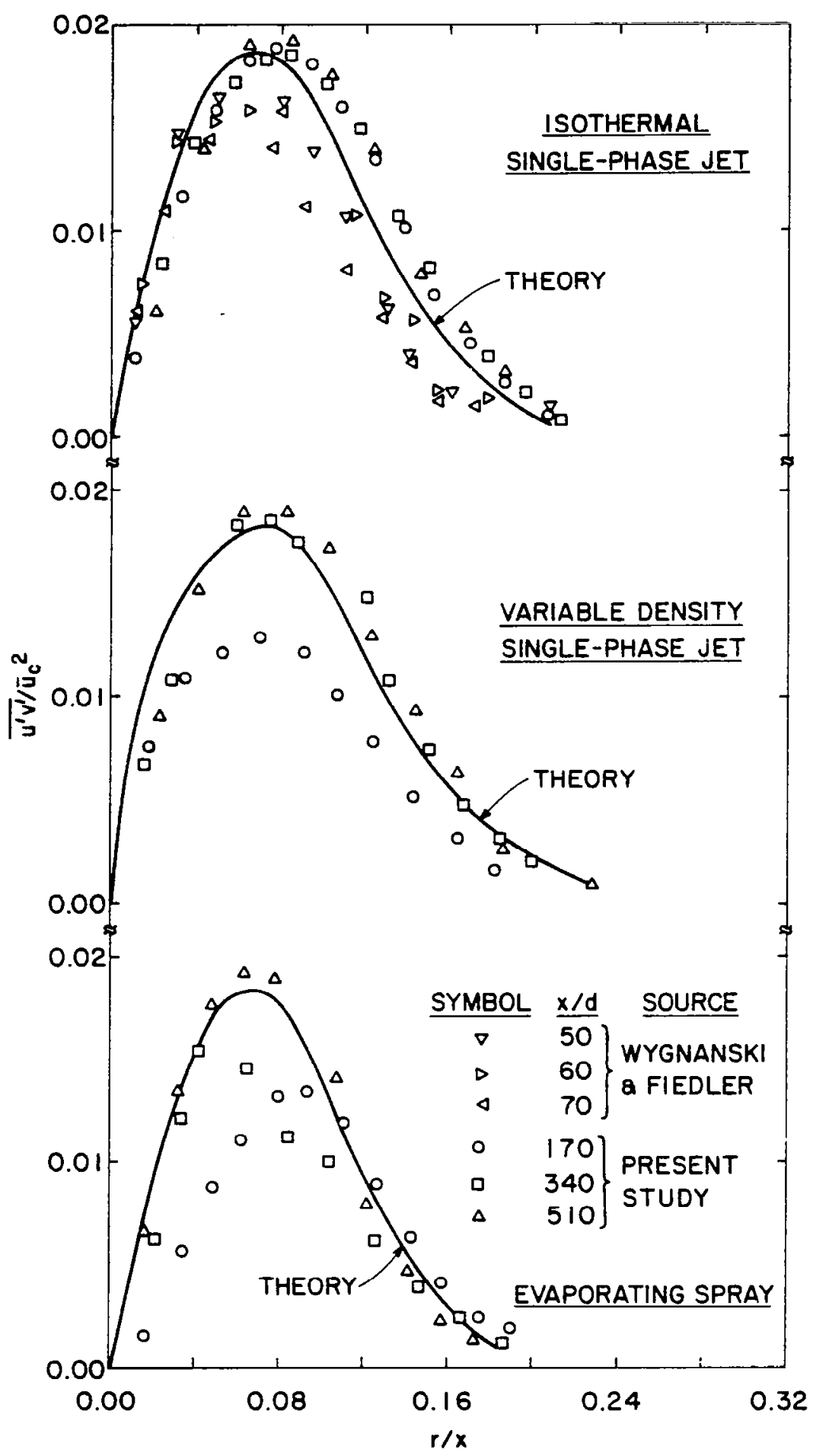

Figure 17 Radial Variation of Reynolds Stress 
The comparison of the theoretical and experimental results for the variable density single-phase jet and the evaporating spray are very much alike. Good agreement is obtained between the theory and the experiment at the larger distances. Deviation between the theory and the experiment at the near position is due to experimental error.

The variation of the turbulent kinetic energy is shown in Figure 18 for isothermal single-phase jets, an isothermal variable density jet, and an evaporating spray. The theoretical model tends to underestimate the turbulent kinetic energy for all three flows near the centerline of the flow. The experimental data also shows a slight variation in the turbulent kinetic energy profiles with $x / d$ which is not predicted by the model.

In general, the theory does a remarkably good job of estimating turbulence quantities in both the single and two-phase flows. This is encouraging, in view of the many simplifications of the turbulence equations for variable density flows. Comparing the spray with the other flows, it does not appear that the presence of drops had a large influence on the turbulence characteristics of the spray. However, it should be recalled that the present measurements were limited to the region far from the injector, where the spray is very dilute (void fraction greater than $99.9 \%$ ).

\subsection{Axial Variation}

The axial variations of the centerline axial velocity and mixture fraction are shown in Figures 19 and 20 for a wide range of single-phase and twophase flows. The axial velocity and mixture fraction at the centerline are normalized by their respective values at the injector exit. The axial distance is normalized by the injector diameter. In general, variation of density ratio between the injected fluid and the surrounding gas has a much stronger influence on the axial variation of flow properties than the normalized radial variations considered in the previous section.

The two-phase air-water jet investigated by Tross (1) had the lowest density ratio of all the flows examined. In this case, the density ratio of the injected fluid to the surrounding fluid was 1 to 1000 . The predicted decay of the axial velocity and mixture fraction at the centerline begins at 1.1 injector diameters from the injector. The theoretical prediction of the axial variation of centerline velocity is in good agreement with the measurements. However, the theory appears to underestimate the decay of the mixture fraction. The theoretical and experimental problems with this flow that were discussed earlier may account for these differences.

The heated air jet analyzed in the present study involved a density ratio of the injected fluid to surrounding fluid of 1 to 2 . The theory predicted that the potential core length would be extended to 5.6 injector diameters for this flow. The theoretical results concerning both the potential core length and the axial decay rates are in good agreement with the experimental results obtained by Corrsin, et al., (54). 


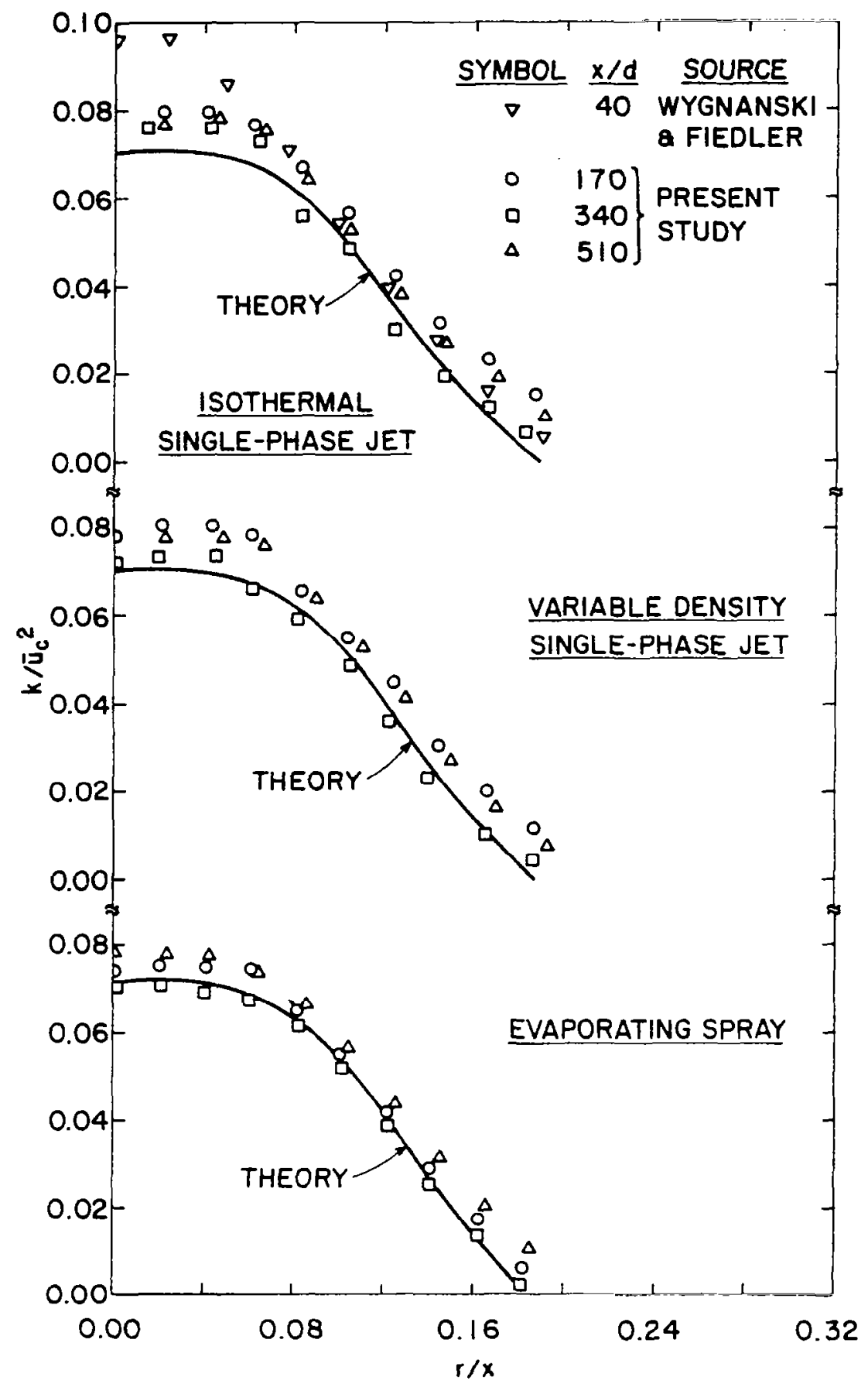

Figure 18 Radial Variation of Turbulent Kinetic Energy 


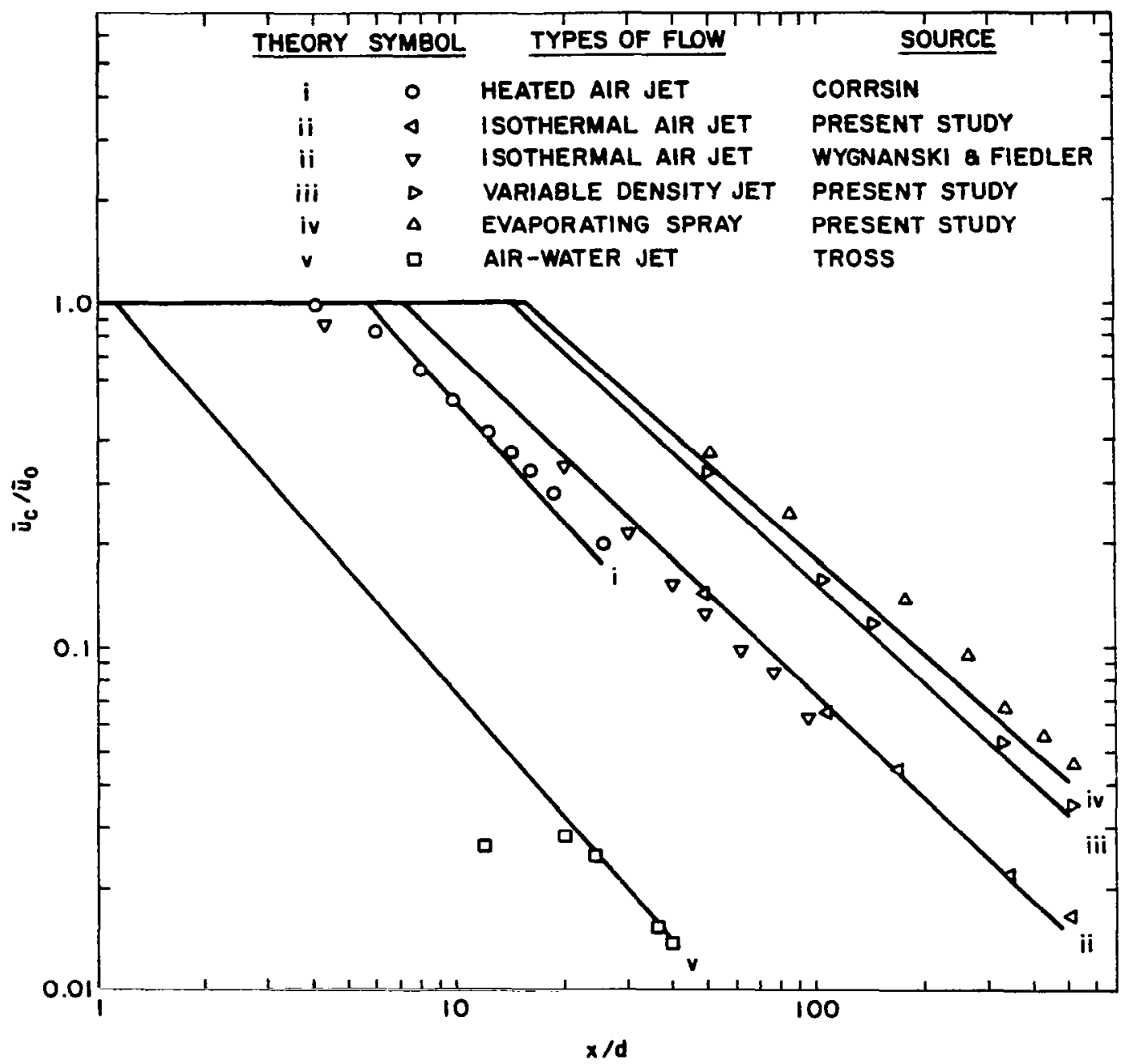

Figure 19 Axial Variation of the Centerline Velocity 


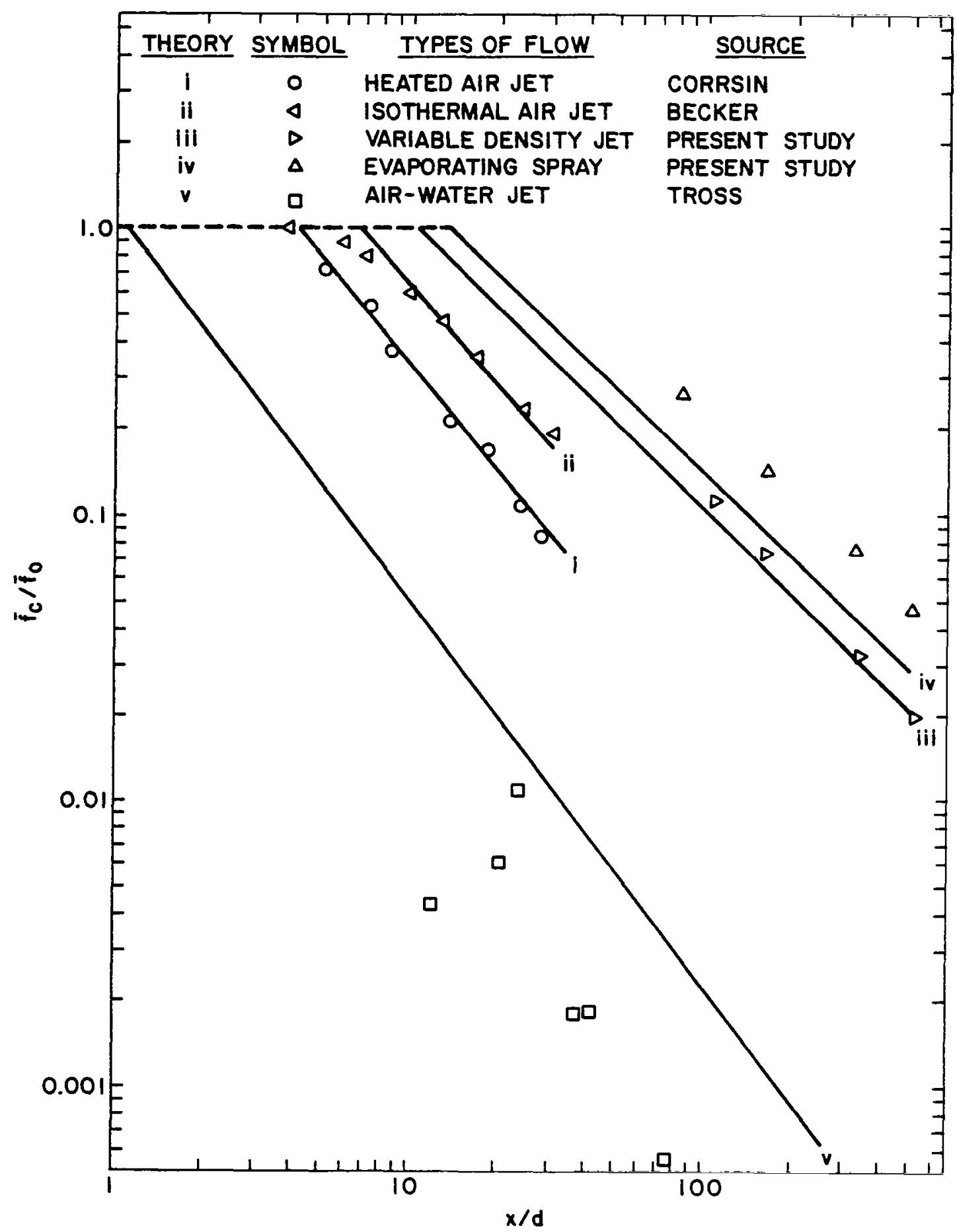

Figure 20 Axial Variation of the Centerline Mean Mixture Fraction 
The theoretical model was also applied to an isothermal air jet injected into aix. In this case, the density ratio between the injected and ambient fluid is equal to unity. The predicted potential core length extends to 7 injector diameters from the injector. The theoretical prediction of the velocity decay was in good agreement with the experimental results of both Wygnanski and Fiedler (51) and the present study. Good agreement was also obtained between the theory and experimenta1 results of Becker, et a1., (52) for mixture fraction variation.

A single-phase sulfur-hexafluoride jet that had an initial density greater than the surrounding air was also examined. In this case, the density ratio of the injected fluid to the surrounding fluid was approximately 1 to 0.2 . The predictions and measurements of velocity and mixture fraction, for this case, are also illustrated in Figures 19 and 20 . The agreement is reasonably good.

After achieving reasonable agreement between the theoretical predictions and the experiments for a wide range of single-phase flows, the locally homogeneous model was examined for an evaporating spray. The theory was compared with the measurements of velocity and mixture fraction for an evaporating Freon-11 spray conducted in the present study, The results are also illustrated in Figures 19 and 20. Agreement between the theory and the experiment for the velocity and mixture fraction is significantly poorer than for the single-phase jets. In the next chapter this difference will be shown to be largely the effect of slip and loss of thermodynamic equilibrium.

The effect of the loss of kinematic and thermodynamic equilibrium can also be observed in the axial variation of temperature in an evaporating spray. Figure 21 is an illustration of the comparison between the prediction of the axial variation of the normalized temperature decrement with the experimental results. The temperature decrement (the difference between the centerline and ambient temperatures) is normalized by its value at the injector exit. The theoretical prediction increases to a maximum value of approximately 1.5 and then decreases throughout the rest of the flow. The increase in the temperature decrement is predicted by the equation of state. The maximum value of the temperature decrement corresponds to the position where the locally homogeneous model predicts that all of the liquid has vaporized. In contrast, the measurements suggest a much slower development of the mean temperature, and liquid was present at all positions in the flow.

Table 5 lists the variation of liquid mass flux along the jet centerline for the evaporating Freon-11 spray. The theoretical model predicted that all of the liquid has vaporized beyond 30 injector diameters from the injector.

The ability of the model to predict the axial variation of the concentration fluctuations was also examined. Figure 22 is an illustration of the theoretical prediction of $g$ and the experimental results of Becker, et al., (52). Reasonable agreement was obtained between the theory and the experiment, at least for this constant density single phase flow. 


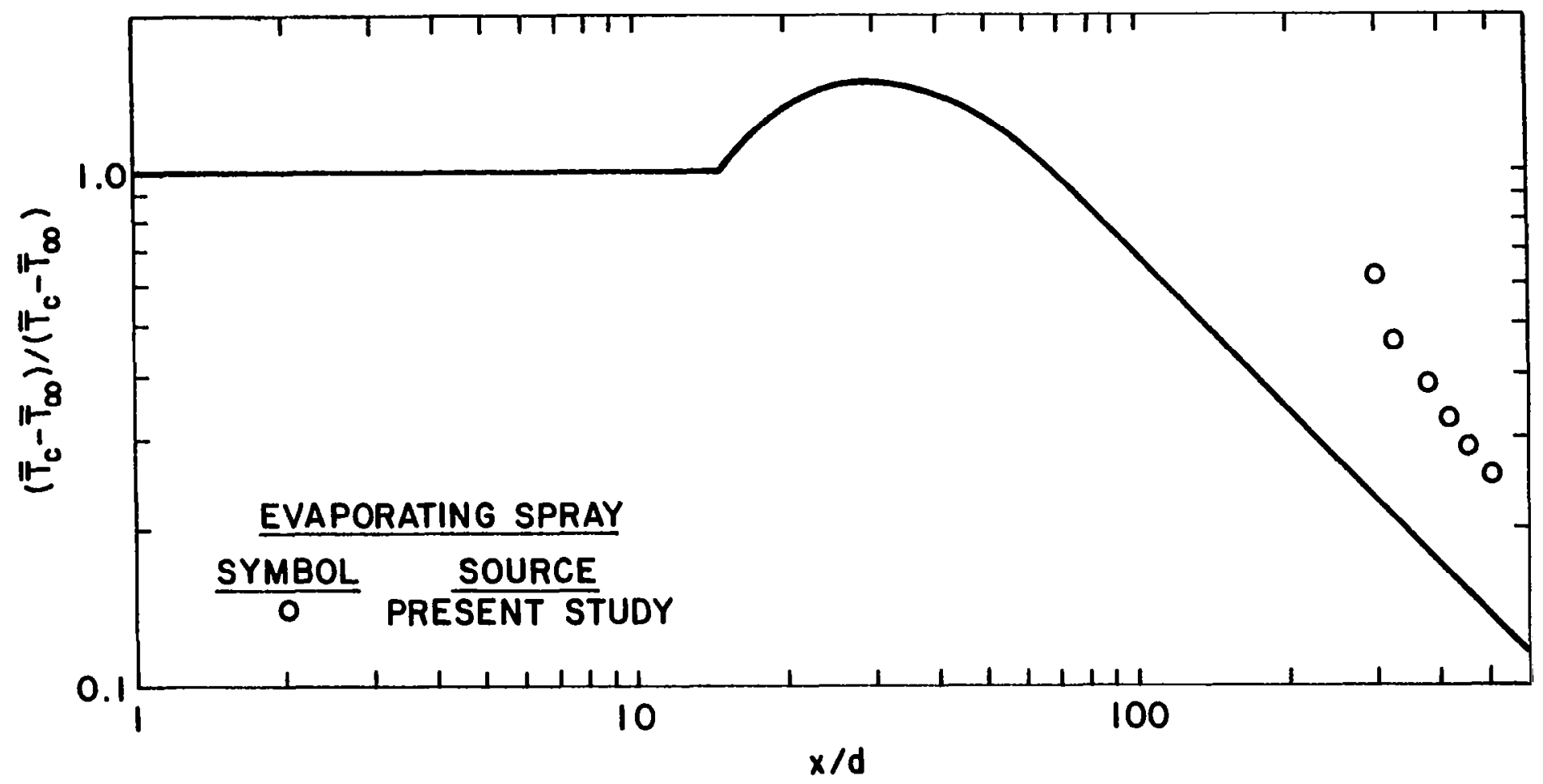

Figure 21 Axial Variation of the Centerline Temperature Decrement in an Evaporating Freon-11 Spray 
Table 5

Axial Variation of Liquid Mass Flux for an

Eyaporating Freon-11 Spray

\begin{tabular}{ll}
\hline$\frac{\mathrm{x}}{\mathrm{d}}$ & $\frac{\dot{\mathrm{m}}_{\mathrm{c}}^{11}}{\mathrm{~m}_{\mathrm{o}}{ }^{\prime \prime}}$ \\
\hline 170 & .028 \\
340 & .020 \\
510 & .011 \\
\hline
\end{tabular}




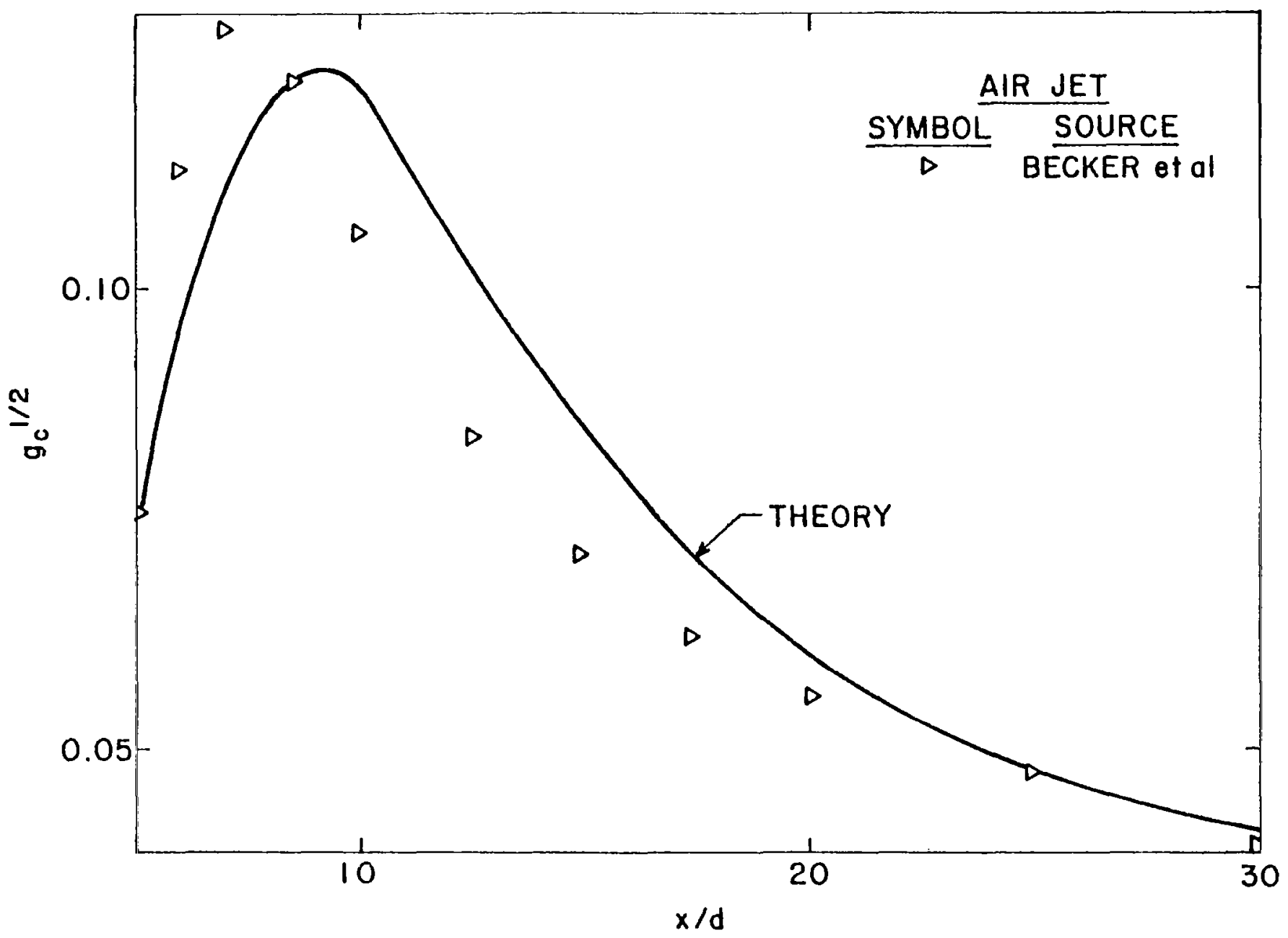

Figure 22 Axial Variation of Concentration Fluctuations in an Isothermal Air-Air Jet 


\subsection{Droplet Size}

The axial and radial variation of the droplet size is shown in Table 6. The Sauter mean diameter remains nearly constant across a radial profile and increases slightly with axial distance. The increase in Sauter mean diameter with distance is caused by the rapid evaporation of small drops leaving only the larger drops at the downstream position. Naturally, features of this type cannot be considered using a locally homogeneous flow model.

\section{CHAPTER V}

\section{DROPLET LIFE-HISTORY CALCULATIONS}

\subsection{Theoretical Mode1 of Droplet Life-History}

The lifetime of a single drop evaporating in a convective environment was modeled in the present study. The calculations considered a drop in the evaporating spray considered in the present test program. Using these results, a direct assessment of the magnitude of the slip and loss of thermodynamic equilibrium between the phases could be obtained. In completing the calculations, an estimation of the local environment of a drop within the spray was obtained from the results of the locally homogeneous flow model.

The drop life-history calculations were calibrated against measurements of a single supported drop evaporating in an air stream of known velocity and temperature, at atmospheric pressure. In this manner, errors in the drop life-history calculations (due to uncertainties in selecting proper average properties for transport parameters) were minimized.

Throughout the analysis, a single droplet in a dilute spray is considered. The droplet is assumed to be spherical in shape and unaffected by the presence of any other droplets. The gas phase is taken to be a quasisteady continuum, fully adjusted to the steady state structure for the imposed droplet boundary conditions at each instant of time. The pressure throughout the flow is assumed to be constant.

The behavior of all species in the gas phase is approximated by the ideal gas law. The surrounding gas is assumed to have negligible solubility in the gas phase. The partial pressure of the vaporized liquid is given by Equation (B.19).

The effects of chemical reaction are assumed to be negligible and the Lewis number is taken to be unity. The other fluid properties are evaluated at the local conditions in the flow. The values of the fluid properties and a description of how the properties are evaluated are presented in Appendix E.

Under these assumptions the governing equations are: 
Table 6

Variation of Sauter Mean Diameter ( $\mu \mathrm{m}$ ) in Evaporating Freon-11 Spray

\begin{tabular}{llll}
\hline $\mathrm{x}$ & & $\mathrm{r} / \mathrm{x}$ & \\
\cline { 2 - 4 } $\mathrm{d}$ & .026 & .050 & .075 \\
\hline 170 & 27.2 & 27.6 & 27.6 \\
340 & 29.4 & 29.5 & 29.2 \\
510 & 30.7 & 30.5 & 30.6 \\
\hline
\end{tabular}


Conservation of Mass

$$
\frac{d D}{d x}=\frac{-4 \lambda N_{R}}{\rho_{f} C_{p} u_{p} D} \ln \left(1+B_{y}\right)
$$

Conservation of Momentum

$$
\frac{d u_{p}}{d x}=\frac{-3 C_{f} \rho}{4 \rho_{f_{p}} u_{p}^{D}}\left(u_{p}-u\right)^{2}+\frac{a}{u_{p}}\left(1-\frac{\rho}{\rho_{f}}\right)
$$

Conservation of Energy

$$
\frac{d T p}{d x}=\frac{12 \lambda N_{R}}{\rho_{f} C_{p_{f}} u_{p} C_{p} D^{2} B_{y}} \ln \left(1+B_{y}\right)\left[C_{p}\left(T-T_{p}\right)-B_{y} h_{f g}\right]
$$

where

$$
\begin{aligned}
& \left.C_{f}=\frac{24}{\operatorname{Re}\left(1+\frac{R e}{6} \cdot 667\right.}\right) \\
& \operatorname{Re}=\frac{D\left(u_{p}-u\right)}{u} \\
& N_{R}=1+0.276 \operatorname{Re}^{1 / 2} \operatorname{Pr}^{1 / 3} /\left(1+1.232 /(\operatorname{RePr})^{4 / 3}\right)^{1 / 2} \\
& B_{y}=\left(Y_{F g}-Y_{F_{\infty}}\right) /\left(1-Y_{F g}\right)
\end{aligned}
$$

The drop position is obtained from the relationship

$$
x=\int_{0}^{t} u_{p} d t
$$

The drops and the gas phase are assumed to be at the same velocity and temperature throughout the potential core.

For the spray, the ambient conditions of the drop were obtained as a function of position from the locally homogeneous flow model. For the calibration experiment, the ambient state was defined by the predictions of the locally homogeneous mode1. In this case, Equations (5.1) and (5.3) were transformed to a function of time by noting

$$
u_{p} \frac{d}{d x}=\frac{d}{d t}
$$


Equations (5.1) - (5.8), along with the vapor pressure relationship between $Y_{F g P}$ and $T_{p}$, obtained from Equation (B.17), are sufficient to solve for the temperature, diameter, position and velocity of the droplet. The system of equations was integrated on a digital computer, using a fourth-order predictor-corrector method.

\subsection{Calibration Apparatus}

The purpose of the experimental apparatus was to provide a convective environment for the observation of an evaporating drop. These experimental results were used to calibrate the drop life-history calculations.

A schematic of the overall experimental apparatus is shown in Figure 23. Motion pictures of the droplet evaporation process were taken to record the variation of droplet size. The droplet was suspended on a fine wire thermocouple which also served to measure the droplet temperature. A Pitot-static velocity probe was used to measure the velocity of the surrounding gas.

Turbulent air flow at the exit of a pipe provided the convective flow field for the droplet evaporation process. Fully developed turbulent pipe flow was obtained from a pipe $32 \mathrm{~mm}$ diameter and $610 \mathrm{~mm}$ in 1 ength. Four 16 mesh screens were placed near the pipe inlet to assist in developing the flow.

The air flow rate was metered and controlled with a combination of a pressure regulator and critical-flow orifice. The dry compressed air was supplied by Matheson Gas Products. A Matheson model 4 regulator was used to control the air pressure upstream of the critical flow orifice. The upstream pressure was measured with a Heise mode1 C-54848 pressure gauge. The orifice was calibrated with a Precision Scientific wet-test meter $(.283$ l/rev.).

The drop temperature was determined by suspending the drop on the junction of a fine wire thermocouple. The thermocouple was manufactured from $0.076 \mathrm{~mm}$ chromel-alumel wire. The junction had a diameter

of $0.5 \mathrm{~mm}$. The reference junction for the thermocouple was placed in an ice bath. A Hewlett-Packard X-Y plotter, model 7044A, was used to record the droplet temperature variation with time.

Motion pictures of the drop evaporation process were used to measure the variation of droplet size with time. A Photosonic 1-B motion picture camera driven with a Kepco SM 36-5 AM d.c. power supply were used throughout the investigation. The film speed was indicated by a timing light on the camera activated by an Adtrol Electronics pulsc generator, model 501. An event marker was used to correlate the photographic and temperature measurements. Kodak plus-x reversal film was used for all tests.

Backlighting for the photographic measurements was supplied by a Pek, mode1 401A, arc lamp using a 75 watt mercury bulb. The light was focused into a parallel beam using the optics located in the arc lamp. A diffuser 


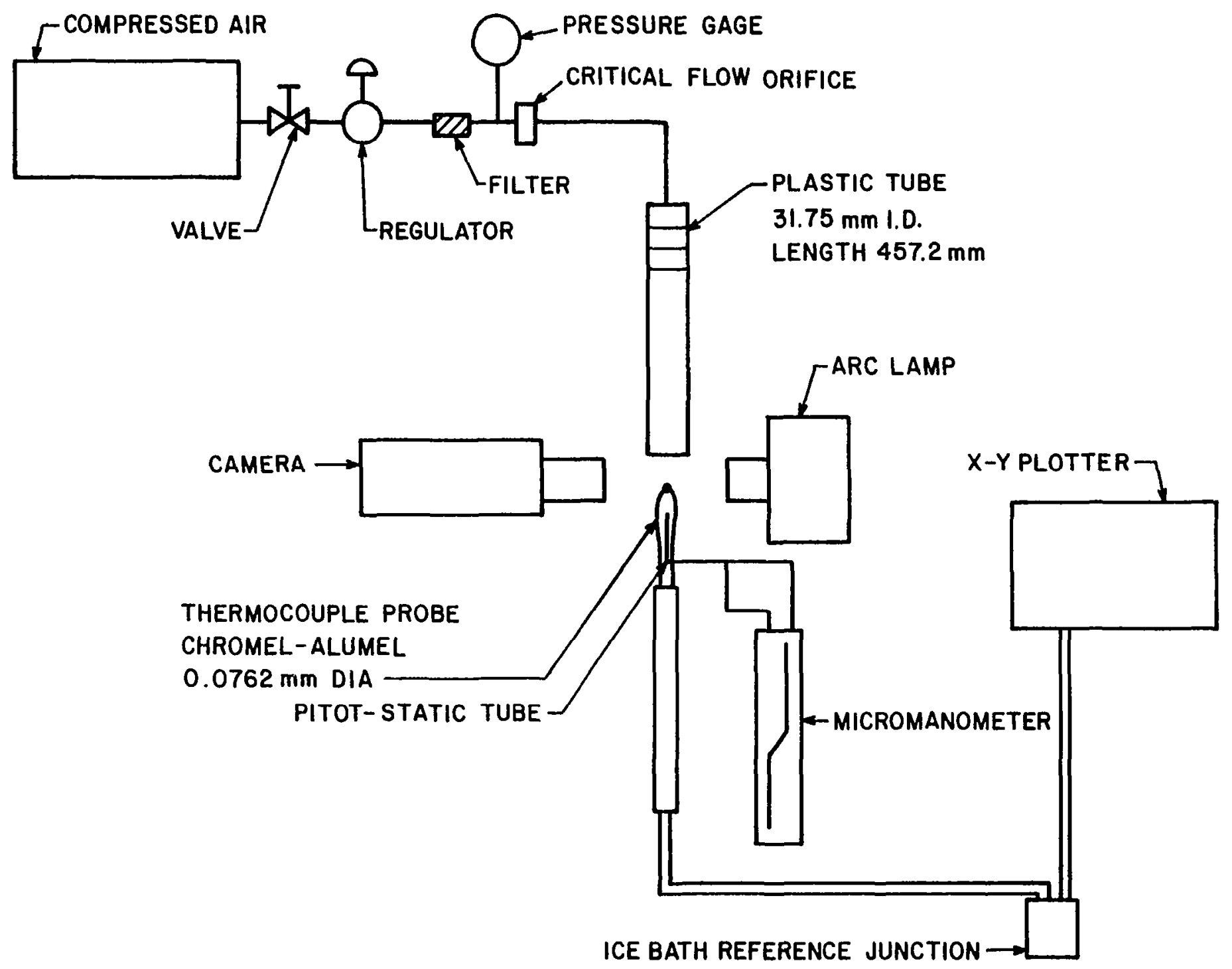

Figure 23 Schematic Diagram of the Drop-Life History Calibration Apparatus 
screen was employed to equalize the background intensity of the light beam.

The air velocity was determined with a Pitot-static probe. The probe was connected to a Meriam model 34FB2 micromanometer in order to measure the difference between the static and stagnation pressure.

Measurements of the droplet evaporation process were controlled by a mechanical timer. As soon as a stable droplet was established on the thermocouple bead, the timer was activated. At the beginning of the cycle, the electrically driven motion picture camera was started and allowed to reach operating speed. The event marker and $X-Y$ plotter were then activated simultaneously. The process was allowed to continue for approximately 4 seconds before the camera and the X-Y plotter were turned off to complete the test.

The temperature trace consisted of three regions; first, a region of rapidly decreasing temperature; second, a constant temperature region; and third, a region where the temperature increases back to the ambient gas temperature. The initial temperature decrease represents the droplet approaching an equilibrium condition with the moving air stream. The constant temperature is the wet-bulb temperature for the evaporation process. At this condition, all of the energy transferred to the drop is used to vaporize the liquid. The final region follows the total evaporation at the liquid when the thermocouple returns to the ambient gas temperature.

The analysis of the droplet evaporation process was confined to the constant temperature region. The films were analyzed on a frame by frame basis using a Vanguard motion picture analyzer. The motion picture analyzer was used to view film and measure the size of the droplet in each frame.

\subsection{Calibration Test Results}

The purpose of the calibration tests was to establish the proper reference condition to evaluate the fluid properties in Equations (5.1) to (5.7). The calibration experiment provided a wel1-defined test condition to evaluate the drop evaporation mode1. The ambient velocity, concentration and temperature were constant with time. The theoretical and experimental results for the variation of droplet size and temperature were examined.

Several test conditions were considered with ambient velocities from $3 \mathrm{~m} / \mathrm{sec}$ to $6 \mathrm{~m} / \mathrm{sec}$. This velocity range was selected so that the drop Reynolds Numbers in the calibration experiment spanned the range encountered in the spray experiment. The ambient gas temperatures were in the range 18-22 C.

The closest agreement between predictions and the measurements was achieved when gas phase properties in Equations (5.1) - (5.8) were evaluated at the droplet surface temperature. Figure 24 is an illustration of some typical theoretical and experimental results. The drop diameter variation is plotted as a function of time for two different gas velocities. 


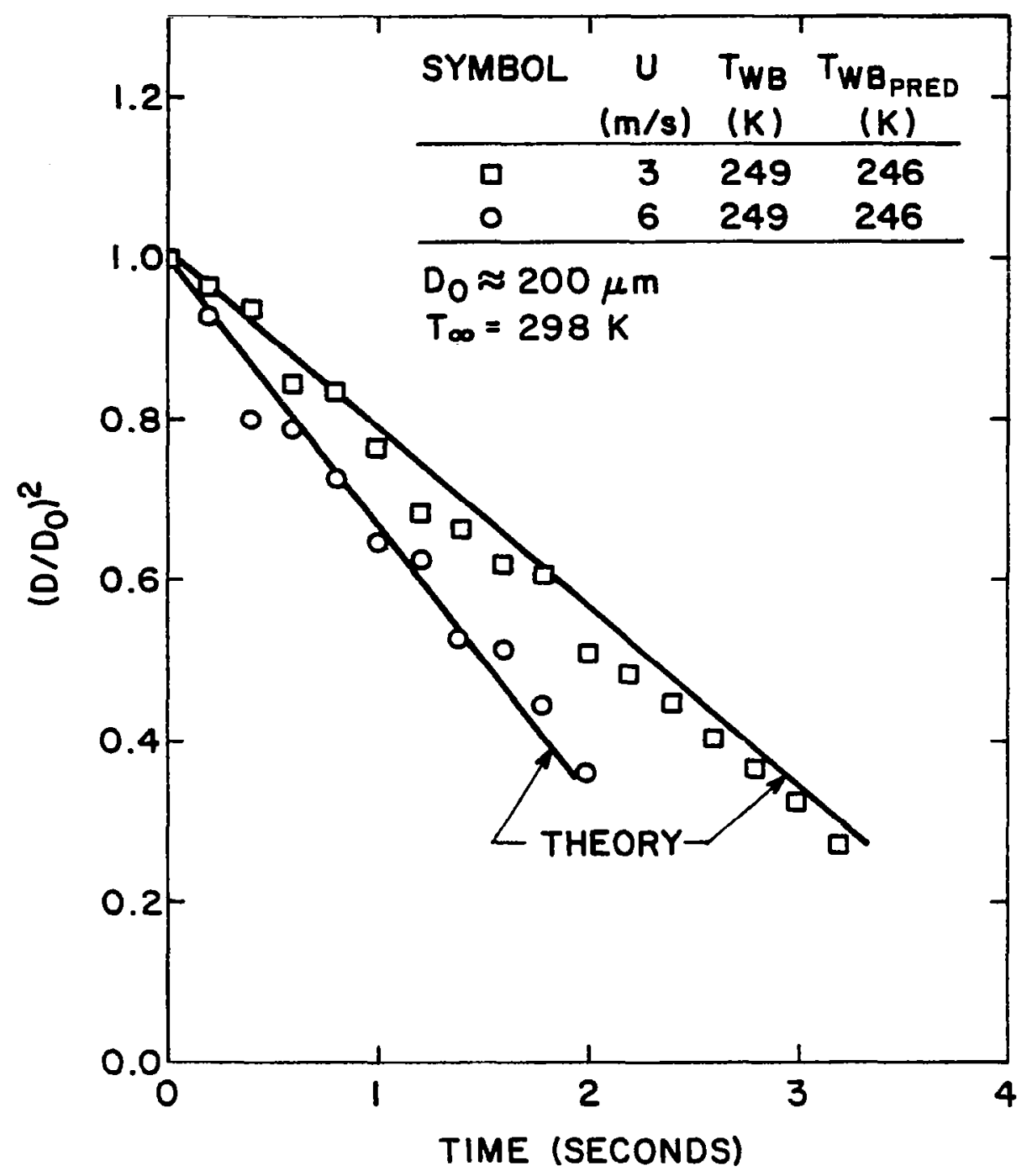

Figure 24 Drop Life-History Calibration Results 
The agreement between prediction and measurements is seen to be quite good. The wet-bulb temperature of the drop is not a strong function of drop size or velocity. The predicted value is within $3 \mathrm{C}$ of the measured value, which is satisfactory for present purposes.

Based on the results of the calibration experiments, the drop surface temperature was employed as the reference temperature for properties in the present drop life-history calculations for spray conditions. No universality of this reference condition should be implied. The uncertainties in average properties and the transport correlations are such that calibration should be undertaken for each system to be investigated

\subsection{Droplet Life-History Calculations in Evaporating Spray}

The comparison between theory and experiment for the spray suggests that slip and loss of thermodynamic equilibrium are retarding the development of the flow. This is not completely convincing, however, since a large number of assigned constants could be adjusted to provide better agreement between theory and experiment. In particular, the values of $\mathrm{C}_{\varepsilon_{2}}$ and

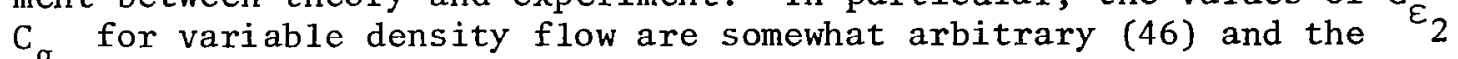
$\mathrm{g}_{2}$ entrainment rate of the flow is quite sensitive to these parameters.

In order to provide a more direct evaluation of the locally homogeneous assumption, drop life-histories were computed in the actual spray evaporation process. This involves determining the variation in drop size, velocity, and temperature as a function of position in the flow.

The drop life-history calculations conducted in the present study considered a drop passing along the centerline of the spray. As an estimate of the environment of the drop, gas velocities, temperatures and composition were obtained from the locally homogeneous flow prediction. The drop is assumed to be in thermal and kinematic equilibrium with the gas phase, until it reaches the end of the potential core.

The calculations were conducted for the conditions of the evaporating spray. Results for drops having initial diameters of 10,30 and $50 \mu \mathrm{m}$ are illustrated in Figure 25. The diameter, velocity and temperature of the drop, and the velocity and temperature of the gas at the centerline of the spray are given as a function of the distance from the injector.

The drop velocities decay much more slowly than the gas velocities. Appreciable levels of slip occur in the region just downstream of the potential core. The difference between the drop velocity and the gas velocity indicates the magnitude of slip present. For these calculations, where the rate of development of the flow is overestimated, the gas temperature falls rapidly near the injector. Farther downstream the gas temperature rises toward the ambient temperature, while the drop temperatures tend toward a constant value, which is below the gas temperature.

The drop life-history calculations indicate that drops are present for $x / d_{0}$ greater than 200 , which agrees with experimental observations. These 

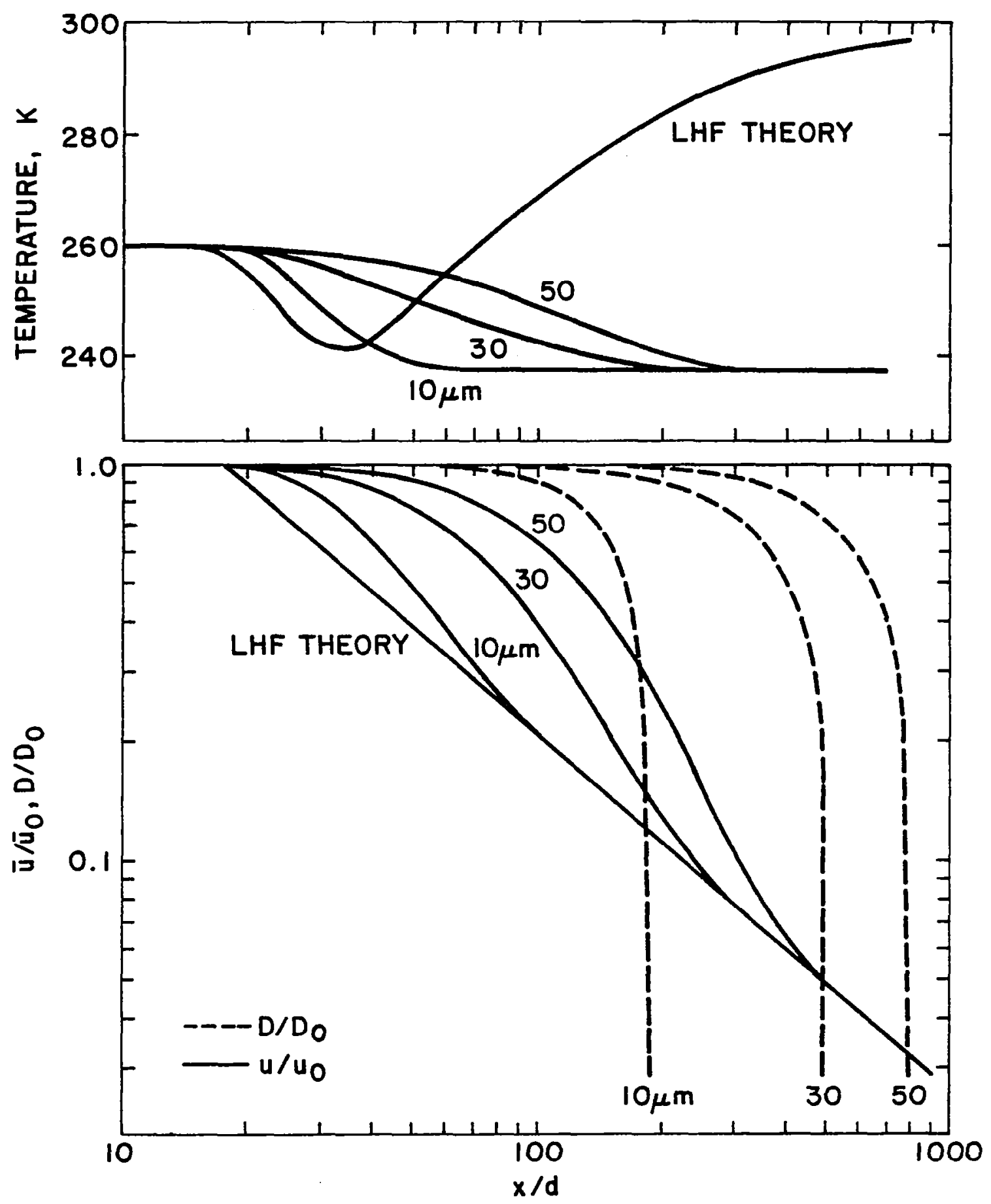

Figure 25 Drop Life-Histories in an Evaporating Freon-11 Spray 
estimations are still conservative, since gas properties were taken from the locally homogeneous flow model, which overestimates the rate at which jet conditions approach the ambiance.

The results shown in Figure 25 indicate that slip and 1oss of thermodynamic equilibrium are important for the present test conditions. This accounts for the overestimation of the rate of development of the spray using the locally homogeneous flow model, even for drops as small as. $10 \mu \mathrm{m}$. From this evidence and the results of Khalil and Whitelaw (18) and Shearer and Faeth (20), it appears that slip must be considered unless information is only required far from the injector.

\section{CHAPTER VI}

SUMMARY AND CONCLUSIONS

\subsection{Summary}

The overall objective of the present study was to develop and cvaluatc a locally homogeneous flow model of spray evaporation which employs a second-order turbulence model. The locally homogeneous flow assumption implies no velocity difference and thermodynamic equilibrium between the phases. The turbulence was represented by a $k-\varepsilon-g$ turbulence model employing a clipped Gaussian probability density function for mixture fraction fluctuations.

The theoretical model of the spray process was based upon the Reynoldsaveraged form of the conservation equations. A modified version of GENMIX (45) combined with an appropriate equation of state was used to solve the governing equations. The program could be applied to both single-phase and two-phase flows.

Experimental measurements of mean and fluctuating velocities were conducted in an isothermal air-air jet, an isothermal sulfur hexafluorideair jet, and an Evaporating Freon-11 spray. A single-channel LDA was used to conduct these measurements and the results were combined to determine the Reynolds stress and turbulent kinetic energy. The measurements were conducted from 170 to 510 injector diameters from the injector.

Experimental measurements of the mixture fraction were conducted in the sulfur hexafluoride-air jet and the evaporating spray. The flows were isokinetically sampled, based on the velocity measurement at each location. The mixture fraction measurements were extended to the region far downstream of the injector (170 - 510 injector diameters).

The Freon-11 spray was further investigated by measuring the gas temperature and drop size throughout the spray. The temperature was measured at positions from 200 to 510 injector diameters from the injector. Water vapor condensing and freezing on the thermocouple junction prohibited measurements at closer positions to the injector. The drop size was measured using a magnesium oxide impaction technique at positions of 170 to 510 injector diameters from the injector. 
The expeximental results of the present study, combined with the experimental results of previous studies (4, 51-54), consider a wide range of flow conditions. The theoretical model was systematically evaluated against each of these flow conditions.

In order to evaluate the possible effect of slip in the two-phase evaporating spray, the behavior of a single drop in the spray was examined. A single drop was assumed to follow the centerline of the spray and the ambient conditions of the drop were those predicted by the locally homogeneous flow model. The axial variation of temperature, velocity and size provided an indication of the degree of slip and the loss of thermodynamic equilibrium between the two phases.

\subsection{Conclusions}

The major conclusions and observations of this study are:

1. The locally homogeneous flow assumption in conjunction with a second-order turbulence model provides a good prediction of the axial and radial variation of mean quantities in single-phase jets. Fair agreement between the experimental and analytical results was achieved for the variation of turbulence quantities. The present model tends to underestimate the radial width of some turbulence quantities.

2. The locally homogeneous flow mode1 provides a reasonably good estimate of the radial variations of mean quantities in an evaporating spray. However, the locally homogeneous flow model tends to overestimate the rate of development of the flow, even for a spray having a Sauter mean diameter of $30 \mu \mathrm{m}$. This is illustrated by examining axial variation of velocity and mixture fraction. While the rate of reduction of velocity and mixture fraction defect is predicted correctly, the measured positions where a particular value is reached 1 ag the predictions by 15 and 40 percent, respectively.

3. The locally homogeneous flow model can be an extremely useful design too1. Because only a minimum amount of initial information is required, the locally homogeneous model can be easily applied to a wide range of flows to provide a reasonable initial estimate of flow characteristics.

4. Analysis of the lifetime of a single drop shows that slip and loss of thermodynamic equilibrium are important even for the well-atomized spray of the present study. It appears that a Sauter mean diameter less than $10 \mu \mathrm{m}$ would be required for quantitative accuracy with the locally homogeneous flow model. These small sizes are needed due to relatively fast decay of the flow due to the small injector diameter. Since injector diameters of sprays are generally small, this finding implies that accurate analysis of most practical sprays will require the use of models which allows for slip and finite rate processes between the phases. 


\subsection{Recommendations for Further Study}

Although the locally homogeneous flow model tends to overestimate the rate of development of the flow, it provides a useful qualitative picture of the spray evaporation process. The locally homogeneous model should be extended to consider two-phase combusting sprays. It is expected that slip and loss of thermodynamic equilibrium would be important in combusting flows, however, the simplicity of the approach and the lack of any need for detailed injection characteristics would establish the model as a useful design tool.

A more complete examination of the spray evaporation and combustion process will require the use of a two-phase flow model. Systematic validation of current two-phase flow models will be required. Further work must determine the effect of particles on turbulence production dissipation, and scale, the effect of particle diffusion in sprays, and the limit of the dilute spray approximation.

A standard procedure for defining injector characteristics must also be developed. More complex slip models will require very detailed information specifying the initial conditions (initial drop size distribution, initial velocity distribution, etc.). Unless this information can be accurately determined, it is doubtful that the two-phase slip models will be any more accurate than a locally homogeneous mode1. 


\section{REFERENCES}

1. Exploring Energy Choices, Preliminary Report, Energy Policy Project, Ford Foundation, Washington, 1974.

2. Faeth, G. M., "Spray Combustion Models-A Review," AIAA Paper 79-0293, 1979 .

3. Weimer, J. C., Faeth, G. M., and 01son, D. R., "Penetration of Vapor Jets Submerged in Subcooled Liquids," AIChE J., Vol. 19, pp. 552-558, 1973 .

4. Tross, S. R., "Characteristics of a Submerged Two-Phase Turbulent Free Jet," M.S. Thesis, The Pennsylvania State University, University Park, Pennsylvania, 1974.

5. Avery, J. F., and Faeth, G. M., "Combustion of a Submerged Gaseous Oxidizer Jet in a Liquid Metal," Fifteenth Symposium (International) on Combustion, The Combustion Institute, Pittsburgh, Pennsylvania, pp. 419-428, 1975.

6. Newman, J. A., and Brzustowski, T. A., "Behavior of a Liquid Jet Near the Thermodynamic Critical Region," AIAA J., Vol. 9, pp. 1595-1602, August, 1971.

7. Wakuri, Y., Fuji, M., Amitani, T., and Tsuneya, R., "Studies on the Penetration of a Fuel Spray in a Diesel Engine," Bulletin the Japanese Society of Mechanical Engineers, Vol. 3, pp. 123, 1960.

8. Kamimoto, T., and Matsuoka, S., "Prediction of Spray Evaporation in Reciprocating Engines," SAE Paper 770413, 1977.

9. Hiroyasu, H., and Kadota, T., "Models for Combustion and Formation of Nitric Oxide and Soot in Direct Injection Dlesel Engines," SAE Paper 760129, 1976.

10. Shahed, S. M., Chiu, W. S., and Yumlu, V. S., "A Preliminary Model for the Formation of Nitric Oxide in Direct Injection Diesel Engines and Its Application in Parametric Studies," SAE Paper 730083, 1973.

11. Khan, I. M., Greeves, G., and Wang, C. H. T., "Factors Affecting Smoke and Gaseous Emissions from Direct Injection Engines and a Method of Calculation," SAE Paper 730169, 1973.

12. Khan, I. M., Greeves, G., and Probert, D. M., "Prediction of Soot and Nitric Oxide Concentrations in Diesel Engine Exhaust," Proc. Inst. Mech. Engrs., Vo1. C142, pp. 205-217, 1971. 
13. Thring, M. W. and Newby, M. P., "Combustion Length of Enclosed Turbulent Jet Flames," Fourth Symposium (International) on Combustion, The Combustion Institute, Pittsburgh, Pennsylvania, pp. 786-796, 1953.

14. Onuma, Y., and Ogasawara, M., "Studies on the Structure of a Spray Combustion Flame," Fifteenth Symposium (Internationa1) on Combustion, The Combustion Institute, Pittsburgh, Pennsylvania, pp. 453-465, 1975.

15. Onuma, Y., and Ogasawara, M., "Further Experiments on a Spray Combustion Flame," Sixteenth Symposium (International) on Combustion, The Combustion Institute, Pittsburgh, Pennsylvania, pp. 561-567, 1976 .

16. Chigier, N. A., and Roett, M. F., "Twin-Fluid Atomizer Spray Combustion," ASME Winter Annual Meeting, New York, Paper No. 72-WA/HT-25, 1972.

17. McCreath, C. G. and Chigier, N. A., "Liquid Spray Burning in the Wake of a Stabilizer Disc," Eourteenth Symposium (International) on Combustion, The Combustion Institute, Pittsburgh, Pennsylvania, pp. 1355-1363, 1973.

18. Khalil, E. E., and Whitelaw, J. H., "Aerodynamic and Thermodynamic Characteristics of Kerosene Spray F1ames," Sixteenth Symposium (International) on Combustion, The Combustion Institute, Pittsburgh, Pennsylvania, pp. 569-576, 1976.

19. Khalil, E. E., "A Simplified Approach for the Calculation of Free and Confined Spray Flames," AIAA Paper No. 78-29, 1978.

20. Shearer, A. J., and Faeth, G. M., "Combustion of Liquid Sprays at High Pressures," NASA CR-135210, March, 1977.

21. Elghobashi, S., Pratt, D. T., Spalding, D.B., and Srivatsa, S. K., "Unsteady Combustion of Fuel Spray in Jet-Engine After-Burners," Third International Symposium on Air-Breathing Engines, 1976.

22. Swithenbank, J., Turan, A., and Felton, P. G., "3-Dimensiona1 2-Phase Mathematical Modeling of Gas Turbine Combustors," Project Squid (ONR) Workshop on Gas Turbine Combustor Design Problems, Purdue University, May, 1978.

23. Boyson, F., and Swithenbank, J., "Spray Evaporation in Recirculating Flow," Seventeenth Symposium (International) on Combustion, The Combustion Institute, Pittsburgh, Pennsylvania, in press.

24. Jones, W. P., and Pridden, C. H., "Predictions of the Flow Field and Local Gas Composition in Gas Turbine Combustors," Seventeenth Symposium (International) on Combustion, The Combustion Institute, Pittsburgh, Pennsylvania, in press. 
25. Reynolds, R. S., Kuhn, T. E., and Mongia, H. C., "An Advanced Combustor Analytical Design Procedure and Its Application in the Design and Development Testing of a Premix/Prevaporized Combustion System," 1977 Spring Technical Meeting, Central States Section, The Combustion Institute, March, 1977.

26. Mongia, H. C., and Smith, K., "An Empirical/Analytical Design Methodology for Gas Turbine Combustors," AIAA Paper No. 78-998, July, 1978 .

27. Anasoulis, R. F., McDonald, H., and Buggelin, R. C., "Development of a Combustor Flow Analysis. Part I: Theoretical Studies," AFAPL-TR-73-98, 1974.

28. Gibeling, H. J., McDonald, H., and Briley, W. R., "Development of a Three-Dimensional Combustor Flow Analysis," AFAPL-TR-75-59, Vol. I., 1975, Vol. III, 1976.

29. Crowe, C. T., Sharma, M. P., and Stock, D. E., "The ParticleSource-in-Cel1 (PSI-Ce11) Model for Gas-Droplet Flows," Trans. ASME, J. Fluids Engr., Vo1. 99, pp. 325-332, 1977.

30. Crowe, C. T., "A Computational Model for the Gas-Droplet Flow in the Vicinity of an Atomizer," Paper 74-23, Western States Section, The Combustion Institute, 1974 .

31. Crowe, C. T., "A Numerical Model for the Gas-Droplet Flow Field Near an Atomizer," 1st International Conference on Liquid Atomization and Spray Systems, Tokyo, August, 1978.

32. Abou Ellail, M. M. M., and Khali1, E. E., "A Prediction Procedure of the Aerodynamic and Thermodynamic Characteristics of Axisymmetric Confined Spray Flames," Seventeenth Symposium (International) on Combustion, The University of Leeds, Leeds, August, 1978.

33. Faeth, G. M., "Current Status of Droplet and Liquid Combustion," Prog. Energy Combust. Sc1., Vo1. 3, pp. 191-224, 1977.

34. Williams, A., Combustion of Sprays of Liquid Fuels, E1ek Science, London, 1976.

35. Williams, A., "Fundamentals of Oil Combustion," Prog. Energy Combust. Sci., Vo1. 2, pp. 167-179, 1976.

36. Williams, A., "Combustion of Droplets of Liquid Fuels: A Review," Combustion and Flame, Vol. 21, pp. 1-31, 1973.

37. Williams, A., "The Mechanism of Combustion of Droplets and Sprays of Liquid Fuels," Oxtdation and Combustion Reviews, Vol. 1, pp. 1-45, 1965. 
38. Krier, H., and Foo, C. L., "A Review and Detailed Derivation of Basic Relations Describing the Burning of Droplets," Oxidation and Combustion Reviews, Vo1. 6, pp. 111-143, 1973.

39. Kanury, A. M., Introduction to Combustion Phenomena, Gordon and Breach, New York, New York, pp. 142-194.

40. Chigier, N. A., "The Atomization and Burning of Liquid Fue1 Sprays," Prog. Energy Combust. Sci., Vol. 2, pp. 97-114, 1977.

41. Hedley, A. B., "Nuruzzaman, A. S. M., and Martin, G. F., "Combustion of Single Droplets and Simplified Spray Systems," J. Inst. Fuel, Vol. 44, pp. 38-54, 1971.

42. Harrje, D. T., and Reardon, F. H. (ed.), Liquid Propellant Rocket Combustion Instability, NASA SP-194, National Aeronautics and Space Administration, Washington, D.C., pp. 37-102, 1972.

43. Soo, S. L., Fluid Dynamics of Multiphase Systems, Blaisdell Publishing Co., Waltham, Massachusetts, pp. 51-60 and 185-218, 1976.

44. Launder, B. E., Morse, A., Rodi, W., and Spalding, D. B., "The Prediction of Free Shear Flows - A Comparison of Six Turbulence Mode1s," NASA Report Number SP-321, Hampton, Virginia, July, 1972 .

45. Pantankar, S. V., and Spalding, D. B., Heat and Mass Transfer in Boundary Layers, 2nd. Ed., Intertext Books, London, 1970.

46. Lockwood, F. C., and Naguib, A. S., "The Prediction of the Fluctuations in the Properties of Free, Round-Jet, Turbulent, Diffusion Flames," Combustion and Flame, Vol. 24, pp. 109-124, 1975 .

47. Gosman, A. D., Lockwood, F. C., and Syed, S. A., "Prediction of a Horizontal Free Turbulent Diffusion Flame," Sixteenth Symposium (International) on Combustion, The Combustion Institute, Pittsburgh, Pennsylvania, pp. 1543-1555, 1976.

48. Gosman, A. D., and Syed, S. A., "TEACH-3P:A General Computer Code for Calculating Three Dimensional Boundary Layer Flows," Imperial College, Mechanical Engineering Department Report, 1976.

49. Kent, J. H., and Bilger, R. W., "The Prediction of Turbulent Diffusion Flame Fields and Nitric Oxide Formation," Sixteenth Symposium (International) on Combustion, The Combustion Institute, Pittsburgh, Pennsylvania, pp. 1643-1656, 1977.

50. Parker, S. F., and Sirignano, W. A., "A Numerical Study of Planar, Turbulent, Reacting Mixing Layers," Paper No. 70, 1978 Fal1 Technical Meeting, Eastern Section of The Combustion Institute, Miami Beach, Florida, November, 1978. 
51. Wygnanski, I., and Fied1er, H. E., "Some Measurements in the Self-Preserving Jet," J. Fluid Mech., Vol. 38, pp. 577-612, 1969.

52. Becker, H. A., Hotte1, H. C., and Williams, G. C., "The NozzleFluid Concentration Field of the Round, Turbulent, Free Jet," J. Fluid Mech., Vol. 30, pp. 285-303, 1967.

53. Hetsroni, G., and Sokolov, M., "Distribution of Mass, Velocity, and Intensity of Turbulence in a Two-Phase Turbulent Jet," Trans. ASME, J. App1. Mech., Vol. 38, pp. 314-327, 1971.

54. Corrsin, S., and Uberoi, M. S., "Further Experiments on the Flow and Heat Transfer in a Heated Turbulent Air Jet," NACA Rept. No. 998,1950 .

55. Durst, F., and Whitelaw, J. H., "Measurements of Mean Velocity, and Shear Stress in Air Using a Single Channel Optical Anemometer," DISA Information, No. 12,pp. 11-16, November, 1971.

56. Ranz, W. F., "Principles of Inertial Impaction," Engineering Research Bulletin, B-66, The Pennsylvania State University, 1956.

57. Spalding, D. B., "Concentration Fluctuations in a Round Turbulent Free Jet," Chemical Engineering Science, Vo1. 26, pp. 95-107, 1971.

58. Spalding, D. B., "Mathematical Models of Turbulent Flames: A Review," Combustion Science and Technology, Vo1. 13, pp. 3-25, 1976.

59. Davies, C. N., Aerosol Science, Academic Press, New York, New York, pp. 393-468, 1976.

60. Lockwood, F. C., "The Modeling of Turbulent Premixed and Diffusion Combustion in the Computation of Engineering Flows," Combustion and Flame, Vol. 29, pp. 111-122, 1977.

61. Spalding, D. B., "Mixing and Chemical Reaction in Steady Confined Turbulent Flames," Thirteenth Symposium (International) on Combustion, The Combustion Institute, Pittsburgh, Pennsylvania, Pp. 649-657, 1971.

62. Mason, H. B., and Spalding, D. B., "Prediction of Reaction Rates in Turbulent Pre-Mixed Boundary Layer Flows," Combustion Institute European Symposium, Academic Press, New York, pp. 601-606, 1973.

63. Bolz, R. E., and Tuve, G. L., Editors, Handbook of Tables for Applied Engineering Science, 2nd Edition, Chemical Rubber Company Press, Cleveland, Ohio, 1973.

64. Razdan, M. K., "Erosive Burning Study of Composite Solid Propeliants by the Turbulent Boundary Layer Approach," Ph.D. Thesis, The Pennsylvania State University, University Park, Pennsylvania, 1979. 
65. Reid, R. C., Prausnitz, J. M., and Sherwood, T. K., The Properties of Gases and Liquids, 3rd Edition, McGraw-Hi11, New York, New York, 1977.

66. ASHRAE Thermodynamic Properties of Refrigerants, American Society of Heating, Refrigerating, and Air-Conditioning Engineers, Inc., New York, New York, 1969. 


\section{APPENDIX A}

EVALUATTON OF TURBUI,FNCE QUANTITIES

Consider a single particle moving through the fringe pattern shown on Figure 26 (A) produced by the beams crossing. The distance between fringes is

$$
d_{f}=\lambda /(2 \sin (\phi / 2))
$$

The velocity is

$$
\mathrm{u}=\mathrm{Fd}_{\mathrm{f}}
$$

The measured frequency is directly proportional to the output of the single processor.

$$
\mathrm{F}=\mathrm{KE}
$$

Combining Equations (A.1), (A.2), and (A.3) yields

$$
\mathrm{E}=\mathrm{Cu}
$$

where

$$
\mathrm{C}=2 \sin \left(\phi /{ }_{1} / 2\right) / \mathrm{K} \lambda
$$

In turbulent flows the velocity consists of mean and fluctuating components producing mean and fluctuating components of the output voltage

$$
\left(\bar{E}+e^{\prime}\right)=\left(\bar{u}+u^{\prime}\right) C
$$

However, it is not required that the flow be perpendicular to the fringe pattern. This is illustrated in Figure $26(\mathrm{~B})$.

$$
\overrightarrow{\mathrm{E}}+\mathrm{e}^{\prime}=\mathrm{C}\left[\overline{\mathrm{u}} \sin \alpha+\overline{\mathrm{v}} \cos \alpha+\mathrm{u}^{\prime} \sin \alpha+\mathrm{v}^{\prime} \cos \alpha\right]
$$

The average of the output voltage is determined by averaging Equation (A.7)

$$
\bar{E}=C[\bar{u} \sin \alpha+\bar{v} \cos \alpha]
$$

The relationship between the fluctuations output voltage and the turbulence quantities is obtained by squaring Equations (A.7) and (A.8) and combining the resulting equations 

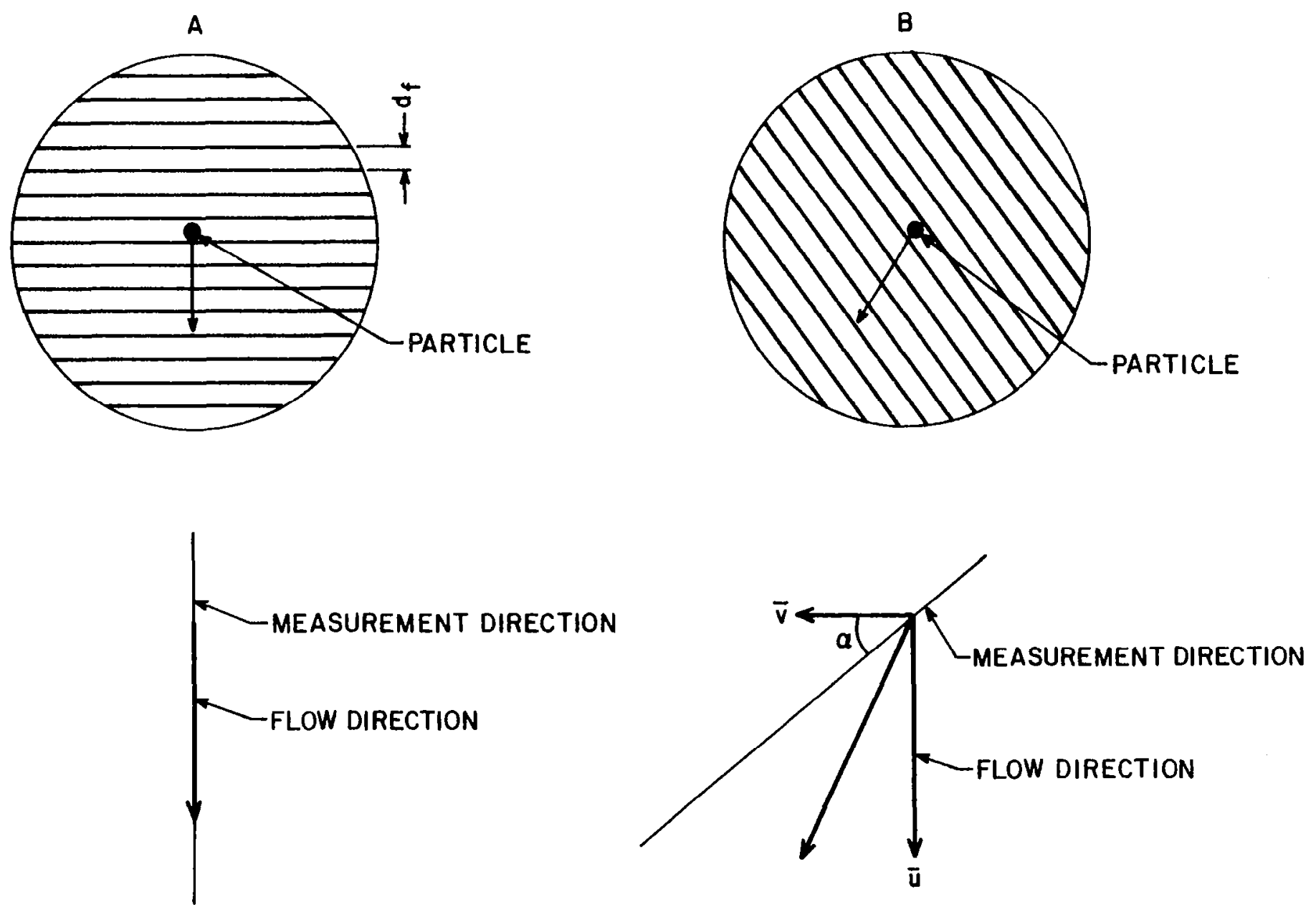

Figure 26 Sketch of a Particle in the LDA Fringe Pattern 


$$
\left.\overline{e^{\prime 2}}=c^{2} \overline{\left[u^{\prime 2}\right.} \sin ^{2} \alpha+\overline{v^{\prime 2}} \cos ^{2} \alpha+\overline{2 u^{\prime} v^{\prime}} \cos \alpha \sin \alpha\right]
$$

Values for $\overline{u^{\prime 2}}, \overline{v^{\prime 2}}$, and $\overline{u^{\prime} v^{t}}$ may be derived by 3 measurements at 3 different values of $\alpha$.

For the special cases $\alpha_{1}=45^{\circ}$ and $\alpha_{2}=135^{\circ}, \overline{u^{\prime} v^{\prime}}$ may be determined from the following equation

$$
\left.\overline{u^{\prime} v^{\prime}}=\overline{\left(e_{1}^{\prime 2}\right.}-\overline{e^{\prime 2}}\right) / 2 c^{2}
$$

APPENDIX B

EQUATIONS OF STATE

\section{B.1 Isothermal Air Jet}

Experimental results from the present study as well as earlier measurements [51-53] were considered in these calculations. The test conditions involved air flowing into stagnant air at room temperature and pressure $(298 \mathrm{~K}, 101 \mathrm{kPa})$.

Since the flow has a constant temperature, pressure and composition

$$
\begin{aligned}
& T=T_{\infty} \\
& \rho=\rho_{\infty}=p_{\infty} / R_{A} T_{\infty}
\end{aligned}
$$

\section{B. 2 Heated Air Jet in Air}

Experimental results reported by Corrsin [54] were considered for this flow. The test conditions involved air heated to $300 \mathrm{C}$, flowing into stagnant room air $(298 \mathrm{~K}, 101 \mathrm{kPa})$.

The air was assumed to have a constant specific heat. Therefore, from Equation (3.4), the enthalpy of the gas mixture is

$$
h=C_{p_{A}}\left[f\left(T_{0}-T_{R}\right)+(1-f)\left(T_{\infty}-T_{R}\right)\right]
$$

where the reference temperature, $T_{R}$, was $298 \mathrm{~K}$. A second expression for the mixture enthalpy can be obtained from Equation (3.3), as follows

$$
h=C_{p A}\left(T-T_{R}\right)
$$


Given $f$, and the initial and boundary conditions, Equations (B.3) and (B.4) provide the mixture temperature.

The density of the mixture was obtained from the ideal gas law

$$
\rho=p / R_{A} T
$$

\section{B.3 Dense Gas Jet in Air}

The experimental results for the dense gas jet in air were obtained during the present investigation. The flow was isothermal, involving pure sulfur hexafluoride injected into stagnant room air $(298 \mathrm{~K}, 101 \mathrm{kPa})$. Noting that the mass fraction of sulfur hexafluoride is unity at the injector exit and zero in the ambiance, Equation (3.1) yields

$$
\begin{aligned}
& Y_{S}=f \\
& Y_{A}=1-f
\end{aligned}
$$

The density of the mixture can be obtained from Equation (3.5)

$$
\rho=\left[f / \rho_{S}+(1-f) / \rho_{A}\right]^{-1}
$$

where the density of the individual components is calculated from the ideal gas law at the temperature and total pressure of the mixture.

\section{B. 4 Air Jet in Water}

Data obtained by Tross [4] was compared with the analysis for this flow. The experiments involved a pure air jet injected into a stagnant bath of water at $298 \mathrm{~K}, 101 \mathrm{kPa}$. While expansion of the gas through the injector resulted in a gas temperature below room temperature at the injector exit, this enthalpy defect is negligible due to the large heat capacity of the water. Therefore, the flow was assumed to be isothermal. The vapor pressure of water in the air was also neglected.

Under these assumptions, the mass fractions of air and water can be found from Equation (3.1) as follows

$$
\begin{aligned}
& Y_{A}=f \\
& Y_{W}=1-f
\end{aligned}
$$

The density of the flow is given by Equation (3.5) 


$$
\rho=\left[f / \rho_{A}+(1-f) \rho_{W}\right]^{-1}
$$

The density of both the water and the air was assumed to be constant. The air density was computed assuming an ideal gas.

\section{B.5 Evaporating Spray in Air}

The data for an evaporating spray was obtained in the present investigation. An air atomizing injector was used with Freon-11 as the evaporating material. Therefore, both air and Freon-11 leave the injector. The spray was injected into stagnant room air at $298 \mathrm{~K}, 101 \mathrm{kPa}$.

Given the mixture fraction, the mass fractions of Freon-11 and air can be determined from Equation (3.1)

$$
\begin{aligned}
& { }_{F}={ }_{F O}{ }^{f} \\
& Y_{A}=1-Y_{F}
\end{aligned}
$$

where $\mathrm{Y}_{F O}$ is known from the injector operating condition.

The enthalpy of the mixture can be determined from Equation (3.3)

$$
h=h_{0} f+h_{A \infty}(1-f)
$$

The enthalpy of air is given by Equation (B.4). The enthalpy of Freon-11 in the liquid and gas phases were expressed as

$$
\begin{aligned}
& h_{F f}=C_{p_{F f}}\left(T-T_{R}\right) \\
& h_{F}=C_{p_{F g}}\left(T-T_{R}\right)+h_{F}{ }_{f g R}
\end{aligned}
$$

where $T_{R}$ was taken to be $298 \mathrm{~K}$.

The enthalpy at the injector exit is the sum of the contributions due to Freon-11 and the injector air.

$$
h_{O}=Y_{A O} h_{A O}+Y_{F O} h_{F O}
$$

The gas phase consists of both Freon-11 vapor and air. Assuming ideal gas behavior, the total pressure is equal to the sum of the partial pressures of the individual components. 


$$
\mathrm{p}=\Sigma \mathrm{p}_{\mathrm{i}}=\mathrm{p}_{\mathrm{A}}+\mathrm{p}_{\mathrm{Fg}}
$$

When the liquid is present, the partial pressure of Freon-11 in the gas phase must equal the vapor pressure. The vapor pressure of Freon-11 can be correlated by the following expression

$$
\log _{10} \mathrm{P}_{\mathrm{Fg}}=\mathrm{A}^{\prime}-\mathrm{B}^{\prime} / \mathrm{T}
$$

Then, since mole fractions in the gas phase are proportional to the partial pressures, the mass fraction of Freon-11 in the gas phase is

$$
\mathrm{Y}_{\mathrm{Fg}}=\mathrm{Y}_{\mathrm{A}} \mathrm{P}_{\mathrm{Fg}} \mathrm{M}_{\mathrm{F}} / \mathrm{P}_{\mathrm{A}} \mathrm{M}_{\mathrm{A}}
$$

Then

$$
Y_{F f}=Y_{F}-Y_{F g}
$$

The enthalpy of the mixture can also be determined from Equation (3.4)

$$
h=Y_{A} h_{F g}+Y_{F f} h_{F f}+Y_{F g} h_{F g}
$$

As long as the mixture is saturated, the mixture temperature and composition can be calculated at any mixture fraction using Equations (B.12)-(B.22). A temperature is estimated and the partial pressure of Freon vapor is determined from Equation (B.19). The mass fractions and mixture enthalpy are then calculated from Equations (B.20)-(B.22). The enthalpy computed in this manner is compared with the enthalpy determined directly from Equation (B.14). An interval halving procedure was employed to adjust the temperature until both calculated values of the mixture enthalpy agreed.

Once all the liquid has vaporized, $Y_{F f}=0$ and the mass fractions of air and Freon-11 vapor can be determined firectly

$$
\begin{aligned}
& Y_{F g}=Y_{F O} f \\
& Y_{A}=1-Y_{F g}
\end{aligned}
$$

The mixture temperature can then be determined from Equations (B.4), (B.14), (B.16) and (B.22). 


$$
\rho=\left[\mathrm{Y}_{\mathrm{Ff}} / \rho_{\mathrm{Ff}}+\mathrm{Y}_{\mathrm{Fg}} / \rho_{\mathrm{Fg}}+\mathrm{Y}_{\mathrm{A}} / \rho_{\mathrm{A}}\right]^{-1}
$$

The density of the Freon-11 liquid was taken to be a linear function of temperature. The air and vapor densities were obtained from the ideal gas expression at the temperature and total pressure of the mixture.

\section{B. 6 Property Data}

The property data [63] employed in the calculations described in Sections B.1-B.5 are summarized in Table 7 . 
Table 7

Summary of Properties Used in the Equation
of State Calculations

Air:

$$
\begin{aligned}
& M=28.966 \mathrm{~kg} / \mathrm{kg} \text { mole } \\
& C_{p}=1.005 \mathrm{~kJ} / \mathrm{kg} \mathrm{K}
\end{aligned}
$$

Sulfur Hexafluoride:

$$
M=146.05 \mathrm{~kg} / \mathrm{kg} \text { mole }
$$

Water:

$$
\rho=997.1 \mathrm{~kg} / \mathrm{m}
$$

Freon-11:

$$
\begin{aligned}
& M=137.37 \mathrm{~kg} / \mathrm{kg} \text { mole } \\
& C_{p g}=0.674 \mathrm{~kJ} / \mathrm{kg} \mathrm{K} \\
& C_{p f}=0.879 \mathrm{~kJ} / \mathrm{kg} \mathrm{K} \\
& { }_{f g}=171.17 \mathrm{~kJ} / \mathrm{kg} \\
& \rho_{f}=2143.7-2.235 \mathrm{~T} \mathrm{~kg} / \mathrm{m}^{3} \\
& \log _{10^{P}} \mathrm{P}_{\mathrm{g}}=\mathrm{A}^{\prime}-\mathrm{B}^{\prime} / \mathrm{T} \mathrm{kPa} \\
& A^{\prime}=6.7828 \\
& B^{\prime}=1416.1
\end{aligned}
$$

$\mathrm{a}_{\mathrm{T}}$ in $\mathrm{K}$, Universal gas constant $=8.3143 \mathrm{~kJ} / \mathrm{kg}$ mole $\mathrm{K}, \mathrm{T}_{\mathrm{R}}=298 \mathrm{~K}$. 
APPENDIX C

PROBABILITY DENSITY FUNCTION TABLE

Evaluation of $\mu$ and $\sigma$ for $P(f)$

The values of $\sigma$ and $\mu$ are given as a function of $\bar{f}$ and $g$ in Tables 8 and 9 . 
Table 8

$\sigma$ as a Function of $\bar{f}$ and $\bar{f} / g^{1 / 2}$

\begin{tabular}{|c|c|c|c|c|c|c|c|c|c|}
\hline$\overline{\mathrm{f}} / \mathrm{g}^{1 / 2}$ & $\overline{\mathrm{f}}=: .001$ & .01 & .05 & .1 & .2 & .3 & .4 & .5 & 1.0 \\
\hline 3.0 & 1. & 1. & 1. & 1. & 1. & 1. & 1. & 1. & 1. \\
\hline 2.5 & 1. & 1. & 1. & 1. & 1. & 1. & 1. & 1. & 1. \\
\hline 2.0 & 1.02 & 1.02 & 1.02 & 1.02 & 1.02 & 1.02 & 1.02 & 1.04 & 1. \\
\hline 1.5 & 1.09 & 1.09 & 1.09 & 1.09 & 1.09 & 1.09 & 1.12 & 1.27 & 1. \\
\hline 1.2 & 1.17 & 1.17 & 1.17 & 1.17 & 1.17 & 1.17 & 1.34 & 1.92 & 1. \\
\hline 1.1 & 1.22 & 1.22 & 1.22 & 1.22 & 1.22 & 1.25 & 1.55 & 2.90 & 10. \\
\hline 1.0 & 1.29 & 1.29 & 1.29 & 1.29 & 1.29 & 1.37 & 1.99 & 10 & 20 \\
\hline 0.9 & 1.38 & 1.38 & 1.38 & 1.38 & 1.38 & 1.59 & 3.50 & 20 & 30. \\
\hline .85 & 1.43 & 1.43 & 1.43 & 1.43 & 1.43 & 1.80 & 6.40 & 30 & 40. \\
\hline .80 & 1.50 & 1.50 & 1.50 & 1.50 & 1.53 & 2.15 & 10 & 40 & 50. \\
\hline .70 & 1.67 & 1.67 & 1.67 & 1.67 & 1.87 & 4.70 & 20 & 50. & 60. \\
\hline .60 & 1.90 & 1.90 & 1.90 & 1.93 & 2.85 & 10 & 30 & 60. & 70. \\
\hline .52 & 2.17 & 2.17 & 2.17 & 2.27 & 7.80 & 20 & 40 & 70 & 80. \\
\hline .40 & 2.90 & 2.90 & 2.90 & 4.0 & 10 & 30 & 50 & 80 & 90. \\
\hline .35 & 3.40 & 3.40 & 3.50 & 12.0 & 20 & 40 & 60. & 90. & 100 \\
\hline .30 & 4.10 & 4.10 & 4.60 & 20 & 30 & 50 & 70 & 100 & 110. \\
\hline .25 & 5.10 & 5.10 & 10.7 & 30 & 50 & 60. & 80. & 110 & 120. \\
\hline .20 & 6.65 & 6.65 & 20 & 40 & 50. & 70 & 90. & 120 & 130 . \\
\hline .15 & 9.40 & 9.90 & 30 & 50 & 60. & 80 & 100 & 130 & 140 . \\
\hline .12 & 12.3 & 17.1 & 40 & 60. & 70 & 90. & 110 & 140 & 150. \\
\hline .11 & 13.6 & 28.5 & 50. & 70 & 80 & 100 & 120 & 150 & 160. \\
\hline .10 & 15.2 & 40. & 60. & 80. & 90. & 110. & 130. & 160. & 170. \\
\hline
\end{tabular}


Table 9

$\mu$ as a Function of $\bar{f}$ and $\sigma / \bar{f}$

\begin{tabular}{|c|c|c|c|c|c|c|c|}
\hline \multirow{2}{*}{$\sigma / \bar{f}$} & \multicolumn{7}{|c|}{$\overrightarrow{\mathrm{f}}$} \\
\hline & .1 & .3 & .4 & .45 & .48 & .5 & 1.0 \\
\hline .4 & 1. & 1. & 1. & 1. & 1 . & 1. & 1. \\
\hline .5 & .996 & .996 & 1. & 1. & 1. & 1 . & 1. \\
\hline .8 & .955 & .995 & .980 & .975 & .985 & 1 . & 1. \\
\hline 1.0 & .901 & .905 & .935 & .960 & .975 & 1. & 1. \\
\hline 1.25 & .810 & .830 & .885 & .930 & .965 & 1. & 1. \\
\hline 1.5 & .675 & .730 & .830 & .905 & .955 & 1. & 1. \\
\hline 2.0 & .376 & .490 & .710 & .845 & .930 & 1. & 1. \\
\hline 2.5 & .005 & .255 & .590 & .785 & .905 & 1. & 1. \\
\hline 3.0 & -.430 & 0.00 & .450 & .720 & .885 & 1. & 1. \\
\hline 3.5 & .92 & -.26 & .305 & .665 & .860 & 1 . & 1. \\
\hline 4.0 & -1.38 & -.55 & .180 & .600 & .835 & 1 . & 1. \\
\hline 5.0 & -2.46 & -1.10 & .03 & .48 & .785 & 1. & 1. \\
\hline 6.25 & -3.92 & -1.70 & -.36 & .335 & .725 & 1. & 1. \\
\hline 7.14 & -5.05 & -2.18 & -.59 & .23 & .68 & 1. & 1. \\
\hline 8.33 & -6.64 & -2.83 & -.86 & .09 & .62 & 1 . & 1. \\
\hline 8.99 & -7.12 & -3.10 & -1.0 & .0 & .59 & 1. & 1. \\
\hline 10.0 & -9.02 & -3.60 & -1.29 & -1.28 & -.14 & 1. & 1 . \\
\hline 20.0 & -25.1 & -10 & -10 & -10 & -10 & 1. & 1 . \\
\hline 37.5 & -46.7 & -10 & -10 & -10 & -10 & 1. & 1. \\
\hline
\end{tabular}




\section{APPENDIX D \\ ORDER OF MAGNITUDE ANALYSIS OF GOVERNING EQUATIONS}

The order of magnitude analysis considered the equations of conservation of mass, momentum, mixture fraction, turbulent kinetic energy, turbulent dissipation, and concentration fluctuations. The governing equations for this analysis follow those proposed by Gosman, Lockwood, and Syed [47] . These equations are limited to steady, axisymmetric, compressible flow. The order of magnitude analysis will not be conducted for dimensionless equations in order to preserve the notation used in the calculations.

For boundary layer flows, where the thickness is very small compared to the axial distance, it is assumed

$$
\bar{u}, \bar{x}, \bar{p} \sim 1 ; \quad r \backsim \delta
$$

The Reynolds averaged equation of conservation of mass for a steady compressible flow is

$$
\begin{array}{lll}
\text { (a) }(\mathrm{b}) & \text { (c) } \\
\frac{\partial}{\partial x}(\bar{\rho} \bar{u})+\frac{\partial}{\partial x}\left(\overline{\rho^{\prime} u^{\prime}}\right)+\frac{1}{r} \frac{\partial}{\partial x}(r \bar{\rho} \bar{v})+\frac{1}{r} \frac{\partial}{\partial r}\left(x \overline{\rho^{\prime} v^{\prime}}\right)=0
\end{array}
$$

The Boussinesq approximation is employed to model the density-velocity correlations appearing in terms (b) and (d) in equation (D.2).

$$
\begin{aligned}
& \overline{\rho^{\prime} u^{\prime}}=\frac{-\mu_{t}}{\sigma_{\rho}} \frac{\partial \bar{\rho}}{\partial x} \\
& \overline{\rho^{\prime} v^{\prime}}=\frac{-\mu_{t}}{\sigma_{\rho}} \frac{\partial \bar{\rho}}{\partial r}
\end{aligned}
$$

Substituting Equations (D.3) and (D.4) into Equation (D.2), and applying the orders of magnitude indicated in Equation (D.1) yields

(a)

$$
\frac{\partial}{\partial x}(\bar{p} \bar{u})-\frac{\partial}{\partial x}
$$$$
\left(\mu_{t} \frac{\partial \bar{\rho}}{\partial x}\right)+\frac{1}{r} \frac{\partial}{\partial r}
$$$$
(r \bar{\rho} \bar{v})
$$

(c)

$\mu_{t} \quad \bar{v} / \delta \quad \mu_{t} / \delta^{2}$


where the order of magnitude has been indicated below each term. In order that Equation (D.5) not be trivial, terms (c) and (d) must be retained. This implies that

$$
\bar{v} \sim \delta, \quad \mu_{t} \sim \delta^{2}
$$

With this assessment, term (b) in Equation (D.5) is higher-order than the rest. Therefore, Equation (D.2) may be rewritten as

$$
\frac{\partial}{\partial \mathbf{x}}(\bar{\rho} \bar{u})+\frac{1}{r} \frac{\partial}{\partial \mathbf{r}}\left(r \bar{\rho} \bar{v}^{0}\right)=0
$$

where

$$
\bar{\rho} \bar{v}^{\circ}=\bar{\rho} \bar{v}+\overline{\rho^{\prime} v^{\prime}}
$$

The combination of mean and fluctuating terms given by Equation (D.8) provides a convenient formulation for the remainder of the analysis. Razdan (64) applies a similar substitution for a two-dimensional planar boundary layer.

The momentum equation in the axial direction may be expressed

(a)

(b)

(c)

(d)

(e)

$$
\begin{aligned}
& \bar{\rho} \bar{u} \frac{\partial \bar{u}}{\partial x}+\bar{\rho} \bar{v}-\frac{\partial \bar{u}}{\partial r}=a\left(\bar{\rho}_{\infty}-\bar{\rho}\right)-\frac{\partial}{\partial x}\left(\overline{\rho u^{\prime} u^{\prime}}\right)-\frac{1}{r} \frac{\partial}{\partial r}\left(r \bar{\rho} \overline{u^{\prime} v^{\prime}}\right) \\
& -\frac{\partial}{\partial x}\left(\overline{u \rho^{\prime} u^{\prime}}\right)-\frac{1}{r} \frac{\partial}{\partial r}\left(r \bar{v} \overline{\rho^{\prime} v^{\prime}}\right)-\frac{\partial}{\partial x}\left(\overline{\rho^{\prime} u^{\prime} u^{\prime}}\right)-\frac{1}{r} \frac{\partial}{\partial r}\left(r \overline{\rho^{\prime} u^{\prime} v^{\prime}}\right) \\
& \text { (k) } \\
& -\overline{\rho^{\prime} u^{\prime}} \frac{\partial \bar{u}}{\partial x}-\overline{\rho^{\prime} v^{\prime}} \frac{\partial \bar{u}}{\partial r}
\end{aligned}
$$

when all terms involving the laminar viscosity have been neglected, which is well-justified for a turbulent free-jet flow (47).

As before, the Boussinesq approximation, Equations(D.3) and (D.4), can be used to model terms ( $f),(g),(j)$ and $(k)$. Gossman, et a1., (47) suggest the following expressions for the Reynolds stress terms:

$$
\begin{aligned}
& \overline{\rho u^{\top} u^{\prime}}=-2 \mu_{t} \frac{\partial \bar{u}}{\partial x}+\frac{2}{3} \frac{\mu_{t}}{\rho} \bar{u} \frac{\partial \bar{\rho}}{\partial x} \\
& \overline{\rho u^{\prime} v^{\top}}=\mu_{t}\left(\frac{\partial \bar{u}}{\partial r}+\frac{\partial \bar{v}}{\partial x}\right)
\end{aligned}
$$


The order of magnitude of $\overline{\rho u^{\prime} u^{\prime}}$ is indicated by the first term on the right hand side of Equation (D.10). Therefore, only this term will be considered in the following in order to simplify the formulation. From Equations (D.1) and (D.6), the second term on the right hand side of Equation (D.11) is higher-order than the first and can be dropped immediately. The triple correlation terms ( $h$ ) and (i) in Equation (D.9) present special problems. These terms may not be small. However, since suitable correlations have not yet been developed for them, they are neglected, similar to Gosman, et a1., (47).

From this discussion, Equation (D.9) may be written, with the order of magnitude of the terms indicated, as follows:
(a)
(b)
(c)
(d)

$$
\begin{aligned}
& \bar{\rho} \bar{u} \frac{\partial \bar{u}}{\partial x}+\bar{\rho} \bar{v} \frac{\partial \bar{u}}{\partial r}=a\left(\bar{\rho}_{\infty}-\bar{\rho}\right)+2 \frac{\partial}{\partial x}\left(\mu_{t} \frac{\partial \bar{u}}{\partial x}\right) \\
& 1 \quad 1 \quad 1 \quad \delta^{2}
\end{aligned}
$$

(g)

$$
\begin{aligned}
& +\frac{1}{r} \frac{\partial}{\partial r}\left(r \mu_{t} \frac{\partial \bar{u}}{\partial r}\right)+\frac{\partial}{\partial x}\left(\bar{u} \frac{\mu_{t}}{\sigma_{\rho}} \frac{\partial \bar{\rho}}{\partial x}\right)+\frac{1}{r} \frac{\partial}{\partial r}\left(r \bar{v} \frac{\mu_{t}}{\sigma_{\rho}} \frac{\partial \bar{\rho}}{\partial r}\right) \\
& 1 \quad \delta^{2}
\end{aligned}
$$

(j)

(k)

$$
+\frac{\mu_{t}}{\sigma_{\rho}} \frac{\partial \bar{\rho}}{\partial x} \frac{\partial \bar{u}}{\partial x}+\frac{\mu_{t}}{\sigma_{\rho}} \frac{\partial \bar{\rho}}{\partial r} \frac{\partial \bar{u}}{\partial r}
$$

$\delta^{2}$

1

Due to their higher order, terms (d), (f), $(g)$ and $(j)$ may be eliminated. With these simplifications, Equation (D.9) becomes

$$
\bar{\rho} \bar{u} \frac{\partial \bar{u}}{\partial x}+\bar{\rho} \bar{v}^{\circ} \frac{\partial \bar{u}}{\partial r}-\frac{1}{r} \frac{\partial}{\partial r}\left(r \mu_{t} \frac{\partial \bar{u}}{\partial r}\right)=a\left(\bar{\rho}_{\infty}-\bar{\rho}\right)
$$

The conservation of mixture fraction equation can be written as follows:

(a)

$$
\begin{aligned}
& \bar{\rho} \bar{u} \frac{\partial \bar{f}}{\partial x}+\bar{\rho} \bar{v} \frac{\partial \bar{f}}{\partial r}=-\frac{\partial}{\partial x} \\
& (f) \\
& -\frac{1}{r} \frac{\partial}{\partial r}\left(r \bar{v} \overline{\rho^{\prime} f^{\prime}}\right)-\frac{\partial}{\partial x}\left(\rho^{\prime}\right. \\
& -\overline{\rho^{\prime} v^{\prime}} \frac{\partial \bar{f}}{\partial \bar{r}}
\end{aligned}
$$

(d)

(e) 
Similar to conservation of momentum, the triple correlation terms $(\mathrm{g})$ and $(\mathrm{h})$ will be neglected (47).

Terms (e) and (f) contain the scalar correlation $\overline{\rho^{\prime} f^{\prime}}$. This correlation could be modeled statistically. Since $\rho$ is solely a function of $f$ under the assumptions of the present analysis, the time averaged value of the correlation can be determined from the relationship

$$
\overline{\rho^{\prime} f^{\prime}}=\int_{0}^{1} \rho^{\prime} f^{\prime} P(f) d f
$$

Equation (D.15) can be written, using the basic Reynolds averaging definitions, as follows

$$
\overline{\rho^{\prime} f^{\prime}}=\int_{0}^{1}(\rho-\bar{\rho})(f-\bar{f}) P(f) d f
$$

Under the assumptions of the present analysis, the equation of state provides $\rho$ as a function of $f$. The solution of the flow equations provides $\bar{\rho}, \bar{f}$ and $\sigma$ and $\mu$ (which are required to complete the specification of $P(f)$. With this information the integral in Equation (D.16) can be evaluated to yield $\overline{\rho^{\prime} f^{\prime}}$, and thus terms (e) and (f) in Equation (D.14).

If the magnitude of the fluctuations is not large, Equation (D.15) can be approximated. Neglecting higher order terms, since $\rho=\rho(f)$, we have

$$
\rho-\bar{\rho}=\left(\frac{d \rho}{d f}\right) \bar{f}(f-\bar{f})
$$

where the derivative is to be evaluated at $\bar{f}$. Substituting Equation (D.17) into (D.16) yields

$$
\overline{\rho^{\prime} f^{\prime}}=\int_{0}^{1}\left(\frac{d \rho}{d f}\right) \bar{f}(f-\bar{f})^{2} P(f) d f
$$

Equations (D.16) and (D.18) reveal that $\overline{\rho^{\prime} f^{\prime}}$ depends very strongly on the form of the probability density function used in the mode1. Since the probability density function is not known very accurately, Gosman, Lockwood and syed (47) chose to ignore the $\overline{\rho^{\prime} f^{\prime}}$ terms. This model gave reasonably good predictions of experimental results; therefore, the same procedure was chosen in the present study. This introduces no additional 
uncertainty for most of the flows considered in this study, since the density vairations are no greater than those encountered in Reference (47). The exception is the air jet into water, where the equation of state illustrated in Figure 7 indicates very large values of $\mathrm{d} \rho / \mathrm{d} f$ in the region near $f=0$ (corresponding to the edge of the $j e t$ ). In this case $\overline{\rho^{\prime} f^{\prime}}$ is definitely not sma11, from Equation (D.18). This point shall be discussed further when the results for the air-water jet are considered.

The Boussinesq approximation for scalar quantities is (47)

$$
\begin{aligned}
& \overline{\phi^{\prime} u^{\prime}}=\frac{-\mu_{t}}{\sigma_{\phi}} \frac{\partial \bar{\phi}}{\partial x} \\
& \overline{\phi^{\prime} v^{\prime}}=\frac{-\mu_{t}}{\sigma_{\phi}} \frac{\partial \bar{\phi}}{\partial r}
\end{aligned}
$$

which can be applied to model terms (c) and (d) Equation (D.14), with $\phi=f$. Equations (D.3) and (D.4) can be used to model terms (i) and (j).

Employing the results of the previous discussion, Equation (D.14) can be rewritten as follows:
(a)
(b)
$\bar{\rho} \bar{u} \frac{\partial \bar{f}}{\partial x}+\bar{\rho} \bar{v} \frac{\partial \bar{f}}{\partial r}=\frac{\partial}{\partial x}$
$\left(\bar{\rho} \frac{\mu_{t}}{\sigma_{f}} \frac{\partial \bar{f}}{\partial x}\right)+\frac{1}{r} \frac{\partial}{\partial r}$
(d)
1
1
$\delta^{2}$
$\left(r \bar{\rho} \frac{\mu_{t}}{\sigma_{f}} \frac{\partial \bar{f}}{\partial r}\right)$
1

(i)

(j)

$$
\begin{gathered}
\frac{\mu_{t}}{\sigma_{\rho}} \frac{\partial \bar{\rho}}{\partial x} \frac{\partial \bar{f}}{\partial x}+\frac{\mu_{t}}{\sigma_{\rho}} \frac{\partial \bar{\rho}}{\partial r} \frac{\partial \bar{f}}{\partial r} \\
\delta^{2}
\end{gathered}
$$

Neglecting higher-order terms and employing Equation (D.8), Equation (D.21) becomes

$$
\bar{\rho} \bar{u} \frac{\partial \bar{f}}{\partial x}+\bar{\rho} \bar{v}^{\circ} \frac{\partial \bar{f}}{\partial r}-\frac{1}{r} \frac{\partial}{\partial r}\left(r \frac{\mu_{t}}{\sigma_{f}} \frac{\partial \bar{f}}{\partial r}\right)=0
$$

The turbulent kinetic energy equation requires modeling additional terms. Employing the argument given by Gosman, et a1., (47), the following equation is obtained after completion of the order of magnitude estimation: 


$$
\bar{\rho} \bar{u} \frac{\partial k}{\partial x}+\bar{\rho} \bar{v}^{\circ} \frac{\partial k}{\partial r}-\frac{1}{r} \frac{\partial}{\partial r}\left(r \frac{\mu_{t}}{\sigma_{k}} \frac{\partial k}{\partial r}\right)=\mu_{t}\left(\frac{\partial \bar{u}}{\partial r}\right)^{2}-\bar{\rho} \varepsilon
$$

In arriving at this equation, a number of density fluctuation terms are ignored and other terms are modeled according to the methods employed for uniform property flow. In fact, the only difference between Equation (D.23) and the constant density form involves retention of the $\overline{\rho^{\prime} v^{\prime}}$ correlation term on the left hand side of the equation. The justification for this largely rests on the success of the method during earlier studies of variable density flows (47).

Similar simplifications are employed for the conservation equations for $\varepsilon$ and $g$. As in the case of the $\overline{\rho^{\prime} f^{\prime}}$ correlation, the $\overline{\rho^{\prime} g^{\prime}}$ correlation (which could be modeled using the probability density function) has also been ignored. The final results are:

$$
\begin{aligned}
& \bar{\rho} \bar{u} \frac{\partial \varepsilon}{\partial x}+\bar{\rho} \bar{v}^{\circ} \frac{\partial \varepsilon}{\partial r}-\frac{1}{r} \frac{\partial}{\partial r}\left(r \frac{\mu_{t}}{\sigma_{\varepsilon}} \frac{\partial \varepsilon}{\partial r}\right)=C_{\varepsilon_{1}} \mu_{t} \frac{\varepsilon}{k}\left(\frac{\partial \bar{u}}{-\partial r}\right)^{2} \\
& -\mathrm{C}_{\varepsilon_{2}} \bar{\rho} \frac{\varepsilon^{2}}{\mathrm{k}} \\
& \bar{\rho} \bar{u} \frac{\partial g}{\partial x}+\bar{\rho} \bar{v}^{\circ} \frac{\partial g}{\partial r}-\frac{1}{r} \frac{\partial}{\partial r}\left(r \frac{\mu_{t}}{\sigma_{g}} \frac{\partial g}{\partial r}\right)=C_{g_{1}} \mu_{t}\left(\frac{\partial \bar{f}}{\partial r}\right)^{2} \\
& -\mathrm{C}_{\mathrm{g}_{2}} \bar{\rho} \frac{\varepsilon \mathrm{g}}{\mathrm{k}}
\end{aligned}
$$

The constants, $\mathrm{C}_{\varepsilon_{1}}, \mathrm{C}_{\varepsilon_{2}}, \mathrm{C}_{\mathrm{g}_{1}}$ and $\mathrm{C}_{\mathrm{g}_{2}}$, as we11 as the values for the
turbulent $\sigma_{k}, \sigma_{\varepsilon}$ and $\sigma_{g}$ are drawn from the values obtained for uni form property

Given the local values of $k$ and $\varepsilon$, the model is completed by obtaining the turbulent viscosity from the following equation (47)

$$
\mu_{t}=c_{\mu} \bar{\rho} k^{2} / \varepsilon
$$

where $C_{\mu}$ is also a constant specified from uniform property flow results. 
APPENDIX E

EVALUATION OF PROPERTIES FOR DROPLET LIFE HISTORY MODEL

\section{E.1 Therma1 Conductivity}

The thermal conductivity of the gaseous mixture was calculated with the Mason and Saxena formulation of the Wassiljewa Equation (65).

$$
\lambda=\sum_{i=1}^{N}\left[\frac{x_{i} \lambda_{i}}{\sum_{j=1}^{N} x_{j} \phi_{i j}}\right]
$$

where

$$
\phi_{i j}=8^{-1 / 2}\left(1+\frac{M_{i}}{M_{j}}\right)^{1 / 2}\left[1+\left(\frac{\mu_{i}}{\mu_{j}}\right)\left(\frac{M_{j}}{M_{i}}\right)^{1 / 4}\right]^{2}
$$

Variation of the thermal conductivity of the gases was taken to be a linear function of temperature in the range of the calculations.

\section{E.2 Viscosity}

The viscosity calculations employed the method of wilke as described by Reference (65).

For a mixture of $\mathrm{N}$ components

$$
\mu=\sum_{i=1}^{N}\left(\frac{\mu_{i}}{\left[1+\sum_{j=1}^{N} \phi_{1 j}\left(\frac{x_{j}}{x_{i}}\right)\right]}\right)
$$

where $\phi$ is given by Equation (E.2). 


\section{E. 3 Gas Properties}

VIscosity

\begin{tabular}{lccc}
\hline & Temperature $(\mathrm{K})$ & $\mu\left(\mathrm{Ns} / \mathrm{m}^{2}\right)$ & Source \\
Freon-11 & 258.15 & $.087 \times 10^{-5}$ & 66 \\
& 303.15 & $1.08 \times 10^{-5}$ & 66 \\
Air & 240 & $1.547 \times 10^{-5}$ & 63 \\
& 300 & $1.846 \times 10^{-5}$ & 63 \\
\hline
\end{tabular}

Therma1 Conductivity

\begin{tabular}{lccc}
\hline & Temperature $(\mathrm{K})$ & $\lambda(\mathrm{W} / \mathrm{mK})$ & Source \\
Freon-11 & 258.15 & $5.892 \times 10^{-3}$ & 66 \\
& 303.15 & $7.799 \times 10^{-3}$ & 66 \\
Air & 240 & $2.145 \times 10^{-2}$ & 63 \\
& 300 & $2.624 \times 10^{-2}$ & 63 \\
\hline
\end{tabular}


APPENDIX F

EXPERIMENTAL DATA

F.1 Axial Variation of Quantities

Isothermal single-phase jet

\begin{tabular}{ll}
\hline$\overline{x / d}$ & $\overline{\mathrm{u}}_{\mathrm{c}} / \overline{\mathrm{u}}_{\mathrm{o}}$ \\
50 & .142 \\
108 & .065 \\
170 & .045 \\
340 & .022 \\
510 & .016 \\
\hline
\end{tabular}

Variable Density Single-Phase Jet

\begin{tabular}{rrrr}
\hline $\bar{x} / \mathrm{d}$ & $u_{c} / \mathrm{u}_{o}$ & $\mathrm{x} / \mathrm{d}$ & $\overline{\mathrm{f}}_{c} / \overline{\mathrm{f}}_{\mathrm{o}}^{\mathrm{a}}$ \\
\hline 50 & .351 & 110 & .112 \\
108 & .163 & 170 & .073 \\
170 & .096 & 340 & .033 \\
340 & .058 & 510 & .019 \\
510 & .041 & & \\
\hline
\end{tabular}

$a_{f_{0}}=1$ 
Evaporating Spray

\begin{tabular}{cccccc}
\hline $\mathrm{x} / \mathrm{d}$ & $\overline{\mathrm{u}}_{\mathrm{c}} / \overline{\mathrm{u}}_{\mathrm{o}}$ & $\mathrm{x} / \mathrm{d}$ & $\overline{\mathrm{f}}_{\mathrm{c}} / \overline{\mathrm{f}}_{\mathrm{o}}^{\mathrm{a}}$ & $\mathrm{x} / \mathrm{d}$ & $\left(\overline{\mathrm{T}}_{\mathrm{c}}-\overline{\mathrm{T}}_{\infty}\right) /\left(\mathrm{T}_{\mathrm{o}}-\overline{\mathrm{T}}_{\infty}\right)$ \\
\hline 50 & .372 & 75 & .268 & 300 & .629 \\
78 & .275 & 170 & .144 & 340 & .465 \\
170 & .157 & 340 & .076 & 375 & .384 \\
267 & .108 & 510 & .047 & 425 & .337 \\
340 & .072 & & 450 & .294 \\
435 & .059 & & 510 & .262 \\
510 & .050 & & & \\
\hline
\end{tabular}

$a_{f}=1$ 
F.2 Radial Variation of Quantities

Isotherma1 Sing1e-Phase Jet

\begin{tabular}{|c|c|c|c|c|c|}
\hline \multirow{2}{*}{$\frac{\mathrm{x} / \mathrm{d}}{\mathrm{r} / \mathrm{x}}$} & 170 & \multicolumn{2}{|c|}{340} & \multicolumn{2}{|c|}{510} \\
\hline & $\overline{\mathrm{u}} / \overline{\mathrm{u}}_{\mathrm{c}}$ & $\mathrm{r} / \mathrm{x}$ & $\overline{\overline{\mathrm{u}} / \overline{\mathrm{u}}_{\mathrm{c}}}$ & $r / x$ & $\overline{\mathrm{u}} / \overline{\mathrm{u}}_{\mathrm{c}}$ \\
\hline .026 & .948 & .019 & .972 & .021 & .936 \\
\hline .039 & .815 & .034 & .896 & .042 & .835 \\
\hline .055 & .783 & .049 & .835 & .064 & .754 \\
\hline .072 & .632 & .061 & .746 & .085 & .561 \\
\hline .088 & .576 & .078 & .637 & .097 & .400 \\
\hline .104 & .470 & .094 & .496 & .146 & .219 \\
\hline .118 & .364 & .109 & .418 & .169 & .123 \\
\hline .136 & .282 & .125 & .315 & .180 & .068 \\
\hline .164 & .141 & .141 & .238 & .209 & .025 \\
\hline .178 & .085 & .154 & .184 & & \\
\hline \multirow[t]{3}{*}{.199} & .042 & .174 & .116 & & \\
\hline & & .185 & .062 & & \\
\hline & & .203 & .034 & & \\
\hline
\end{tabular}


Isothermal Single-Phase Jet

\begin{tabular}{|c|c|c|c|c|c|}
\hline \multicolumn{2}{|c|}{$\begin{array}{ll}\mathrm{x} / \mathrm{d} & 170 \\
\end{array}$} & \multicolumn{2}{|c|}{340} & \multicolumn{2}{|c|}{510} \\
\hline$r / x$ & $\mathrm{k} / \bar{u}^{-2}$ & $r / x$ & $\mathrm{k} / \overline{\mathrm{u}}_{\mathrm{c}}^{2}$ & $r / x$ & $k / u_{c}^{2}$ \\
\hline .015 & .0768 & .022 & .0802 & .023 & .0765 \\
\hline .043 & .0778 & .042 & .0802 & .044 & .0765 \\
\hline .062 & .0730 & .062 & .0771 & .066 & .0756 \\
\hline .084 & .0561 & .083 & .0672 & .087 & .0642 \\
\hline .104 & .0486 & .103 & .0568 & .105 & .0533 \\
\hline .124 & .0304 & .125 & .0427 & .128 & .0383 \\
\hline .146 & .0197 & .144 & .0321 & .147 & .0272 \\
\hline .166 & .0124 & .166 & .0238 & .170 & .0190 \\
\hline .183 & .0078 & .187 & .0155 & .192 & .0105 \\
\hline
\end{tabular}


Isothermal Single-Phase Jet

\begin{tabular}{|c|c|c|c|c|c|}
\hline \multirow{2}{*}{$\frac{\bar{x} / d}{r / x}$} & \multirow{2}{*}{$\frac{170}{u^{\prime} v^{\prime} / u^{2}}$} & \multicolumn{2}{|c|}{340} & \multicolumn{2}{|c|}{510} \\
\hline & & $r / x$ & $\overline{u^{\top} v^{\top} / \bar{u}_{c}^{2}}$ & $r / x$ & $\overline{u^{\prime} v^{\prime}} / \bar{u}_{c}^{-2}$ \\
\hline .021 & .0038 & .024 & .0094 & .021 & .0062 \\
\hline .033 & .0117 & .039 & .0142 & .042 & .0139 \\
\hline .049 & .0158 & .058 & .0171 & .063 & .0189 \\
\hline .063 & .0183 & .072 & .0182 & .085 & .0192 \\
\hline .078 & .0188 & .084 & .0183 & .104 & .0175 \\
\hline .094 & .0181 & .102 & .0172 & .125 & P140 \\
\hline .109 & .0160 & .118 & .0150 & .146 & .0088 \\
\hline .124 & .0134 & .135 & .0109 & .168 & .0053 \\
\hline .138 & .0101 & .150 & .0082 & .186 & .0033 \\
\hline .152 & .0069 & .179 & .0039 & .209 & .0015 \\
\hline .170 & .0044 & .196 & .0022 & & \\
\hline .186 & .0026 & .211 & .0009 & & \\
\hline .207 & .0011 & & & & \\
\hline
\end{tabular}


Variable Density Single-Phase Jet

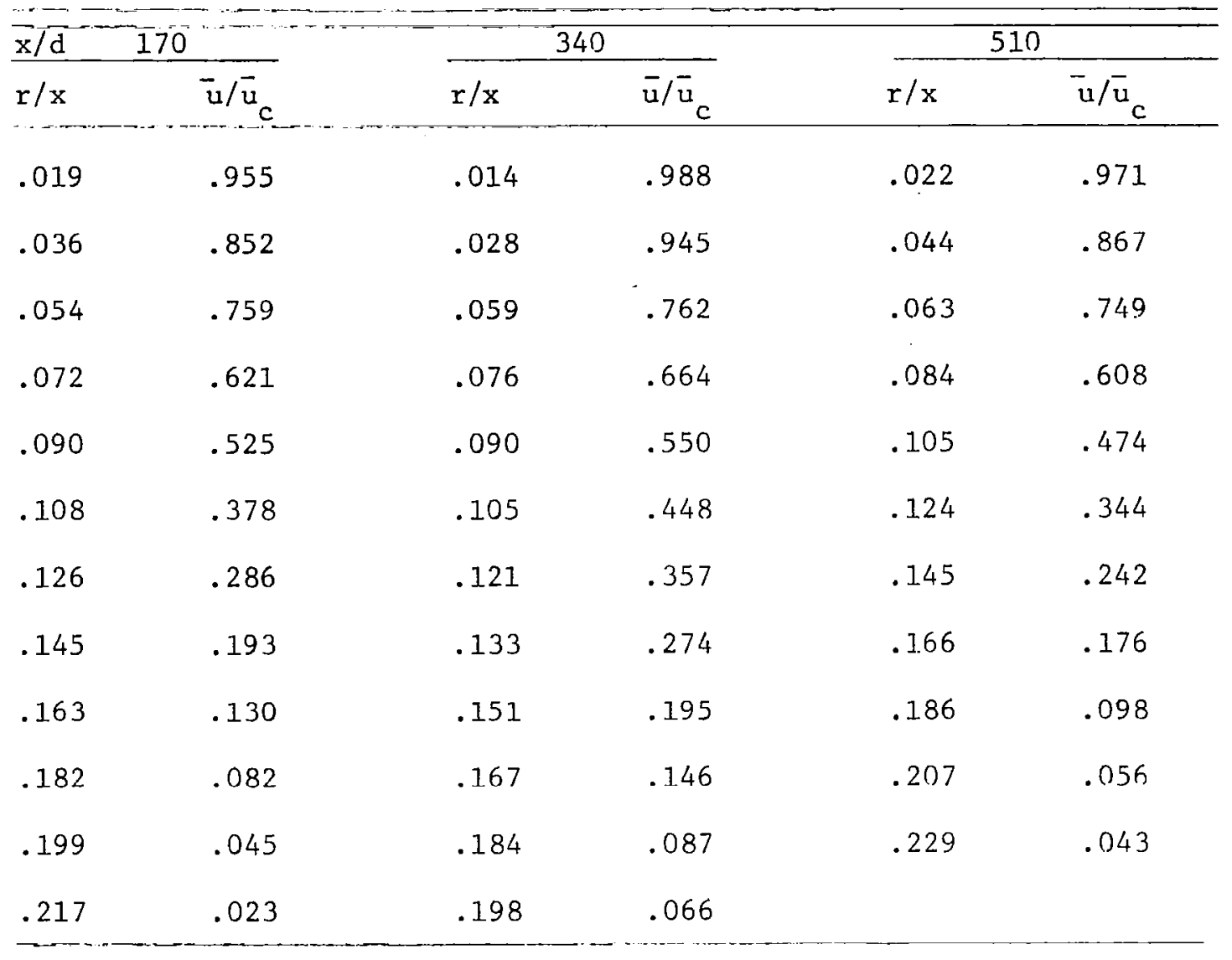


Variable Single-Phase Density Jet

\begin{tabular}{|c|c|c|c|c|c|}
\hline \multirow{2}{*}{$\frac{x / d}{r / x}$} & \multirow{2}{*}{$\begin{array}{l}170 \\
\overline{\mathrm{f}} / \overline{\mathrm{f}}_{\mathrm{c}}\end{array}$} & \multicolumn{2}{|c|}{340} & \multicolumn{2}{|c|}{510} \\
\hline & & $r / x$ & $\overline{\mathrm{f}} / \overline{\mathrm{f}}_{\mathrm{c}}$ & $r / x$ & $\overline{\mathrm{f}} / \overline{\mathrm{f}}_{\mathrm{c}}$ \\
\hline .037 & .880 & .018 & .991 & .023 & .979 \\
\hline .054 & .782 & .028 & .955 & .046 & .845 \\
\hline .074 & .638 & .042 & .983 & .067 & .768 \\
\hline .093 & .536 & .062 & .782 & .085 & .627 \\
\hline .107 & .412 & .074 & .658 & .106 & .491 \\
\hline .126 & .310 & .092 & .565 & .126 & .365 \\
\hline .145 & .233 & .106 & .462 & .146 & .283 \\
\hline .150 & .163 & .119 & .344 & .165 & .136 \\
\hline .182 & .099 & .134 & .290 & .190 & .121 \\
\hline \multirow[t]{4}{*}{.200} & .067 & .151 & .221 & .210 & .087 \\
\hline & & .168 & .170 & & \\
\hline & & .184 & .119 & & \\
\hline & & .199 & .094 & & \\
\hline
\end{tabular}


Variable Density Single-Phase Jet

\begin{tabular}{|c|c|c|c|c|c|}
\hline $\mathrm{x} / \mathrm{d}$ & 170 & & & & \\
\hline$r / x$ & $k / u_{c}^{-2}$ & $r / x$ & $\mathrm{k} / \mathrm{u}_{\mathrm{c}}^{2}$ & $r / x$ & $k / \bar{u}_{c}^{-2}$ \\
\hline 0 & .0726 & 0 & .0789 & 0 & .0813 \\
\hline .021 & .0728 & .022 & .0816 & .025 & .0784 \\
\hline .045 & .0735 & .044 & .0810 & .049 & .0783 \\
\hline .062 & .0663 & .062 & .0788 & .068 & .0765 \\
\hline .082 & .0592 & .084 & .0656 & .091 & .0647 \\
\hline .106 & .0487 & .105 & .0553 & .111 & .0530 \\
\hline .123 & .0359 & .125 & .0451 & .130 & .0414 \\
\hline .140 & .0232 & .145 & .0306 & .150 & .0273 \\
\hline .166 & .0104 & .167 & .0205 & .170 & .0165 \\
\hline .187 & .0048 & .187 & .0124 & .192 & .0048 \\
\hline
\end{tabular}


Variable Density Single-Phase Jet

\begin{tabular}{|c|c|c|c|c|c|}
\hline \multirow{2}{*}{$\frac{x / d}{r / x}$} & \multirow{2}{*}{$\frac{170}{u^{3} v^{1} / u_{c}^{2}}$} & \multicolumn{2}{|c|}{340} & \multicolumn{2}{|c|}{510} \\
\hline & & $r / x$ & $\bar{u}^{\prime} v^{1} / u_{c}^{2}$ & $r / x$ & $u^{\prime} v^{\prime} / u_{c}^{2}$ \\
\hline .019 & .0076 & .018 & .0067 & .024 & .0091 \\
\hline .036 & .0119 & .029 & .0108 & .042 & .0152 \\
\hline .053 & .0122 & .060 & .0183 & .062 & .0188 \\
\hline .072 & .0127 & .076 & .0186 & .084 & .0191 \\
\hline .092 & .0121 & .088 & .0175 & .104 & .0172 \\
\hline .108 & .0102 & .121 & .0148 & .124 & .0128 \\
\hline .124 & .0078 & .132 & .0107 & .145 & .0093 \\
\hline .145 & .0051 & .152 & .0076 & .165 & .0062 \\
\hline .167 & .0031 & .168 & .0049 & .186 & .0025 \\
\hline .183 & .0016 & .185 & .0031 & .228 & .0009 \\
\hline & & .200 & .0022 & & \\
\hline
\end{tabular}


Evaporating Spray

\begin{tabular}{|c|c|c|c|c|c|}
\hline \multirow{2}{*}{$\frac{\mathrm{x} / \mathrm{d}}{\mathrm{r} / \mathrm{x}}$} & 170 & \multicolumn{2}{|c|}{340} & \multicolumn{2}{|c|}{510} \\
\hline & $\overline{\mathrm{u}} / \overline{\mathrm{u}}_{\mathrm{c}}$ & $r / x$ & $\overline{\mathrm{u}} / \overline{\mathrm{u}}_{\mathrm{c}}$ & $r / x$ & $\overline{\mathrm{u}} / \overline{\mathrm{u}}{ }_{\mathrm{c}}$ \\
\hline .033 & .905 & .016 & .947 & .022 & .971 \\
\hline .049 & .817 & .028 & .913 & .043 & .878 \\
\hline .063 & .693 & .045 & .829 & .065 & .749 \\
\hline .079 & .788 & .064 & .662 & .084 & .585 \\
\hline .096 & .476 & .077 & .608 & .094 & .450 \\
\hline .110 & .355 & .092 & .496 & .123 & . 328 \\
\hline .126 & .280 & .107 & .386 & .145 & .210 \\
\hline .156 & .137 & .120 & .283 & .166 & .113 \\
\hline .188 & .039 & .137 & .207 & .188 & .061 \\
\hline & & .152 & .160 & & \\
\hline & & .163 & .092 & & \\
\hline
\end{tabular}


Evaporating Spray

\begin{tabular}{|c|c|c|c|c|c|}
\hline \multirow{2}{*}{$\frac{x / d}{r / x}$} & \multirow{2}{*}{170} & \multicolumn{2}{|c|}{340} & \multicolumn{2}{|c|}{510} \\
\hline & & $r / x$ & $\overline{\mathrm{f}} / \overline{\mathrm{f}}_{\mathrm{c}}$ & $r / x$ & $\overline{\mathrm{f}} / \overline{\mathrm{f}}_{\mathrm{c}}$ \\
\hline .025 & .981 & .023 & .957 & .016 & .992 \\
\hline .049 & .876 & .043 & .915 & .034 & .939 \\
\hline .076 & .723 & .063 & .788 & .048 & .921 \\
\hline .095 & .568 & .085 & .654 & .062 & .817 \\
\hline .117 & .452 & .107 & .523 & .078 & .705 \\
\hline .132 & .323 & .124 & .455 & .094 & .618 \\
\hline .166 & .188 & .162 & .247 & .125 & .428 \\
\hline \multirow[t]{3}{*}{.189} & .102 & .186 & .138 & .141 & .364 \\
\hline & & & & .155 & .248 \\
\hline & & & & .172 & .187 \\
\hline
\end{tabular}


Evaporating Spray

\begin{tabular}{|c|c|c|c|c|c|}
\hline \multirow{2}{*}{$\frac{x / d}{r / x}$} & 170 & \multicolumn{2}{|c|}{340} & \multicolumn{2}{|c|}{510} \\
\hline & $k / \bar{u}_{c}^{2}$ & $r / x$ & $\mathrm{k} / \overline{\mathrm{u}}_{\mathrm{c}}^{2}$ & $r / x$ & $k / u_{c}^{-2}$ \\
\hline 0 & .0701 & 0 & .0743 & 0 & .0791 \\
\hline .022 & .0708 & .020 & .0750 & .024 & .0780 \\
\hline .041 & .0685 & .041 & .0752 & .043 & .0777 \\
\hline .061 & .0671 & .061 & .0748 & .065 & .0736 \\
\hline .082 & .0613 & .082 & .0652 & .087 & .0662 \\
\hline .102 & .0517 & .102 & .0548 & .105 & .0563 \\
\hline .122 & .0385 & .122 & .0422 & .126 & .0446 \\
\hline .141 & .0255 & .140 & .0293 & .146 & .0318 \\
\hline .163 & .0137 & .163 & .0175 & .166 & .0207 \\
\hline .182 & .0026 & .182 & .0027 & .185 & .0108 \\
\hline
\end{tabular}


Evaporating Spray

\begin{tabular}{|c|c|c|c|c|c|}
\hline \multirow{2}{*}{$\mathrm{x} / \mathrm{d}$} & \multirow{2}{*}{$\frac{170}{\mathrm{u}^{\prime} \mathrm{v}^{\top} / \mathrm{u}_{\mathrm{c}}^{-2}}$} & \multicolumn{2}{|c|}{340} & \multicolumn{2}{|c|}{510} \\
\hline & & $r / x$ & $\overline{u^{\prime} v^{\prime} / \bar{u}_{c}^{2}}$ & $r / x$ & $u^{\prime} v^{\top} / u_{c}^{2}$ \\
\hline .017 & .0016 & .021 & .0061 & .017 & .0067 \\
\hline .035 & .0057 & .033 & .0122 & .032 & .0135 \\
\hline .048 & .0088 & .041 & .0153 & .048 & .0176 \\
\hline .063 & .0112 & .064 & .0144 & .062 & .0193 \\
\hline .078 & .0132 & .085 & .0113 & .078 & .0190 \\
\hline .094 & .0135 & .104 & .0102 & .108 & .0141 \\
\hline .109 & .0120 & .126 & .0061 & .112 & .0080 \\
\hline .127 & .0089 & .147 & .0039 & .142 & .0047 \\
\hline .142 & .0063 & .168 & .0025 & .158 & .0022 \\
\hline .157 & .0042 & .187 & .0012 & .173 & .0013 \\
\hline .174 & .0024 & & & & \\
\hline .189 & .0020 & & & & \\
\hline
\end{tabular}


Evaporating Spray

\begin{tabular}{|c|c|c|c|}
\hline \multicolumn{2}{|c|}{$\bar{x} / \mathrm{d} \quad 340$} & \multicolumn{2}{|c|}{510} \\
\hline$r / \mathrm{x}$ & $\left(\overline{\mathrm{T}}-\overline{\mathrm{T}}_{\infty}\right) /\left(\overline{\mathrm{T}}_{\mathrm{c}}-\overline{\mathrm{T}}_{\infty}\right)$ & $r / x$ & $\left(\overline{\mathrm{T}}-\overline{\mathrm{T}}_{\infty}\right) /\left(\overline{\mathrm{T}}_{\mathrm{c}}-\overline{\mathrm{T}}_{\infty}\right)$ \\
\hline .023 & .907 & .021 & .931 \\
\hline .047 & .698 & .042 & .783 \\
\hline .075 & .543 & .062 & .663 \\
\hline .094 & .387 & .082 & .510 \\
\hline .116 & .271 & .104 & .426 \\
\hline .141 & .223 & .125 & .318 \\
\hline .163 & .128 & .145 & .198 \\
\hline \multirow[t]{2}{*}{.188} & .063 & .167 & .125 \\
\hline & & .186 & .085 \\
\hline
\end{tabular}




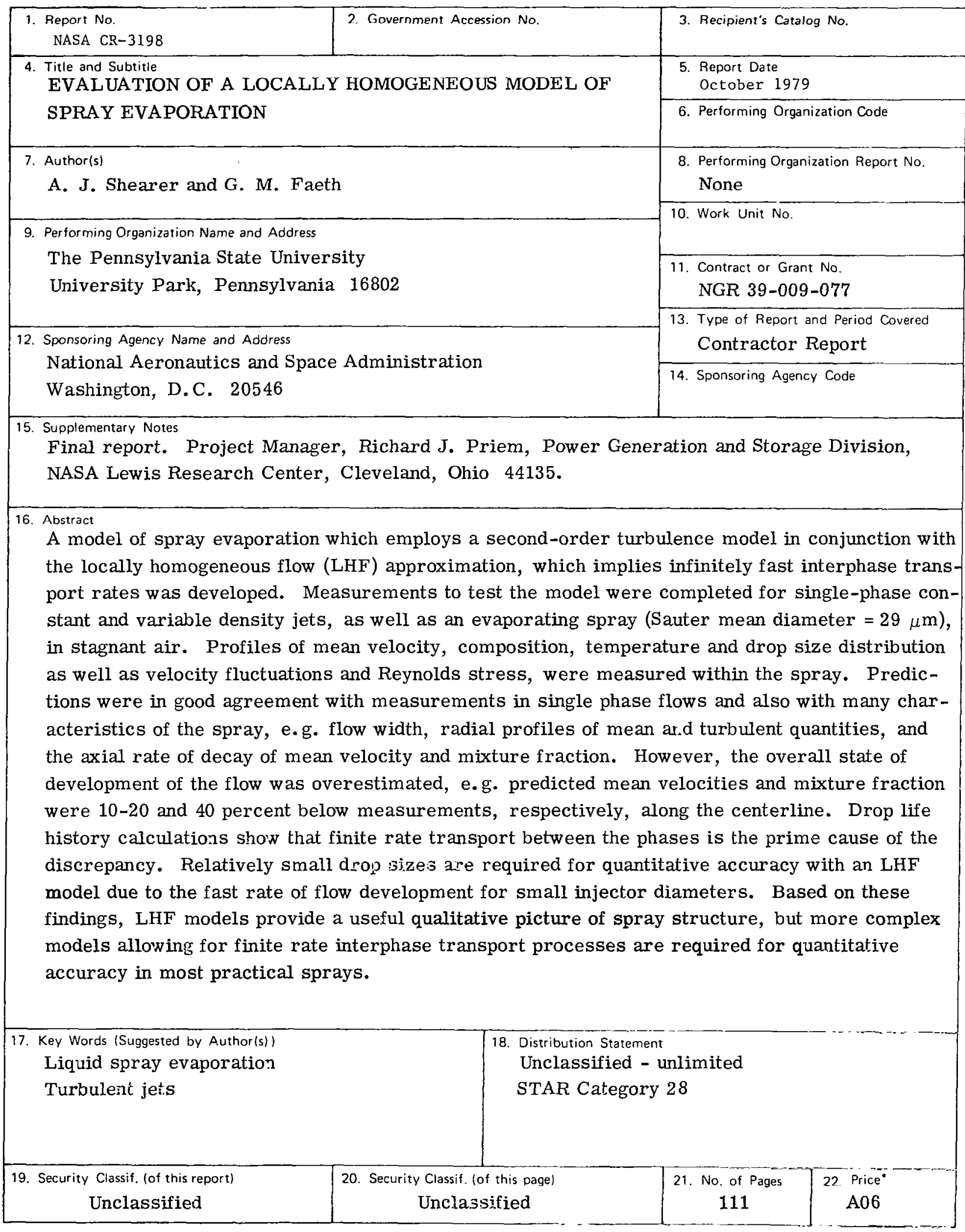

"For sale by the National Technical Information Service. Springfield, Virginia 22161 